Sheffield Hallam University

Centre for

Regional Economic and Social Research

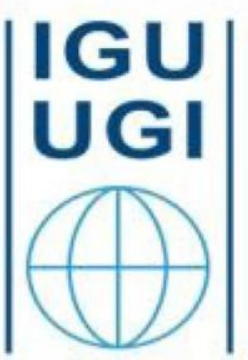

IGU COMMISSION GEOGRAPHY OF GOVERNANCE

\title{
Local Government Responses to the COVID-19 Pandemic in the UK: A Thematic Review
}

\author{
March 2021
}




\section{Local Government Responses to the COVID-19 Pandemic in the UK: A Thematic Review}

Working Paper \#3 - International Geographical Union Commission on Geography of Governance Project: "Local Government Response Towards Covid-19 Pandemic: A Worldwide Survey and Comparison"

Author(s):

Tony Gore

Emma Bimpson

Julian Dobson

Steve Parkes

Centre for Regional Economic and Social Research, Sheffield Hallam University

March 2021

10.7190/cresr.2021.6172521344 


\section{Acknowledgements}

This report represents a contribution to the Action Plan of the International Geographical Union (IGU) Commission on Geography of Governance entitled "Local Government Response Towards Covid-19 Pandemic: a Worldwide Survey and Comparison" (for further details visit https://sites.google.com/view/igucgog-covid19/home). Our review would not have been possible without the impetus provided by this framework and its driving force Carlos Nunes Silva, convenor of the Commission and Professor of Geography and Spatial Planning at the University of Lisbon. The authors are also grateful for the support and encouragement of Professor Ed Ferrari, Director of the Centre for Regional Economic and Social Research (CRESR), Sheffield Hallam University, and to the University's Architecture, Built Environment and Planning REF Panel for the allocation of working days to enable our research to be undertaken. We would also like to thank the Local Government Association for granting permission to reproduce the image on page 2 .

Although this report is the product of a collective effort by all four authors, primary responsibility for the different sections is as follows:

- Tony Gore: sections 1, 2, 3, 4 and 8.

- Emma Bimpson: section 5.

- Julian Dobson: section 6.

- $\quad$ Steve Parkes: section 7.

Any errors and all views expressed are the responsibility of the authors and cannot be attributed to either Sheffield Hallam University or the IGU Commission on Geography of Governance.

CRESR, Sheffield Hallam University

Authors' Email: t.gore@shu.ac.uk

Website: https://www4.shu.ac.uk/research/cresr/

General enquiries: cresr@shu.ac.uk

IGU Commission on Geography of Governance

Website: https://sites.google.com/site/igugeogov/home

Project website: https://sites.google.com/view/igucgog-covid19/home

Commission E-mail: igu.geogov@gmail.com 


\section{Contents}

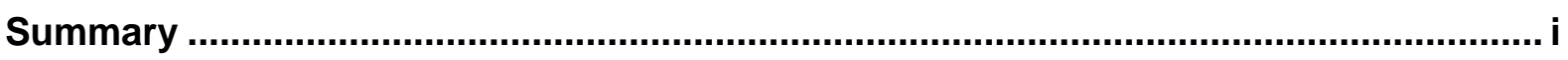

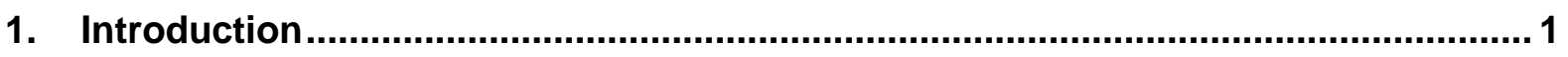

2. Local Government in the UK: The Background Context........................................ 4

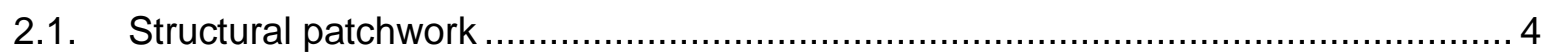

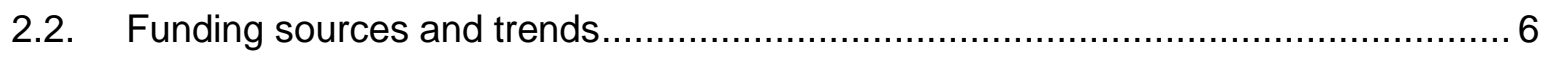

2.3. Position and role of local authorities in the UK's overall governance structure ........ 7

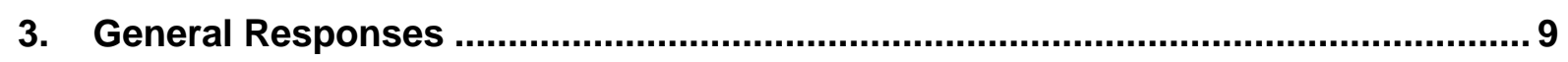

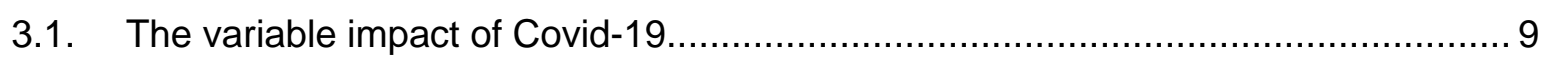

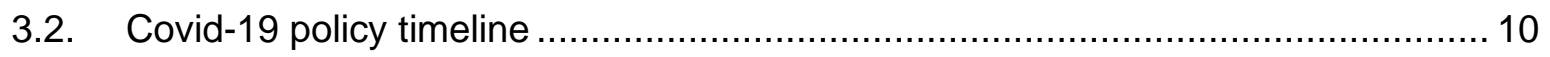

3.3. Local outbreak management plans ............................................................. 11

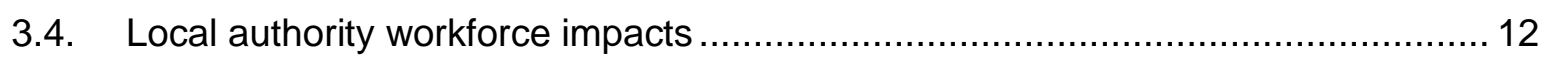

3.5. Additional Financial Support to Local Authorities ............................................ 12

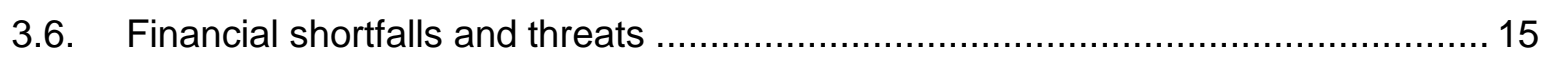

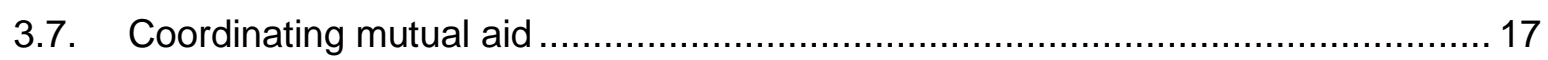

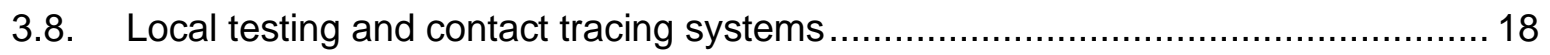

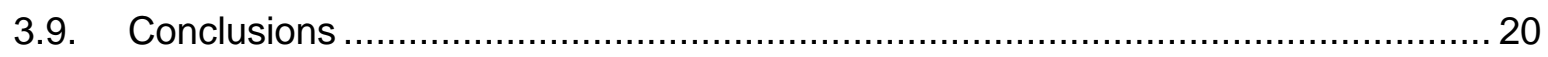

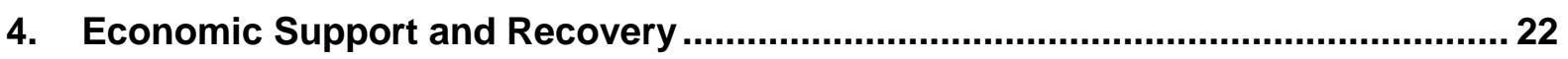

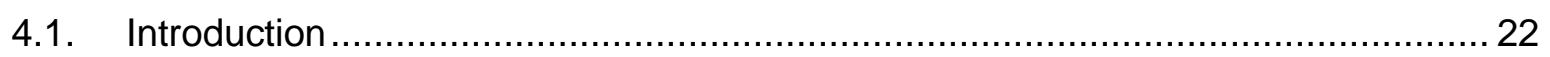

4.2. Central Government business support schemes ............................................. 23

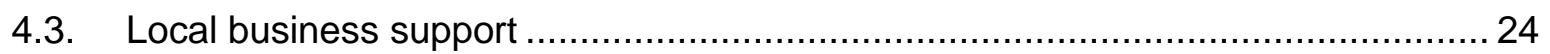

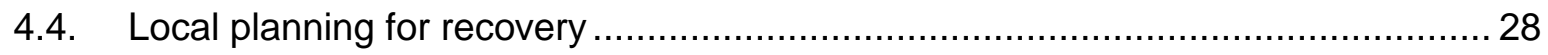

4.5. Conclusions: Knowledge gaps and future research questions …………............ 31

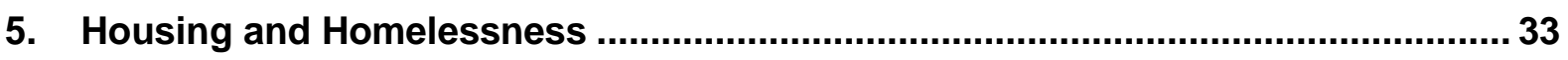

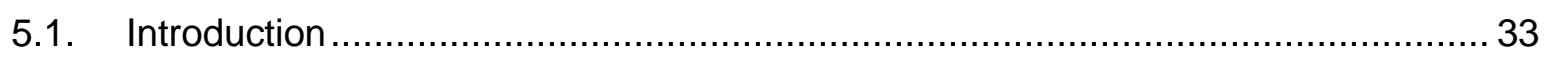

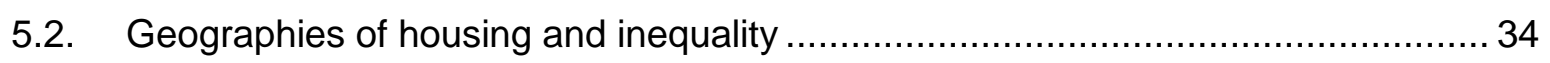

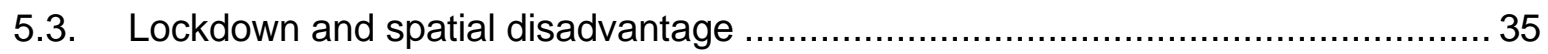

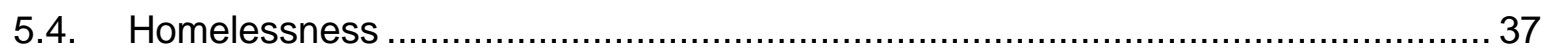

5.5. Conclusions: Knowledge gaps and future research questions ............................. 40

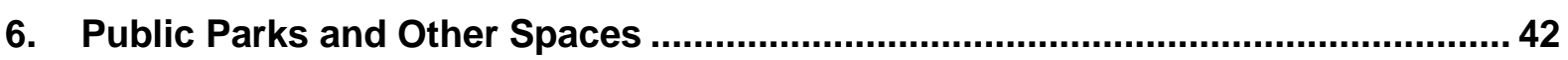




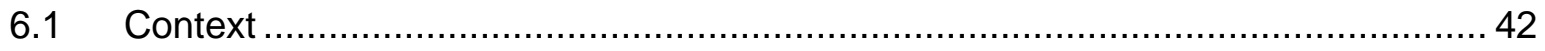

6.2 Local government responses during the pandemic .......................................... 43

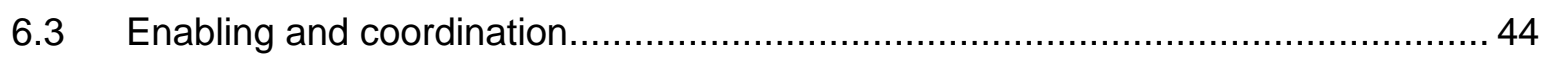

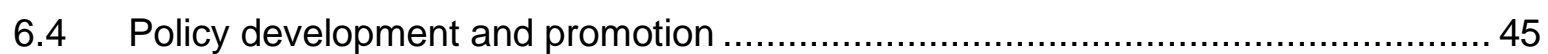

6.5 Conclusions: Knowledge gaps and future research questions ............................47

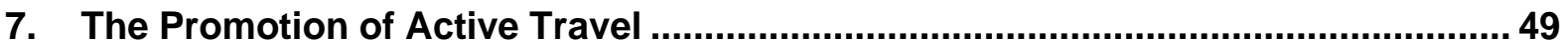

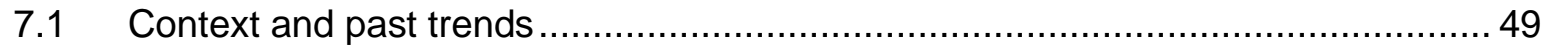

7.2 Local government responses during the pandemic ........................................ 50

7.3 Enabling and coordinating the local government response .................................53

7.4 Policy changes and promotion of active travel ............................................ 55

7.5 Conclusions: Knowledge gaps and future research questions ..........................57

8. Conclusions: Towards a Future Research Agenda ................................................ 58

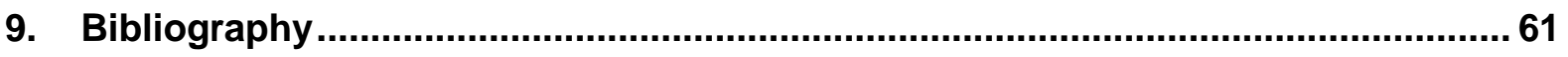




\section{Summary}

This report examines a range of ways in which local government bodies in the UK have responded to the pressing issues associated with the Covid-19 pandemic during 2020. Based on a review of currently available evidence, it looks in turn at aspects of the general support provided to local residents and their communities; at financial and other assistance to local businesses, as well as at measures being put in place to chart a path towards future economic recovery; at revised arrangements to protect those affected by homelessness and other forms of housing insecurity; at the management of parks and other public spaces as key venues for exercise during lockdown; and at efforts to boost active travel modes and to foster cleaner and safer residential environments through road space reallocation and traffic management.

The far-reaching impacts of the pandemic have meant that local responses have required the involvement of not just official government bodies, but also organisations in all segments of society. Despite inevitable variations, most localities have seen concerted and wellcoordinated efforts to meet the needs of local residents, communities and businesses. This has entailed substantial joint working not just between different public service providers alongside long-established voluntary sector bodies, but also drawing in a myriad of neighbourhood mutual aid groups, concerned local businesses and members of the general public.

In many places, positive 'complementary' relationships between these actors have been fostered and embedded into remodelled ways of working. This is reflected in the high satisfaction levels with local authority key workers during the pandemic. A potential consequence for such areas is a longer term strengthening of local governance, featuring a commitment to closer joint operations in the future. In view of the reduction in resources and capacity imposed on local government over the previous decade, this is certainly an impressive achievement. In the best cases it may justifiably be claimed to represent an exemplary instance of collaborative local governance in practice.

However, there have been inevitable variations both between different places and across different policy domains, the latter often within the same locality. The collaborative, consultative approach has not been universal either in terms of geography or policy domain, with some councils starting out with inclusive intentions but finding them difficult to sustain over time. In other places good intentions to collaborate have been hampered by differences in organisational cultures, priorities and performance regimes.

To some extent variations between policy domains reflect the predominance of positive or negative reporting styles on different topics. Thus, coordination of support mechanisms tends to be illustrated by warm stories of appropriate help being delivered to people in need, whereas reports on active travel and low traffic neighbourhood interventions generally focus on initiatives that have prompted vociferous opposition from certain quarters. To counter these tendencies, each section of the report endeavours to look beyond these headlines to furnish a more balanced perspective. The review also keeps in sight of the wider context in which much of what can be done by local government in the UK is driven by national governments' policy-making and resource allocation, as well as their attitude on how local authorities fit into the UK's overall system of territorial governance. 
The review also exposes a rather ambivalent attitude on the part of the UK Government with respect to local authority roles in addressing Covid-19. On the one hand, the general emergency funding provided to English local authorities afforded them discretion to direct resources to the most pressing needs in each area, and the ring-fenced specific purpose allocations illustrate a fair degree of faith in councils to ensure the support reaches intended beneficiaries as speedily as possible. On the other hand, excluding most local authorities and health bodies from testing and contact tracing, even after the failings of the contracted national system were evident, implies a lack of understanding of the relevant experience and expertise that such local teams could contribute. In contrast, the more collegiate approach between devolved administrations in Wales, Scotland and Northern Ireland seems to have enabled greater coherence of both actions and messaging.

This is not to imply that local authorities lack any scope for developing distinctive approaches, whether this be launching additional business support measures to fill the gaps in nationally administered schemes, or adopting the role of flexible response coordinators rather than centralised directors in community support initiatives. Nevertheless, a great deal has rested on the scale of additional resources that a given local council has been able to muster, either from its own reserves, via loan finance or through emergency government funding. Again, both availability and extent of involvement have varied considerably between different places as a result, and the exact nature of what has been possible and how it has been achieved will require further comparative research once local authority expenditure returns have been finalised. Similarly, the extent to which different local authorities have managed to introduce streamlined grant application and regulatory procedures remains unclear, as does their effectiveness; again, this will require further detailed research.

In terms of financial support to business local authorities in England have administered around $20 \%$ of what has been distributed from HM Treasury, principally in the form of flat rate payments related to the valuation of the commercial premises occupied. In many places this has been supplemented by local authority discretionary funds directed to small firms and selfemployed operators who are ineligible for the national schemes. Again, this rests on the variable ability of councils to access funds from reserves or other sources. At the same time many councils have streamlined both their grant assessment and their other business regulation procedures.

Local and sub-regional agencies have also been busy trying to prepare for future economic recovery and realignment. A major difficulty here is the lack of clarity on the part of the UK Government concerning both strategic direction and practical measures and initiatives. This is especially the case in England, where strategy formulation for local recovery is taking place in something of a vacuum. It is little surprise that many of the plans already produced represent requests for funding as much as blueprints for action. In contrast, in Scotland and Wales both national governments have launched exercises aimed at setting a context within which local economic recovery planning can proceed. Their inclusive consultative approach bodes well for the extent to which local agencies can align their own approaches to nationally set priorities and targets.

In broader terms claims about how this swathe of local responses to the pandemic have created a permanent transformation in the ways in which public services are designed and delivered similarly require further investigation. Thus, reframing homelessness in terms of public health has broken with the previously dominant individualising discourses inherent within the neoliberal approach, but whether this rolls forward in the post-pandemic period remains uncertain. Further research is needed to track the nature of subsequent Central Government funding initiatives, the distribution of those resources to local authorities, and the range and effectiveness of measures used to deploy them. In terms of housing provision more broadly, the extent to which partnerships have been strengthened between local authorities and accommodation providers in both social and private sectors will be another important avenue for future research, especially in terms of their persistence over time. 
The overwhelming importance of parks and other public spaces for people's physical and mental health has underlined the anomaly whereby the essential role of the public realm is not matched by any legal duty nor dedicated financial resources to manage and maintain it, still less to extend it as a means of achieving more equal access. Even before the pandemic local authorities have had to find varying solutions to the difficulties of maintaining good quality public spaces. Without a rethink on the part of Central Government this will remain the case, despite the manifest public health benefits. The potential varied range of innovative practice will need to be subject to continued research, so that lessons can be shared, and pitfalls avoided. Future developments are likely to continue relying on productive local authority/civil society relationships, which as the report emphasises take time and nurturing to come to fruition. It appears that the same approach needs to become embedded in the adjustments linked to active travel and traffic management in residential areas. Here further research will be required to distil the ingredients of the approaches taken by local authorities over a sustained period in building a context in which new installations can become commonplace and uncontroversial.

Each section of the report concludes with an outline of some of the key questions that would form the core of an emerging research agenda. Clearly this is not just about immediate responses to Covid-19; as with so many other things, the pandemic has brought to the fore needs and issues which have been brewing for some time. These also point towards a need for governance across the UK to be more inclusive and equitable. In this sense, the local lessons emerging from this review, around the need for productive collaboration, coordination and negotiation, might equally apply to the fractured and poorly coordinated nature of governance of the UK in general.

Successive governments have attempted to continue centralised control despite the realities of 20 years of devolution, and a consequent lack of appreciation that the country is now less a unitary state and more a patchwork of national, sub-regional and local governing authorities. As such Central Government is part and parcel of the networks and relationships that comprise this overall system of governance, albeit the most important component. This in turn implies replacing the current dictatorial, adversarial model with a set of constructive relationships that enables it to steer others in the same general direction. Part of this 'metagovernance' role involves recognition of the increasingly blurred boundaries between the state and civil society, especially at the local scale, and as part of this empowering local government bodies to entrench the enabling and coordinating roles that have been so important in getting support to where it is needed during the pandemic. 


\section{Introduction}

In Britain local government responsibility for the health and wellbeing of residents has a long tradition, harking back to the Victorian era of improved housing, sanitation and other factors in the fight against infectious diseases. During the $20^{\text {th }}$ century the continued development of effective medical treatments shifted the focus of health improvement towards hospitals, clinics and general practice, with local authorities taking more of a background role. However, the emergence of 'modern' ailments linked to a combination of environmental conditions and people's behavioural patterns prompted an equal emphasis on what are called the 'social determinants of health' (see Figure 1.1). This has meant a renewed importance in health matters for local government in recent decades, given that most of the items identified fall within its arena of interest, and hence in its potential to address some of the root causes of poor health.

\section{Figure 1.1: The social determinants of health}

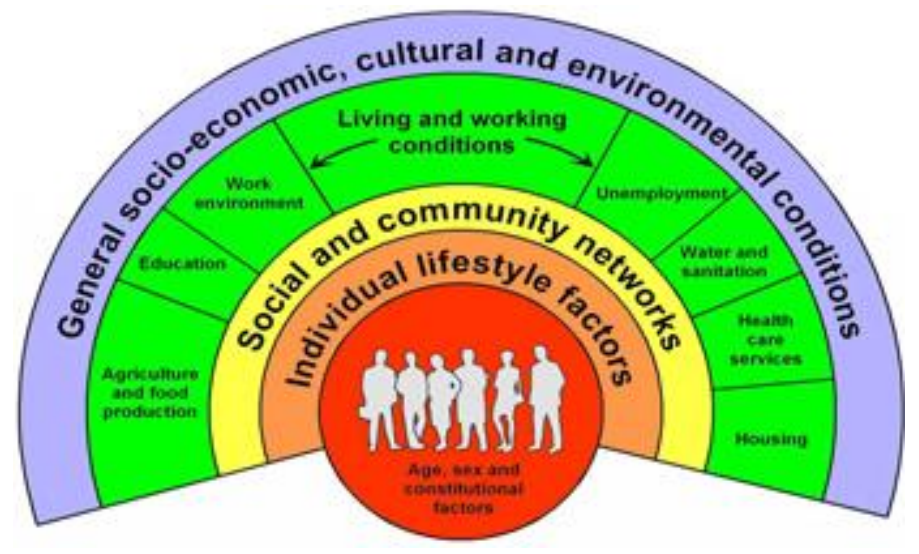

Source: Dahlgren and Whitehead (1993).

This was explicitly recognised in a Local Government Association (LGA) report, originally published in 2012 but recently updated in the face of the current coronavirus crisis (LGA, 2020d). This included an adapted version of the Dahlgren-Whitehead 'rainbow' designed to highlight the extensive contribution made by local authorities to improving these socio-economic conditions (see Figure 1.2). Here eight broad categories of 'social determinant' are linked with the numerous functions performed at the municipal scale. The diagram implies that these links are far from a 'one-way street' of causes and effects. Rather, they entail a complex web of multi-directional interrelationships between the overarching categories, the public services provided and people's health outcomes and needs. It is in this sense that the 'social determinants' paradigm frames this review, albeit within the limits of what can be achieved in an initial scoping exercise. 
Figure 1.2: The social determinants of health and well-being: How local government can make a difference

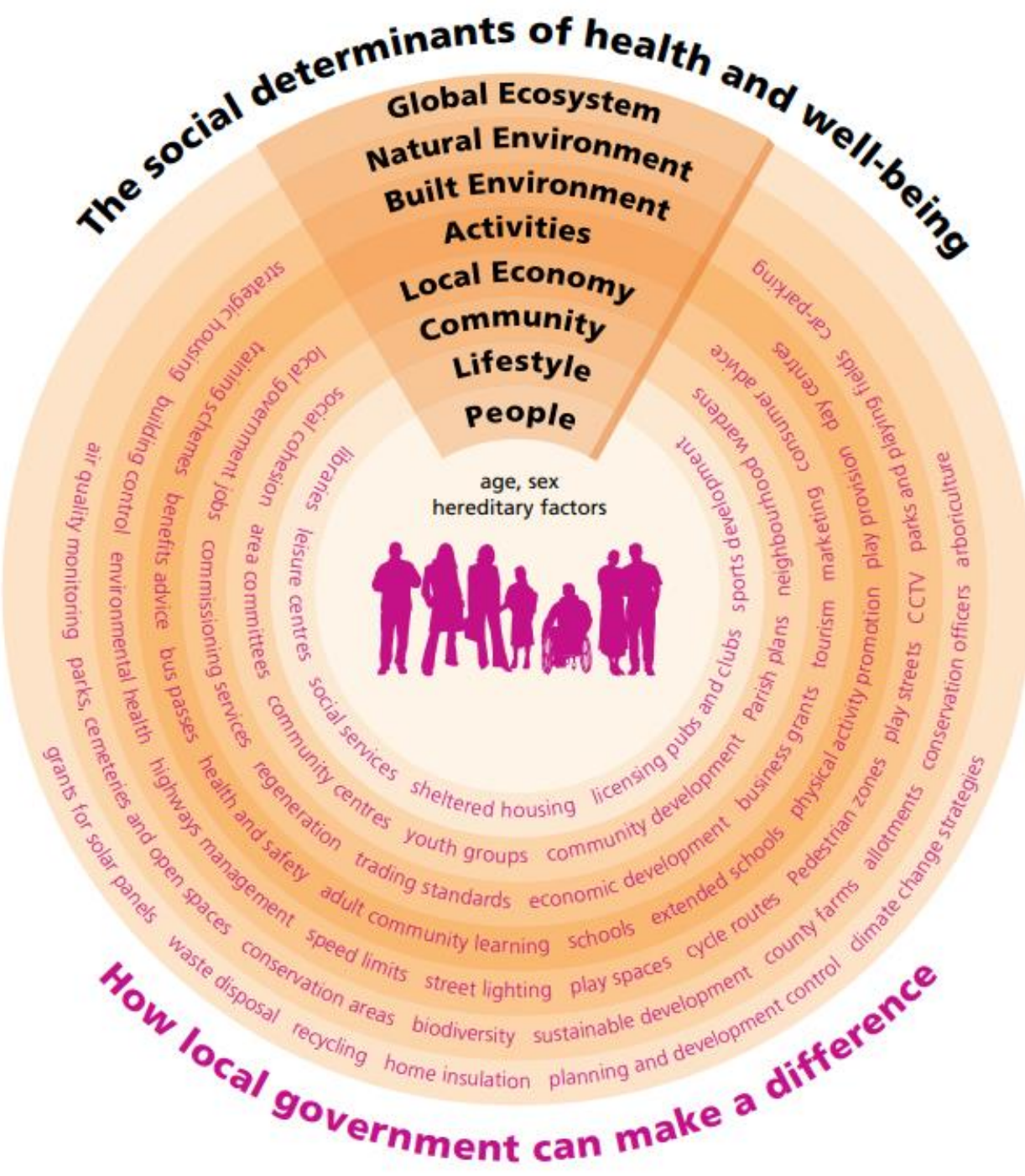

Source: Local Government Association (2020d, p.14)

As a recent report commented, '(t)he social determinants approach continues to be highly relevant to local authorities, particularly given the strong focus on place, wellbeing and cross-sectoral working by local governments....' (Marmot et al., 2020a, p.10). The LGA report itself identifies five broad roles under which the wide-ranging activities of local authorities can be grouped in terms of public health relevance: through civic leadership; as an employer and anchor institution; via the commissioning, contracting and provision of services; through planning, licensing and other regulatory activity; and as a champion and enabler of both preventative and health-promoting behaviours.

The worldwide spread of the Coronavirus Disease 2019 (Covid-19) in the early months of 2020 heightened the importance of these five roles as the focus of government at all scales narrowed to the striking of a balance between prevention (or containment) of infection and the maintenance of essential economic and social activities, including the provision of public services. This has involved a rapid - and rapidly changing response from national, regional and local government bodies in all countries, albeit with different degrees of consistency and coordination. In this sense the United Kingdom (UK) is no different, even though its asymmetrical sub-national and local 
government structures have produced their own idiosyncrasies. This report constitutes an initial scoping review of the local level responses to the Covid-19 crisis in the UK. Rather than attempt comprehensive coverage of all service areas the review has adopted a thematic approach. Following an outline of key aspects of the general response, the report examines in turn the following policy themes:

- Economic support and recovery.

- Housing and homelessness.

- Parks and other public spaces.

- Promotion of active travel.

Other service areas may be mentioned in passing but they are not examined in detail. These include schools and education; adult and children's social care; public transport; planning and development; environmental services; culture and tourism; fire and rescue; and policing.

While the review is primarily framed within the multi-directional 'social determinants of health' paradigm mentioned above, at the same time it draws on insights from the literature on governance in order to explore central aspects associated with, and issues arising from, the speedy responses required in a traditionally slow-moving decision-making forum. In doing so it reveals gaps in knowledge that might form the basis for a future applied policy research agenda, as well as allowing some reflections on the nature of governance arrangements and relationships within the UK.

This report represents a contribution to the international research initiative on local government responses to the Covid-19 pandemic being coordinated by the International Geographical Union's Commission on the Geography of Governance (CGoG). As such it sits alongside parallel working papers that examine the situation in other countries, with a view to building a body of material that can form the basis for future comparative cross-national research. The review draws exclusively on deskbased research, identifying, summarising and reviewing secondary material from different sources, including local authorities themselves, local government representative bodies, think tanks and lobbying groups, media reports and our own funded research. While the emphasis is placed on the activities of local authorities of various types, where appropriate the work undertaken by organisations providing public services or performing local government functions on a collaborative, 'contracted out' or 'arm's length' basis is also included. The period covered by the review extends from the initial full lockdown in late March up to the reimposition of severe restrictions at different points and for varying durations in the final quarter of 2020 in the four countries of the UK. 


\section{Local Government in the UK: The Background Context}

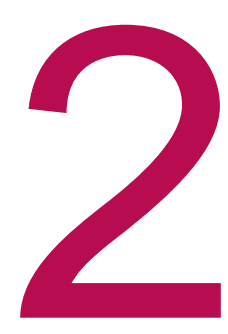

\subsection{Structural patchwork}

Over the last 25 years the structure and operation of sub-national government in the UK has been subject to piecemeal yet significant change along four main dimensions: devolution, restructuring, collaboration and financing. The devolution settlements for Scotland, Wales and Northern Ireland in the late 1990s included direct responsibility for local government, so that local authorities in those territories are now regulated and supported by the respective devolved governments. In England the absence of a separate assembly means that it is a specific department in UK Central Government that acts in that capacity (the Ministry of Housing, Communities and Local Government (MHCLG)).

In the three devolved administrations local government has undergone wholesale reorganisation, moving from the previous two-tier system to a set of unitary authorities in each. In contrast, in England the pattern has been much more variegated, with a move to unitary authorities in some areas but retention of the division between shire counties and districts in others. While the unitary approach is common to all metropolitan urban areas (including London), to date it has been adopted wholesale in just one English region (the North East). Table 2.1 illustrates the nature of this structural patchwork.

Table 2.1: Local Government Arrangements in the UK's Constituent Parts

\begin{tabular}{|l|l|l|l|l|l|}
\hline & $\begin{array}{l}\text { Metropolitan } \\
\text { Boroughs* }\end{array}$ & $\begin{array}{l}\text { Unitary } \\
\text { Authoritiest }\end{array}$ & $\begin{array}{l}\text { Shire } \\
\text { Counties }\end{array}$ & $\begin{array}{l}\text { Shire } \\
\text { Districts }\end{array}$ & Districts \\
\hline England & 69 & 55 & 25 & 188 & 0 \\
\hline $\begin{array}{l}\text { Northern } \\
\text { Ireland }\end{array}$ & 0 & 0 & 0 & 0 & 11 \\
\hline Scotland & 0 & 32 & 0 & 0 & 0 \\
\hline Wales & 0 & 22 & 0 & 0 & 0 \\
\hline
\end{tabular}

*Includes London Boroughs

†Council Areas in Scotland; County Boroughs in Wales

In the devolved administrations reorganisation occurred at a single point in time: 1996 in Scotland and Wales (actually before devolution was implemented); and 2015 in Northern Ireland. In contrast, changes in England have occurred intermittently, starting in 1986 with the abolition of the Greater London Council and the metropolitan counties, then in two main tranches (1995-1998 and 2009) with the conversion of certain counties, some urban boroughs and a few amalgamated districts into unitary authorities. Occasional additions have been made in the following decade, the most recent in April 2020, with further conversions under discussion. 
The third aspect of recent change has revolved around increased collaboration between neighbouring authorities. One of the main institutional expressions of this has been the emergence of Combined Authorities (CAs) in England's city regions, starting with Greater Manchester in 2011. While this had a relatively smooth gestation, elsewhere there was a considerable amount of "unedifying wrangling" (Smulian, 2016, p.28) over membership, rooted particularly in the fear of domination by 'big city' interests. Nevertheless, there are now $10 \mathrm{CAs}$ in existence, with a remit to coordinate policy in shared areas of interest such as economic development, training and skills, transport, housing and social care. At present 8 of them are led by an elected mayor, with another (West Yorkshire) scheduled to adopt this model in the near future. Each has agreed a 'devolution deal' with Central Government which transfers varying powers and resources to this city region scale. Otherwise, councils have generally been encouraged to coordinate their operations with neighbours, and there are a number of examples where they have combined their 'back office' administrative functions.

In England this increased inter-area collaboration has also been exemplified by the establishment of Local Enterprise Partnerships (LEPs) at a sub-regional scale. Created by the Coalition government in 2011 as replacement for New Labour's regional governance infrastructure, these brought together a range of public and private sector organisations (including local authorities) to act as the main vehicle for planning and implementing sub-national economic development. In essence they grew out of the burgeoning emphasis on the city region scale as a 'functional economic geography', yet in this case transferred to disparate spatial contexts such as county council areas and motorway 'corridors' (Gore, 2018). Originally local authorities could align themselves with more than one LEP area, but more recent rationalisation abolished this possibility, so that there now exist 38 self-contained LEP sub-regions covering the whole of England. Parallel cross-boundary collaboration has also occurred in Scotland and Wales, albeit on a less formalised basis, with major metropolitan or 'city and hinterland' arrangements in place in localities such as Edinburgh, Glasgow, Cardiff and Swansea.

Another feature of local government in the UK is the variation in responsibility for public health interventions. Despite the direct contribution to public health matters outlined in Section 1, until recently this has remained a centralised concern, in some ways reflecting the expert, medicalised approach to health care in general. Indeed, oversight of public health has been retained by the devolved governments in Northern Ireland, Scotland and Wales, albeit working in a policy framework that fosters active partnerships with local councils (de Gruchy and McManus, 2020). In Northern Ireland this central control extends to other domains such as education, housing, transport, highways and local taxation, with the result that the District Councils mainly act as basic public service providers and community place-shapers rather than overall area coordinators (Pow, 2018). Again, the position in England is different, with public health responsibilities being restored to upper tier authorities (metropolitan boroughs, unitary authorities and shire counties) in 2013. This had a twofold purpose: firstly, to ensure that public health concerns are incorporated into all policy and service areas; and secondly, to liaise with the National Health Service (NHS) and other partners in health promotion and protection, particularly via local health and wellbeing boards (Hunter, 2020).

The final point to note about local governance in the UK is the contribution of small area organisations such as parish, community, neighbourhood or town councils. Most of these have a democratic basis, their activities being steered by a set of locally elected representatives. Some of them have a formal presence in governance infrastructure, acting principally in a consultative and advisory capacity to local authorities and other state bodies, though occasionally adopting a more proactive stance to secure positive developments in their area. There are around 10,000 such 
bodies in England, mainly in rural but also many urban areas, whilst Wales has just over 700. In both countries they are able to set a 'precept' or 'rate' which is collected by the local council from residents of the relevant areas as part of the Council Tax payment. In Scotland there are 1,200 community councils which rely on their local authority for funds to cover their running costs, which limits their capacity to take action on their own behalf. In addition, there is a plethora of other local organisations such as residents' associations or neighbourhood groups with a more informal connection to governance procedures, though these are increasingly included as stakeholder participants (or at least consultees) by the main decision-makers.

\subsection{Funding sources and trends}

In the decade since the election of the Coalition Government in 2010 the watchword in local authority finance in the UK has been 'austerity'. Purporting to represent a key contribution to restoring the health of the country's finances in the wake of the 2008 banking crisis, reductions in the resources available to local councils have been severe. According to Amin-Smith and Phillips (2020), local government spending on services in England fell on average by just over a fifth in real terms between 2009-10 and 201718. These cuts have been unevenly distributed between services. Thus, there have been sharp downturns for those services that are discretionary, whilst relative protection has been given to certain mandatory services such as adult social care (down 5\%) and children's social care services (up 10\%). In contrast, spending on children's and youth centres, planning and development, highways and transport, housing and culture and leisure fell by more than $40 \%$. According to a recent study the reduction in local authority public health budgets between 2015-16 and 2019-20 in England amounted to $£ 850$ million, but once population growth and inflation are factored into the equation it will require an additional $£ 1$ billion to return to the original level (Buck, 2020). On a geographical basis these reductions have been spread very unevenly, with councils serving the most deprived fifth of communities having an average spending reduction of over $30 \%$, compared with $17 \%$ for those containing the least deprived fifth.

The main instrument for achieving these budget decreases has been a year-on-year fall in the size of the grants provided by Central Government to each council to pay for key public services. While this has meant that local authorities have become increasingly reliant on local sources of revenue (mainly from property taxes), a tight rein has been kept on these by Central Government measures capping any proposed increases. Annual budgets have to be approved centrally, and the only way for local government to access further guaranteed funding is by tapping into new, generally ringfenced and hence prescriptive funding streams set up by Central Government. These grant-based sources are often made available on a competitive bidding basis, again meaning that any benefits are distributed in an uneven geographical manner. There is limited scope to develop other local revenue sources such as car parking fees, planning application charges and leisure centre pricing, so some councils have tried to diversify their income by investing in commercial ventures such as property and energy supply. However, this can be a high-risk strategy; so far it seems to have had mixed results. In any event, tight budget-setting controls mean that much of any increase in returns is added mainly to cash reserves rather than being immediately available for service improvement or expansion. Insall (2020, p.3) argues that this "localisation of revenue sources has not equated to the localisation of authority over (how to use) them", leading to "centralisation by default".

In terms of public health, the effectiveness of any contributions that local authority services can make is dependent largely on the level of resources available, and the breadth and depth of staff capacity and capability that this can support. According to de Gruchy and McManus (2020) the sustained funding reductions to local councils in general, and to public health services in particular have narrowed the focus to 
mandatory service commissioning, rather than allowing more open-ended system leadership or coordinating roles that could embed effective public health practices across a much wider swathe of public and private sector organisations.

\subsection{Position and role of local authorities in the UK's overall governance structure}

Insall (2020) suggests that the role of local government in the UK is twofold: firstly, to deliver centrally prescribed services locally; and secondly, as a local democratic body, to respond to citizen needs and aspirations. However, these are very much 'headline' tasks; they mask a host of other functions and activities which effectively render the local authority as the keystone of a local system of governance. Although local authorities in the UK can be viewed narrowly as creations of, and to some extent constrained by, parliamentary statute (rather than having a formal constitutional basis) (Wilson, 2005), they have always had some room for manoeuvre in terms of interpretation of their powers. This wider role has been recognised by legislative provisions firstly allowing the general promotion of 'local well-being' (in 2000), and later (from 2012) affording a 'general power of competence' for councils to be able "to do anything an individual can do provided it is not prohibited by other legislation" (LGA, 2013 , p.8). Although these powers have been used sparingly to date, they do underline the widened role that local government is now expected to play. This wider role includes:

- Commissioning or contracting out services to private and voluntary sector providers.

- $\quad$ Supporting enterprise, community-based and other networks.

- $\quad$ Providing advice and support to citizens and businesses.

- $\quad$ Fostering good practice by local stakeholders that can help to meet wider goals.

- Enabling social and charitable action that ensures a wide range of opportunities and support for all segments of the local population.

- Coordinating policies, plans and interventions with other public sector organisations and neighbouring authorities.

During 10 years of austerity performing all these roles has not been straightforward, especially as funding constraints have largely shifted the emphasis to meeting statutory obligations and addressing acute needs in reactive ways, following the 'market paradigm' already mentioned (Local Trust/NLGN, 2020). More recently many local authorities have started to reorient practice to more of a 'community paradigm', involving partnerships built around localisation, devolution and deliberation, allowing frontline staff to be more person-centred and collaborative in their approach. This approach remains relatively patchy, both within and between places. The exception appears to be in Scotland, where moves in this direction are progressing under an agreement between the Scottish Government, the 32 Council Areas and their representative body the Convention of Scottish Local Authorities (COSLA). A corollary of this model is the 'community wealth building' approach whereby the aim is to ensure that all local services achieve some wider form of social or economic benefit, for example through procurement from locally based suppliers (McKinley et al., 2020).

The contrast between Scotland and Wales on the one hand, and England on the other, is instructive. In the former the relationship between the devolved governments and local councils appears to be one of collegial partnership, mediated respectively by COSLA and the Welsh Local Government Association (WLGA). Both representative bodies still undertake lobbying to meet the interests of their members, but both governments seem to accept this in a constructive manner (Sergeant, 2020). In 
England, by contrast, the relationship between central and local levels is generally hierarchical and often framed in adversarial terms, with limited notions of working in partnership to achieve common aims. Here the representative body (the Local Government Association or LGA) tends to be viewed centrally more as a lobbying group than as a valuable channel of communication. Notwithstanding the prescriptive approach mentioned above, lines of communication appear to be haphazard and inconsistent, and to be characterised by dictation rather than dialogue. This may be because the previous blend of austerity, deregulation and the removal of external review has effectively put local government in England in a downgraded, even isolated position relative to other parts of the nation's governance structure (Bennett, 2020). However, the same author also acknowledges that local government remains a key part of the interdependencies upon which this structure rests. While the ultimate outcome is yet to emerge, the intensive local partnership working that has been such a feature of the response to the Covid-19 pandemic in many places may help to reestablish a modicum of autonomy and influence for local authorities in the overall governance not only of England but of all countries of the UK. 


\section{General Responses}

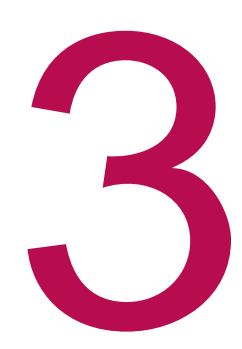

\subsection{The variable impact of Covid-19}

Although the statistics on Covid-19 infections, hospitalisations and associated deaths clearly remain a moving target, it is already inevitable that the UK will be amongst the worst affected countries in the developed world. Although the densely populated nature of the country and its role as an international trading centre have played a part, in the eyes of many this high toll may be attributed to a failure of government at the national scale. This relates not only to inadequacies of the immediate response and the ever-shifting provisions in the aftermath, but as much to lack of preparedness at all levels of government. According the chair of the review into the low impact 2009 H1N1 swine flu outbreak in the UK (Hine, 2010), successive governments had 'taken their eye off the ball' and failed to prepare fully, despite the threat of a global pandemic consistently being at the top of their risk register (Clarke, 2020).

While this is not the place to assess the performance of Central Government in detail, it is important to acknowledge it as a key part of the broader landscape within which actions at a local scale have unfolded. Marmot et al. (2020b) examine the systemic inadequacies which have built up over the past decade, and which underpin the heavy impact of the virus in the UK. They identify four fundamental factors:

- Governance and political culture: the aforementioned 'market paradigm' has damaged social cohesion and inclusiveness, undermined trust, de-emphasised the importance of the common good, and failed to prioritise the health and wellbeing of the population.

- Widening inequality: the last decade has seen the gap in incomes, wealth and power increase at a rapid rate, generating huge inequality between individuals, communities and regions, with clear repercussions for health outcomes (see also de Gruchy, 2020).

- Government policies of austerity: these have almost universally had negative consequences, with welfare and public services in a depleted state and the tax and benefit system regeared to the disadvantage of lower income groups.

- Cessation of health improvement: the other three factors have combined to produce a marked increase in the conditions that increase susceptibility to Covid19 risk, such as obesity, heart disease, asthma and diabetes.

Analysis of morbidity and mortality figures for first variant Covid-19 clearly reveals the higher levels of risk for certain people: those experiencing high levels of deprivation, living in overcrowded housing, employed in key worker roles with close proximity to others, being from a Black, Asian and Minority Ethnic (BAME) group, having underlying health conditions, being in an older age group and being male (Marmot et al., 2020b). In turn this implies that certain types of geographical area are also susceptible to higher risk, for example urban settings with above average proportions of overcrowded and multiple-occupation dwellings, diverse populations and labour-intensive factory or 
warehouse employment. Much of this has been shown to coincide with 'older industrial Britain' and concentrated in northern, western and coastal areas (Beatty and Fothergill, 2021). In line with this, some local authority areas have experienced much higher infection rates than others, making their responses not only more difficult, but also more essential. In this sense, the pandemic has amplified existing inequalities in health and their underlying determinants, with additional economic and social harm associated with lockdown-related measures likely to worsen physical and mental health in a similarly disproportionate way (Marmot et al., 2020b).

The rest of this section examines some of the general local government responses across the UK, including a geographical summation of the additional emergency financial support allocated to local councils in England by Central Government.

\subsection{Covid-19 policy timeline}

Table 3.1 sets out a simplified timeline of the varied restrictions on economic and social activities imposed by the four national governments in the UK as a means of containing the spread of Covid-19. This extends from the mutually agreed full national lockdown introduced on $23^{\text {rd }}$ March 2020 through to the different measures used to address the 'second spike' in November and the subsequent comprehensive regionalised approach. This brief summary underlines the extent to which local authorities in different parts of the UK have had to adapt to an ever-changing mixture of permissions and proscriptions, often at very short notice. It also highlights the divergence in practice between the UK government and the devolved administrations, a function mainly of differential infection rates and timings, but nevertheless with unmistakeable overtones of political mistrust and autonomy, not least in Scotland.

Table 3.1: UK Covid-19 Restrictions Timeline, 2020

\begin{tabular}{|c|c|c|c|c|}
\hline & England & Scotland & Wales & Northern Ireland \\
\hline From 23 ${ }^{\text {rd }}$ March & \multirow{3}{*}{\multicolumn{4}{|c|}{ Full lockdown }} \\
\hline April & & & & \\
\hline May & & & & \\
\hline June & \multirow{2}{*}{$\begin{array}{l}\text { Restrictions } \\
\text { gradually relaxed }\end{array}$} & \multicolumn{2}{|l|}{ Full lockdown } & \multirow{2}{*}{$\begin{array}{l}\text { Restrictions } \\
\text { gradually relaxed }\end{array}$} \\
\hline July & & \multirow{2}{*}{\multicolumn{2}{|c|}{ Restrictions gradually relaxed }} & \\
\hline August & \multirow[t]{2}{*}{$\begin{array}{l}\text { Limited } \\
\text { restrictions }\end{array}$} & & & $\begin{array}{l}\text { Limited } \\
\text { restrictions }\end{array}$ \\
\hline September & & \multicolumn{3}{|c|}{ Some local restrictions reintroduced } \\
\hline October & $\begin{array}{l}\text { Local } \\
\text { designations then } \\
3 \text { 'tier' system }\end{array}$ & $\begin{array}{l}\text { Gradual national } \\
\text { reintroduction of } \\
\text { restrictions }\end{array}$ & $\begin{array}{l}\text { 2-week } \\
\text { 'firebreak' partial } \\
\text { lockdown from } \\
\text { Monday } 19^{\text {th }}\end{array}$ & $\begin{array}{l}\text { Gradual national } \\
\text { reintroduction of } \\
\text { restrictions }\end{array}$ \\
\hline November & $\begin{array}{l}\text { 4-week partial } \\
\text { lockdown }\end{array}$ & $\begin{array}{l}\text { Move to a } 5 \\
\text { 'level' system } \\
\text { (Levels } 0 \text { to } 4 \text { ) }\end{array}$ & $\begin{array}{l}\text { Some relaxation, } \\
\text { then further local } \\
\text { restrictions } \\
\text { imposed }\end{array}$ & $\begin{array}{l}\text { Continued } \\
\text { national } \\
\text { restrictions }\end{array}$ \\
\hline December & $\begin{array}{l}\text { Comprehensive } \\
3 / 4 \text { 'tier' system }\end{array}$ & $\begin{array}{l}\text { Most of country } \\
\text { placed in highest } \\
\text { Level } 4\end{array}$ & $\begin{array}{l}\text { National } \\
\text { lockdown } \\
\text { reimposed on } \\
\text { Friday 18th }\end{array}$ & $\begin{array}{l}\text { 2-week 'circuit } \\
\text { breaker' partial } \\
\text { lockdown }\end{array}$ \\
\hline
\end{tabular}




\subsection{Local outbreak management plans}

Under the government's Covid-19 Contain framework in England 'upper tier' local authorities with responsibility for public health were required to draw up a 'local outbreak management plan' (LOMP) to guide themselves and partner agencies in coordinating actions and embedding a preventative approach. These plans have centred on 7 core themes (Department of Health and Social Care, 2020):

- Healthcare and education settings.

- High-risk workplaces, communities and locations.

- Rapid local testing deployment to such places.

- Contact tracing in complex settings.

- Local and national data integration.

- Support for vulnerable people and diverse communities in self-isolating.

- Ensuring effective governance and public communications via local boards.

In order to expedite urgent responses eligible local authorities have been given additional powers to order the closure of individual premises and public outdoor spaces, and to prevent specific events from proceeding, without recourse to standard legal processes.

Apart from specific provisions that reflect the distinctiveness of a local area, the nature of the pandemic means that most LOMPs have very similar content. The one produced by Haringey Borough in London provides a flavour of this. Its plan hinges around a series of key priorities (Haringey Borough Council, 2020):

- Regular and timely sharing of statistics and other relevant information on Covid19 infections with all partners.

- Communication and engagement with local residents, businesses and other organisations with regard to the latest rules and developments, using different media and in alternative language formats, especially to meet the needs of Black, Asian and Minority Ethnic (BAME) communities.

- Operational management of any severe or localised outbreaks, in partnership with relevant bodies and neighbouring authorities.

- Ensuring that complementary testing capacity is available where needed (this has been assembled in conjunction with four other neighbouring councils).

- Outbreak prevention and management in specific settings such as care homes and schools.

- Helping people to plan in advance in case they need to self-isolate, with specific focus on older, more vulnerable and BAME residents.

Although there is no comprehensive data on how different councils have approached the vital issue of public communications, personal observation suggests some variance in practice. Thus, City of Bradford Council has sent every household a printed contacts sheet, in different languages, listing phone numbers and email addresses of public and voluntary sector support organisations for those facing particular issues such as debt. It also runs a sign-up email messaging service to provide regular updates on the latest rules and guidance applicable to the area, also available in alternative languages. In contrast, Sheffield City Council has mainly relied upon ensuring that the information on its website is regularly updated, leaving it to residents to access any new postings on their own initiative. 


\subsection{Local authority workforce impacts}

Most commentators agree that the immediate response of local government bodies across the UK was rapid and decisive. Thus, according to the WLGA (2020a, p.3) “...within days and weeks, councils redesigned and reprioritised essential local services, suspending some services and introducing new operating models, with thousands of workers working remotely and many thousands of workers in other services volunteering to temporarily change roles overnight to help contribute to the emergency effort." This involved considerable disruption in terms of staff management, with extensive redeployment and repurposing, alongside adjustment to working from home using virtual means, as well as some employees being placed on furlough. In line with the deep-rooted ethos of public service the local authority workforce has generally shown great flexibility and commitment in serving their local communities (LGA, 2020e).

In England the LGA has been conducting a fortnightly survey of its members since the end of March, asking standard questions about changing staff patterns. Not surprisingly widespread redeployment to urgent tasks was reported by $87 \%$ of respondents in May, and $62 \%$ in November. The sudden increase in support tasks falling on local councils prompted the recruitment of additional staff by $74 \%$ of respondents in May and 34\% in November. At the same time, while furloughing of staff has occurred, it has generally involved small numbers of people and been relatively short term (16\% of local authorities reported as having taken this step in May, rising to $25 \%$ in November). Nor has local government been immune to the direct effects of the pandemic, with staff absence running at higher rates than normal, with an average of $7 \%$ in May and $5 \%$ in November. The overall effect, alongside the impacts of the pandemic itself, led $27 \%$ of respondents to report 'moderate or severe disruption to operation' in May, with $21 \%$ saying the same in November.

\subsection{Additional Financial Support to Local Authorities}

In recognition of the extreme pressures faced by local authorities the four national governments have made a series of additional financial allocations to underwrite their responses. This has involved a mixture of discretionary and ring-fenced funding, with the former allowing individual councils to direct the resources to where they are most needed locally, and the latter provided for particular purposes specified by each government. Detailed data on the amounts allocated is readily available for local authorities in England, but less easy to identify for Scotland, Wales and Northern Ireland.

Local authorities in England received a total of $£ 4.61$ billion in emergency discretionary funding between March and October 2020. This was provided in four tranches:

- An initial £1.6 billion was allocated in late March (to coincide with full national lockdown) on the basis of historic assessments of adult social care spending.

- A further $£ 1.6$ billion followed in mid-April and was distributed on a simple per capita basis.

- $\quad £ 0.5$ billion was added in July, with allocations this time calculated according to a 'relative needs formula' (RNF) which took geographical variations in deprivation levels into account, plus an 'area cost adjustment' which factored in the varying labour and capital costs of delivering services in different parts of the country (Calkin, 2020).

- An extra £0.92 billion was provided in October, again using the RNF, but with further supplements for areas where stronger restrictions were reimposed as part of Tier 3 ('very high alert') designations. 
This general funding has been used for a range of purposes, in particular to extend the reach and increase the speed of vital service delivery, especially services that help to protect the most vulnerable residents; to make emergency payments to families whose incomes have disappeared; and to provide personal protective equipment (PPE) for voluntary carers. Councils have also used it to offer grants to businesses allowed to remain open during full lockdown but suffering from depleted demand, and subsequently to accelerate regulatory procedures for businesses reopened but operating in a socially distanced fashion.

In addition, a raft of additional ring-fenced funding streams has been put in place for English local authorities. These include:

- The Compliance and Enforcement Grant ( $£ 60$ million shared equally with local police forces) covered training and salary costs for Covid-19 marshals or ambassadors charged with encouraging compliance with social distancing rules in public places.

- $\quad$ The Test and Trace Service Support Grant ( $£ 300$ million) is intended to enable upper tier local authorities to contribute to or take prime responsibility for tracing the recent contacts of those who have received a positive result from a Covid-19 test under the nationally run scheme.

- The Local Authority Emergency Assistance Fund for Food and Essential Supplies (£63 million) was earmarked to support charities and community groups which are helping people struggling to afford and/or obtain food and other essential supplies due to shielding or self-isolating.

- The Council Tax Covid-19 Hardship Fund provided $£ 500$ million so that councils could reduce the burden on low-income households by $£ 150$ for the 2020/21 financial year. Priority was given to those already eligible for partial relief under the working age local council tax support (LCTS) arrangements. Any surplus remaining after these commitments had been met could then be used to support other households in need (MHCLG, 2020h).

- The Adult Social Care Infection Control Fund was implemented in two rounds, the first ( $£ 600$ million in total) in May/June to support providers in keeping residential care homes safe; and the second ( $£ 546$ million) in September split 70:30 between a top-up to care homes and support to reduce infection risk in community care provider premises.

- $\quad$ Further money was provided via the Department for Culture, Media and Sport (DCMS) to support the safe reopening and operation of council leisure centres (£100 million).

- The Local Government Income Compensation Scheme will offset lost revenue from sales, fees, rents and charges. As it relies on local authority claims which are difficult to predict, to date no limit to the budget for this has been set.

- The Local Restrictions Support Grants and the Control Outbreak Management Fund were both specific to those areas mostly in the north of England that moved into Tier 3 in October. They involved a flat rate per head of population to underwrite further business grants and to enable more intensive public health actions.

- The Additional Restrictions Grant did the same but with lower per capita rates for all other local authorities placed in Tiers 1 and 2.

- In October the Contain Outbreak Management Fund provided an extra £4 per head of population per month for areas assigned to Tier 3, and £2 per head per month for those placed in Tier 2. Given the uncertainty over how long areas remain in each Tier there are no definitive figures on the total cost of this. 
- Extra amounts have also been allocated to address homelessness ( $£ 0.1$ billion see Section 5) and other services ( $£ 0.4$ billion), although there are no breakdowns for individual local authorities available for these.

Similar financial support has been provided to local authorities in the three devolved administrations. Unfortunately, it has not been possible to obtain figures disaggregated by purpose or local authority area. The overall amounts allocated in each nation are as follows:

- $\quad$ Northern Ireland - $£ 120$ million in 2 tranches.

- Scotland - $£ 864.6$ million to end of June, $43 \%$ of which was to compensate for the Council Tax payment holiday.

- Wales - $£ 490$ million in two tranches.

Figure 3.1 illustrates the geographical distribution of this additional funding across the UK, standardised on a per capita basis. It should be noted that not all possible extra funding has been included for England, partly because specifically targeted business assistance is analysed in more detail in section four and partly because some of the funding streams represent resources already committed but brought forward to meet a pressing need (e.g., the active travel allocations examined in greater detail in section seven). Moreover, direct comparison between English regions and the devolved territories should be avoided, as the latter cover all additional payments rather than an equivalent selection.

The chart clearly highlights the greater priority given to those areas where infection rates were highest in the first and second waves of the pandemic in the UK. This holds for both general and ring-fenced funding, and underlines the greater levels of deprivation and hence more pressing need to contain infection rates in the north of England, the West Midlands and London. The higher average levels for Scotland and Wales doubtless reflect the inclusion of all business payments in their totals, whilst the lower figure for Northern Ireland is a function of the narrower range of powers and responsibilities exercised by its District Councils.

Figure 3.2 assesses the additional grant allocations to support social and community care providers in England on the basis of local capacity (i.e., the total potential number of people that the local system can serve, in the form of care home beds and day centre places). The highest average amounts have gone to regions in the south and east of the country. This probably reflects the higher costs of provision in these areas, especially in terms of property in the care homes sector. The much lower figure for Greater London is explained by a greater proportion of its mix being made up of less expensive community care provision. 
Figure 3.1: Additional Covid-19 Local Authority Funding Allocations by Region and Country, UK

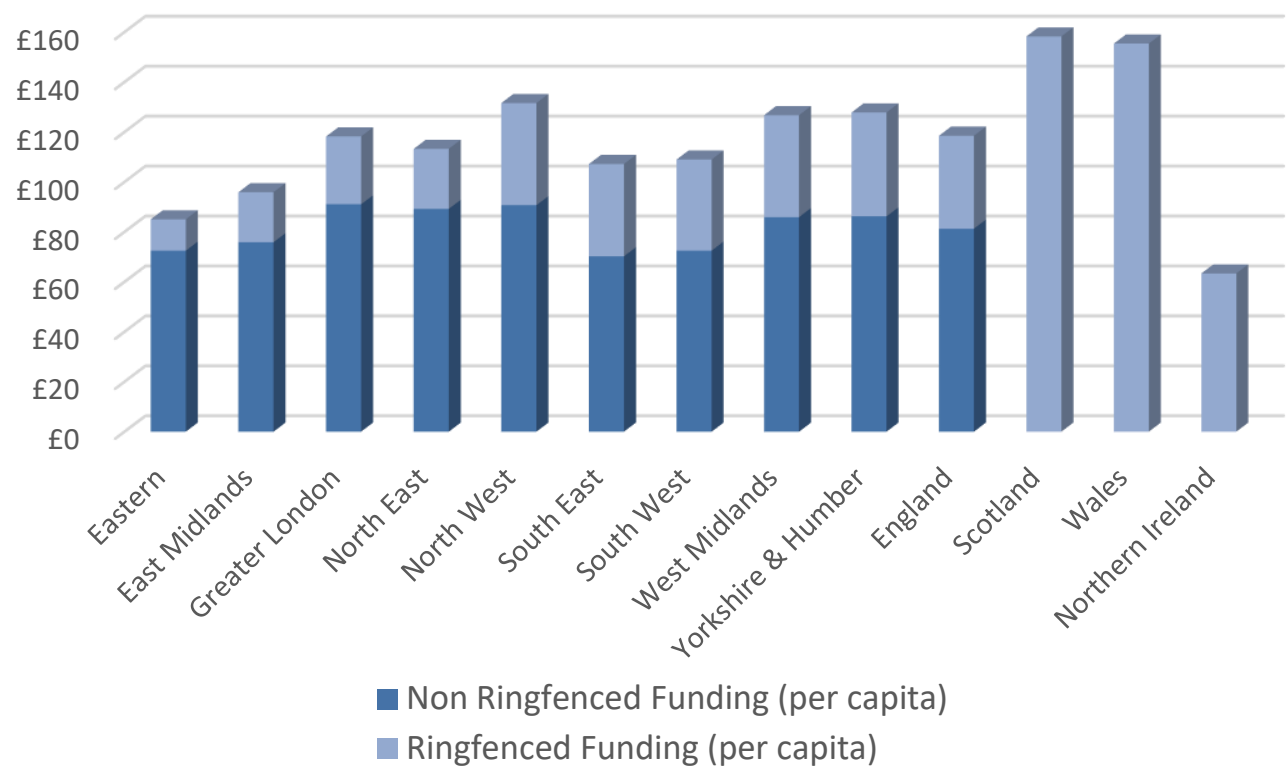

Figure 3.2: Additional Covid-19 Local Authority Funding for Adult Social Care by English Region

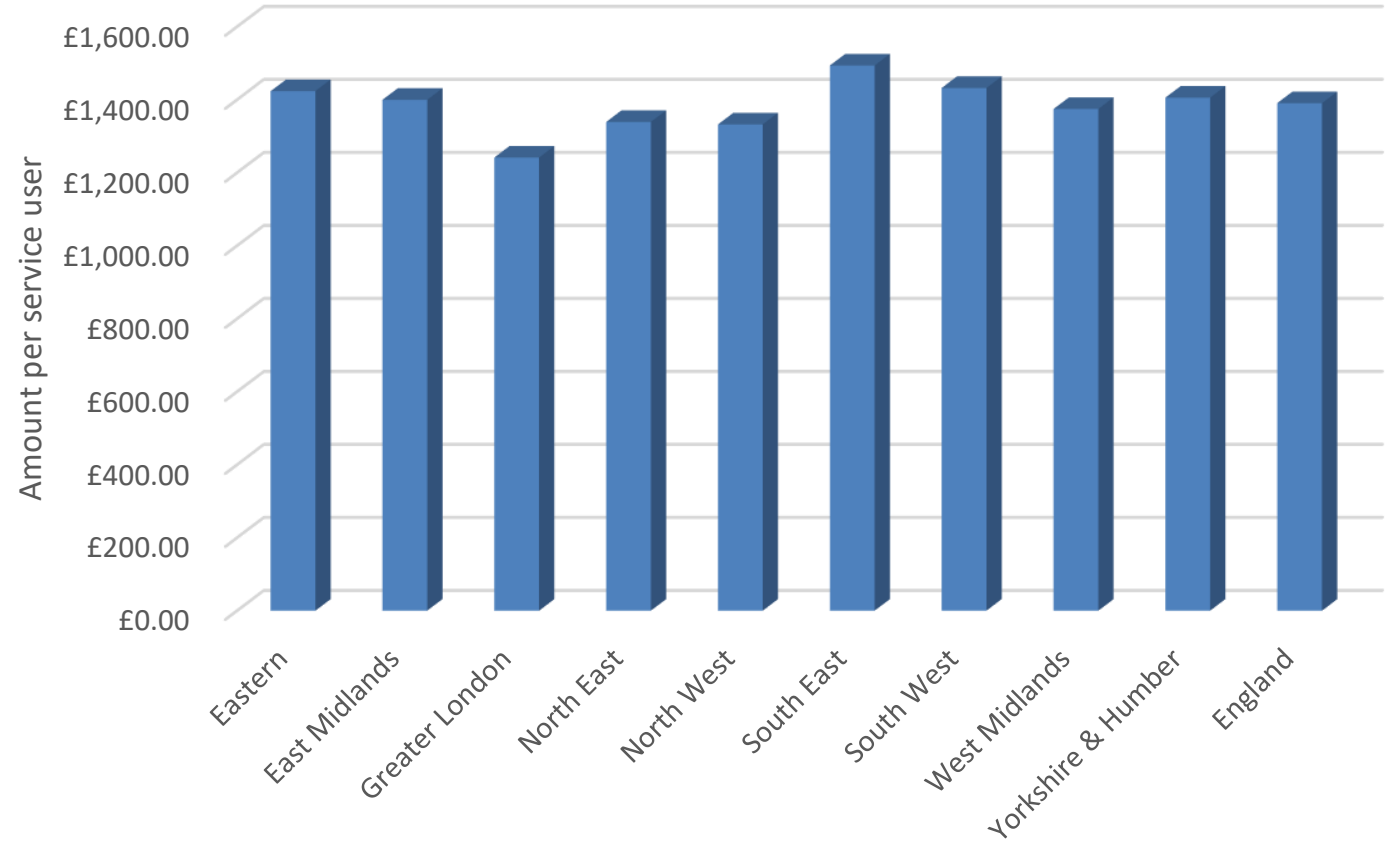

\subsection{Financial shortfalls and threats}

According to Sandford (2020) local authorities across the UK have reported substantial reductions in locally generated revenue due to restrictions on social, economic and leisure activity. The main areas where such losses have been incurred are as follows:

- Council Tax: In order to help residents with financial difficulties, several authorities have announced a 'council tax holiday' whereby payment can be deferred. 
Revised regulations and rising unemployment have also made more people eligible for partial exemption from paying the tax.

- Commercial property: Businesses renting council-owned property have been forced to close and the consequent lack of cashflow has prevented them from maintaining rental payments. Many local authorities have allowed deferral or temporary waiving of such payments as a form of indirect business support.

- $\quad$ Other commercial income: Income from chargeable services such as car parks and leisure centres fell steeply during full lockdown, with the latter struggling to attract customers even with the relaxation of restrictions during the summer.

- Business Rates: There are national schemes that have removed or reduced liability for these local property tax payments for businesses that have been forced to close or operate on lower capacity. However, arrangements have been put in place to reimburse local authorities for any revenue lost as a consequence (see section five for further analysis).

- The total decrease in local authority revenue in England for 2020/21 has been estimated at between $£ 6$ billion and £10 billion (Lilly et al., 2020; Sandford, 2020). Around a third of this is expected to involve 'other commercial income'. Ogden and Phillips (2020b) have estimated that the result will be an average $5 \%$ shortfall in total non-tax revenue compared with what had been budgeted for. Others have speculated that this will force councils to make cuts in services before the end of the financial year (Butler and Barr, 2020). However, the impacts are likely to vary between different types of local authority given their contrasting mixture of funding sources. Thus, lower-tier authorities (Shire Districts) tend to be more reliant on income from sales, fees and charges, and hence may suffer much larger hit to their finances. The range of possibilities is indicated by a further set of estimates produced by Ogden and Phillips (2020b), whereby the fall in non-tax revenues for a third of English local authorities will be under $5 \%$ below budget, whereas one in six are expected to lose at least $20 \%$.

Many councils have made use of their revenue reserves to supplement the additional funding provided by Central Government, although at present the extent of this remains unclear (Phillips, 2020). Analysis of the scale of such unallocated reserves immediately prior to the onset of the pandemic suggests considerable variation, with one estimate indicating that they may be insufficient to meet projected shortfalls in $80 \%$ of 'upper tier' authorities in England. Many of these are in older industrial areas where the effects of Covid-19 have been most severe (see Section 3.1) (Billingham, 2020). However, some cities like Sheffield have been able to tap into a mixture of general reserves and additional borrowing to build up a 'war chest' to plug the gaps (Ashton, 2020a; 2020b). Similar variation also exists in Wales, where the level of usable reserves as a percentage of the net annual cost of providing services ranged from $5 \%$ to $33 \%$, with two-fifths of councils seeing a reduction in total reserves over the 2019/20 financial year (Audit Wales, 2020).

In July 2020 English local authorities reported to MHCLG that they expected to spend $£ 5$ billion more than originally budgeted in $2020 / 21$, with half of this related to extra adult social care costs (Ogden et al., 2020). The additional emergency funding has gone a long way to bridge this gap, but most commentators think that there will still be a shortfall; the uncertainty is over how large this will be (Grant Thornton, 2020). One forecasting model indicated that it might be as high as $£ 1.9$ billion for local authorities across the UK as a whole, though some councils are more confident than others about being able to manage their financial position in the short term (Matsu and Woolley, 2020; Ogden et al., 2020). More recent analysis suggested that collectively councils in England alone might end the current financial year £1.7 billion over budget (Scott, 2021). Despite dire warnings from local authority leaders (BBC News, 2020; Proctor, 2020) no council has declared itself bankrupt as a result of the financial pressures 
engendered by the pandemic. Indeed, the only such 'Section 114' notification (by Croydon Council in south London) resulted from injudicious investment decisions some years previously (Atkins, 2020).

This is not to imply that the crisis has been weathered. Adverse longer term impacts will be related not just to the pace of recovery from Covid-19 effects, but also to other global, national and local changes in international trade relationships, government policy and moves towards more integrated service operation (for example, in health and social care). All councils have been concerned for some time about their financial position from 2021/22 onwards, and the pandemic has magnified these long-standing issues (Sandford and Muldoon-Smith, 2020). Various studies have produced a range of alarming calculations:

- $\quad$ County Councils in England are likely to have a funding shortfall of between $£ 1.4$ billion and £2.2 billion in 2021-22, and $80 \%$ will have to make severe cuts to avoid insolvency (County Councils Network, 2020).

- $\quad$ Around half of all councils will face complete depletion of their reserves within five years (Matsu and Woolley, 2020).

- In order to maintain services at current levels local authorities would require an extra £2.5 billion in 2021/22, rising to $£ 3.3$ billion in 2024/25 (Ogden et al., 2020).

- Following the announcement of a $4.5 \%$ increase in local authority funding allocations for $2021 / 22$, an estimated funding gap of between $£ 0.8$ billion and $£ 1.6$ billion for the same financial year still remained (Ogden and Phillips, 2020d). Since then, however, further central government allocations have reduced this deficit to £0.6 billion (NAO, 2021).

- In a third of local authorities this gap will represent $5 \%$ or more of their revenue expenditure, and most have already or are planning to use their reserves to make up the shortfall. Those that are unable to do so are at greatest risk of financial failure (NAO, 2021).

Accepting the uncertainties surrounding such projections, without additional funding the vast majority of local councils in England expect to reduce service budgets in 202122, with inevitably adverse impacts on service levels and standards (NAO, 2021). Whether the "fuller, more comprehensive solution" on local authority finance promised by MHCLG to the House of Commons Public Accounts Committee (2020) will fill the gap remains to be seen.

\subsection{Coordinating mutual aid}

One of the most outstanding features of the civic response to the pandemic in the UK has been the spontaneous emergence of around 3,500 mutual aid support groups, mostly at a neighbourhood scale, in all types of community. Their rapid success has been founded on their ability to work quickly, flexibly, responsively and in a personcentred manner (Tiratelli and Kaye, 2020). They have devised solutions to a range of problems faced by individuals and households, firstly during full lockdown, and subsequently during periods of more relaxed or reimposed restrictions. Tasks undertaken include ensuring access to supermarket priority delivery slots; assembling food parcels and organising transport for their delivery; solving digital access for those shielding or self-isolating or needing to continue their education; establishing 'buddy' schemes for isolated vulnerable people; helping schools to develop their home learning approach; and enhancing and adjusting support to community and family carers (Heritage, 2020; WLGA, 2020a).

The role of local government in fostering, supporting and coordinating such activity appears to be mixed. In many places there has been a positive 'complementary' 
relationship, providing these groups with the space and support that has enabled them to flourish (Dayson and Damm, 2020; Tiratelli and Kaye, 2020). However, some local authorities have adopted a controlling stance, either through highly prescriptive regulatory requirements or via micromanagement to align groups' activities with council plans and strategies. Others have tended to ignore these community-based responses, sometimes at the risk of duplicating efforts, whilst there are cases where there have been several shifts in approach, starting with a relatively open 'anything goes' approach, followed by a more structured increase in collaboration, innovative ideas and compassion, but culminating relatively quickly in more familiar negative system processes and behaviours (Cox, 2020). The latter mainly involved gradual reimposition of control over the flow of information; development of more clearly defined but frequently over-prescriptive procedures and eligibility rules as a way of stretching limited resources; and a step back in the sharing of power in the form of topdown 'command and control' directives. Further research is already under way to explore the varying circumstances and conditions within which these different relationships emerge and evolve (Macmillan, 2021).

As well as local authorities, the coordinating and enabling effort has involved governance organisations at a smaller scale too, including community and town councils (for example, Frome in Somerset) and existing residents' associations in affluent and low-income areas alike (Harris, 2020b). In some instances, this has involved working in tandem to ensure that no-one in need falls through any potential gaps, or to link people into the most relevant organisation. Although not exclusively the case, such joint working appears to have been most successful in localities where councils had already begun to operate in a more 'community-facing' way before the pandemic struck (Cretu et al., 2020; Local Trust/NLGN, 2020).

This has occurred especially in Scotland, where a comprehensive move towards community planning was already under way, involving devolution of much decisionmaking to local partnerships and the deployment of neighbourhood officers to encourage engagement and communication (Coutts et al., 2020). This groundwork has underpinned effective coordination of civil society responses in councils such as Perth and Kinross (SURF, 2020). Evolution of this facilitative approach is also evident in some English and Welsh councils. Its main distinguishing features are that it relies on 'gentle steering' rather than 'top-down' commands; it offers in-kind support and helps to connect people and networks together; it involves collaborative budgeting and consistency in contact and coordination; and it seeks to build community leadership skills on as broad a basis as possible (Tiratelli and Kaye, 2020). A good example of what can be achieved through such collaboration can be found in Oxford, where the City Council tied its existing call centre operations into a wider community response digital system called Oxford Together (Willis and Fernandez, 2020). A similar countywide 24-hour helpline was put together for Kent (NLGN, 2020), whilst joint working in Barking and Dagenham in east London enabled the creation of Community Solutions, an integrated 'front door' to key support services (Compass, 2020; Lawson, 2020).

\subsection{Local testing and contact tracing systems}

A key aspect of controlling an infectious outbreak such as Covid-19 is to ensure that those who have caught it, and those with whom they have been in contact, enter a period of self-isolation so that they do not infect anyone else. For this to occur widespread testing and comprehensive and effective contact tracing are essential. The original system overseen by Public Health England was suspended at the end of March, eventually being replaced at the end of May by a £22 billion Central Government contract to a private provider consortium with minimal experience of operating this type of intervention (NAO, 2020b). In principle local authorities were to perform an essential supporting role, particularly in terms of local contact tracing, and an extra $£ 300 \mathrm{~m}$ of funding for this responsibility was provided (see Section 3.5 above). 
In the early stages it was unclear exactly which local agencies the contractors should be working alongside, resulting in considerable fragmentation and delay in full implementation. Even once these issues were resolved difficulties around time lags in receiving test results, poor quality contact details and gaps in data sharing placed severe limits on what local councils could achieve. This prompted the Department of Health and Social Care to set up pilots with 11 "beacon" areas in England (including Leeds, Leicestershire and Newcastle) to test practices and procedures for local authority involvement (Harris, 2020a).

Even then the problems with the national system persisted, only reaching around $60 \%$ of those on its contact lists and hence failing to contain the spread of infection. In response several local authorities established their own contact-tracing systems. This particularly involved areas in the North and Midlands with the highest infection rates. The first to launch its own service was Blackburn with Darwen Council, which assembled a large team of staff, mostly seconded from other departments. With support from Public Health England and guided by environmental health officers well versed in such 'shoe leather epidemiology', its task was to track down people who had not been reached by the national system after 48 hours. If local officials still did not make contact after two days, council workers would visit their address to pass on advice and offer support. The Blackburn model also factored in potential language issues, as well as other vulnerabilities using the knowledge of community-based teams (Halliday and Elgot, 2020).

Similar approaches were soon under way in other council areas including Calderdale, Greater Manchester, Kirklees, Leicester, Liverpool and Sandwell. These schemes have succeeded in making contact with over $90 \%$ of those who had previously fallen through the gaps. Some of them, as in Calderdale, have even taken over prime responsibility for contacting those who have returned a positive result after testing. All are sent a text message with a local number to call, and a home visit follows if no reply is received within 24 hours. The success of the approach rests upon the deployment of a large team of specialist contact tracers with extensive local knowledge (Halliday and Pidd, 2020). Equivalent arrangements have also been made in many local authority areas in Wales.

It could be argued that local authorities' participation in contact tracing could have started on their own initiative much earlier, rather than as a reaction to the failings of the national system. The interventions taken by Ceredigion Council, a rural local authority in west Wales, are instructive here. Not only did it reach agreement with the major local employers (a university and the seaside tourism industry) to close a couple of weeks prior to the full lockdown in March 2020, but it also worked with the health service to instigate its own contact tracing scheme. Recent contact lists were compiled for all those with a positive test or reported by GPs to be suffering from Covid-19 symptoms, and the people identified chased up to ensure that they entered a period of self-isolation, with appropriate practical support to make this feasible. The result was an infection rate four to five times lower than equivalent councils elsewhere in rural Wales (Clements, 2020). While some of this advantage was eroded after the summer relaxation and the return of tourists from other parts of the UK, the area's infection rate still remains amongst the lowest in the UK. It shares this with other rural areas, especially in remote parts of Scotland. In the islands cooperation between national and local government and the ferry companies has restricted travel to delivery vehicles and other essential journeys (Carrell, 2020).

More recently the availability of lateral flow testing for Covid-19 has allowed some councils to introduce their own mass testing regimes. In Liverpool this involved Army personnel as well as health workers and redeployed City Council staff, and was rolled out in a range of community as well as central venues. In Stoke-on-Trent it involved health workers such as district and school nurses, fire service staff and council home 
care assistants, amongst others. Similar approaches were introduced in Renfrewshire in Scotland and Merthyr Tydfil in Wales, before being extended to more councils, including 102 upper tier authorities across England. Although the tests have mixed reliability, the rapid results at least meant that little time has been lost in isolating those with a positive outcome. Initial evidence from early rounds of application was that they are beneficial particularly in terms of identifying people who are asymptomatic, and in enabling key public sector workers and care home staff to continue working (Brown, 2020). At the same time, there have been delays to roll-out in several areas due to lack of clarity over the availability of funding (NAO, 2020b).

A major fear is that this good work may be too little, too late. The words of Dame Deirdre Hine, the chair of the review of the country's 2009 response to the swine flu outbreak, are again instructive. "I could not understand why governments moved away from test, track and isolate - that is the basis for the control of any infectious disease. They could have got it up and running much faster. In my view, the (local) public health approach with laboratories right across the country - the little ships rather than the large destroyers or aircraft carriers we have now - would have been more effective and could have been mobilised very quickly" (quoted by Clarke, 2020).

\subsection{Conclusions}

The far-reaching impacts of the Covid-19 pandemic have stimulated local responses involving organisations in all corners of society. Although there have been inevitable variations, in most places there has been a concerted and reasonably well-coordinated effort to meet the needs of local residents and businesses. This is reflected in the high satisfaction levels with local authority key workers during the pandemic reported in a recent survey (APSE, 2020). These positive working relationships stretched well beyond local authorities, health service organisations and even established voluntary sector bodies, being driven in large part by both new and existing neighbourhood mutual aid groups. Through them many local state institutions have reinforced or recalibrated their relationships with civil society into 'complementary' forms (Dayson and Damm, 2020). A potential consequence is the strengthening of local governance and a commitment to closer joint operations in the future (Cretu et al., 2020; Munro and Burbidge, 2020). This is an impressive feat given the reduction in resources and capacity experienced over the previous decade, and the short timescale and pressing needs that have framed its emergence. Indeed, in the best cases it could be claimed that this represents an exemplary instance of collaborative local governance in practice.

However, the variations between and within local authorities should be acknowledged; this collaborative, consultative approach has not been universal either in terms of geography or policy domain. Some councils may have started out with these inclusive intentions but have found them difficult to sustain over time. In other places good intentions to collaborate have been hampered by differences in organisational cultures, priorities and performance regimes (Munro and Burbidge, 2020). Nevertheless, key lessons are emerging for local leaders, around nurturing relationships with partners; agreeing clear shared objectives; ensuring local politicians are centrally involved; fostering a conducive organisational culture; and workforce and leadership development to embed the ethos.

Of course, much of what local government is able to do is dictated by Central Government, especially in England, and the extent to which councils are trusted to deliver what is required. The evidence in this section implies a rather ambivalent attitude with respect to local roles in addressing Covid-19, rather than "the largely dysfunctional central/ local government dynamic" claimed by Munro and Burbidge (2020, p.5). On the one hand, the £4.6 billion of general emergency funding provided to English local authorities has given them discretion to direct resources to the most 
pressing needs in each area, and the ring-fenced specific purpose allocations illustrate a fair degree of faith in councils to ensure the support reaches intended beneficiaries as speedily as possible. On the other hand, the sidelining of most local authorities and health bodies from testing and contact tracing, even after the failings of the contracted national system were evident, implies a lack of understanding of the relevant experience and expertise that such local teams could contribute (Stone, 2020; Sillett, 2020). There have also been occasions when Central Government has failed to consult, or even inform, council leaders in affected areas before announcing new sets of restrictions aimed at containing the spread of the virus (LGIU, 2020; Walker, 2020).

Despite the positives it is clear that considerable frustration exists at the local scale. Thus, most local authority chief executives interviewed for a Royal Society of Arts (RSA) report agreed that the national context was unhelpful, particularly the way that Central Government behaved. Similarly, a review by the C-19 National Foresight Group concluded that the local resilience forums did not feel understood or trusted by Central Government ministers and officials. "The lack of trust in the local structures from ministers and government departments and representatives...impacts on their ability to feel included as part of a greater UK wide management of the pandemic"; this in turn "undermines any building of integrity and trust in the local as they are the public face of the government approach at local level" (Hill et al., 2020, p.6).

Here the contrast with Wales is stark: national and local government have worked in close partnership, with regular dialogue between Ministers and WLGA representatives and weekly meetings between all 22 Council leaders and Ministers. This helped communication of national priorities and strategy directly to local leaders on the one side, and brought significant local issues and innovations to the attention of Ministers on the other (WLGA, 2020b). Parallel collegiate approaches are being followed in Scotland and Northern Ireland, a trend which underlines the need for comparative cross-UK research to investigate ways in which local and sub-national governance systems can achieve an acceptable blend of democracy, subsidiarity and universality in meeting the population's needs. 


\section{Economic Support and Recovery}

\subsection{Introduction}

The economic consequences of national lockdown and subsequent varied restriction regimes have been severe, with all industrial and service sectors affected in some way. Those classed as 'non-essential' during initial lockdown and later subject to curbs on their operation (or even continued closure) have probably been the hardest hit. This has chiefly involved establishments that rely on customers gathering in one place, so continued operation (or reopening) has been contingent mainly on the scope for maintaining social distancing between customers. However, adverse impacts have not just been aligned on a sectoral basis; different modes of business organisation amongst small and medium-sized enterprises (SMEs) have encountered difficulties both in maintaining workflow and in fitting government criteria for financial support. This includes business owners who rely on dividends and those in certain forms of self-employment.

At the start of national lockdown in March 2020 the UK Government designated a range of business sectors as 'non-essential' and ordered them to cease trading while full restrictions applied. The main activities on the list were:

- Restaurants, cafés, public houses, bars and nightclubs.

- All retail outlets (including outdoor markets) other than food shops, pharmacies, petrol stations, bicycle shops, newsagents, post offices and banks.

- Hotels, guest houses, hostels, caravan parks and campsites.

- Cinemas, theatres, concert halls, professional sports venues, casinos and betting shops.

- Libraries, community and youth centres, leisure centres and gyms, places of worship, museums and galleries.

- Outdoor sports facilities.

During the summer relaxation period many (but not all) of these were allowed to reopen, and subsequent reimposition of tighter restrictions has entailed a shorter list of proscribed activities. For example, builders' merchants have remained open, allowing the resumption of outdoor construction work to continue. The main sectors affected throughout have therefore been tourism, hospitality, entertainment and leisure.

This section examines the main forms of business support provided, beginning with an outline of the main UK-wide schemes, followed by an initial analysis of the grants and payment reliefs offered through local authorities on behalf of the respective 
national governments. A brief review of other practical forms of business support provided at the local scale ensues. The section then turns to a preliminary assessment of the plans and strategies that have been developed at local level to steer and support recovery from the adverse economic impacts of the pandemic.

\subsection{Central Government business support schemes}

Government guidance for both private and public sector activities has been for staff to work at home wherever possible. Clearly this is not practicable for many types of business, so a wide-ranging government support package was rapidly devised and introduced as lockdown started in late March. A great deal of this financial support was provided directly via HM Treasury and the Department for Business, Energy and Industrial Strategy (BEIS) on a UK-wide basis, mainly on the grounds of efficiency and consistency. The main schemes have taken three main forms. Firstly, wage or salary replacement payments have allowed employees who are unable to work to be placed 'on furlough' and for some business owners and the self-employed to substitute some or all of the income lost during lockdown. Secondly, a range of business financing arrangements has been introduced for different types and sizes of firm, principally taking the shape of loans and other forms of debt. Thirdly, a range of business tax obligations have been deferred or cancelled altogether. The latter is the only one to involve local authorities, which have been compensated for loss of Business Rates revenue (see section 4.3).

One centrally administered initiative where local authorities have played an active role has been the Kickstart scheme. This allows employers across the UK to apply for funding from a £2 billion pot to create new job placements for 16 to 24 year-olds who are claiming Universal Credit and who are at risk of long-term unemployment. Placements should provide at least 25 hours work each week for 6 months, and a further money is available to pay for training and support to help each participant to find a permanent job. The funding covers the full National Minimum Wage and National Insurance costs. Applications must be for a minimum of 30 job placements, but smaller employers can team up with others via 'gateway' agencies. As well as trade bodies and voluntary sector organisations, several local authorities have taken on this intermediary role, though the exact number is not yet clear. However, a major concern is that the scheme may prompt a further decrease in standard apprenticeship starts, on top of the existing 50\% fall during 2020 (FE News Editor, 2020).

The projected total cost for these various schemes cost to government to date amounts to almost $£ 150$ billion. This is almost 5 times the amount that has so far been channelled through local authorities for onward disbursement to businesses in their area, as is shown in Section 4.3. The hitherto unknown additional amounts paid out of local authority reserves is unlikely to alter this balance by very much. While local authority support has doubtless been invaluable, not least in its potentially more effective targeting due to local knowledge, the disparity in scale gives some indication of the relative importance of local authorities in the overall governance of Covid-related assistance to business in the UK.

While all these initiatives have been implemented in the devolved territories, here there have also been supplementary schemes, usually to fill significant gaps. Thus, in Scotland additional emphasis has been given to ensuring the survival of a wide range of organisations in the cultural sector (e.g., galleries, museums, theatres, touring companies, outdoor education centres, etc.), as well as helping social care workers avoid financial hardship if they have to self-isolate. These funding streams are each being overseen by different national level agencies. Similarly, Business Wales (the business support arm of the Welsh Government) has offered extra financial support through the three-phase Economic Resilience Fund (ERF), the Business Wales Barriers Grant to encourage self-employment, and a $£ 100$ million Development Bank 
of Wales loan scheme. In Northern Ireland the approach has taken much the same path, with payments handled exclusively by the business advice and guidance service Invest Northern Ireland, with little involvement of the District Councils.

\subsection{Local business support}

Local authorities have also been able to supplement this range of financial support with grants and loans derived either from their own reserves, from the general emergency funding provided by national governments and in England from specific local allocations intended mainly for establishments in the tourism and hospitality sector. They have also been active in providing practical support to local businesses.

In England government funding allocations to local authorities to enable financial support for local businesses have taken 5 main forms:

- Business (or Non-domestic) Rates relief: All establishments in the retail, hospitality and tourism sectors designated as non-essential and therefore forced to close during lockdown periods have been given a 12-month payment holiday with respect to local property taxation. The amounts involved differ according to the rateable value of the property that they occupy. Arcane rules appear to have produced some stark anomalies in the amount of relief on offer, especially for those close to or just beyond the eligibility thresholds (Ogden and Phillips, 2020a). Local authorities have been compensated for the revenue foregone due to this measure, amounting to around £10.8 billion (Hutton and Keep, p.14).

- $\quad$ The Small Business Grants Fund (SBGF) involved one-off payment of $£ 10,000$ for those businesses falling within the lowest rateable value band used for assigning them to the business rates relief categories.

- $\quad$ The Retail, Hospitality and Leisure Business Grants Fund (RHLGF) was a parallel scheme for those in the next highest rates relief category and provided grant payments of $£ 25,000$. The SBGF and RHLGF between them saw $£ 11.1$ billion paid out to owners of over 900,000 eligible business outlets (Hutton and Keep, p.15).

- The Local Authority Discretionary Grants Fund (LADGF) was launched in May 2020 as a supplementary initiative for small and micro businesses with fixed property costs such as rent that were not eligible for the SBGF or RHLGF. Intended recipients were firms in shared offices or other flexible workspace, market traders, home-based businesses such as bed \& breakfasts that pay domestic Council Tax and charity-owned properties, plus any others that a local authority deemed eligible. The maximum grant amount was $£ 25,000$ (Browning, 2020). This stream accounted for over £562 million being paid to around 93,000 businesses (Hutton and Keep, p.15).

- The Local Restrictions Support Grant (LRSG) and the Additional Restrictions Grant (ARG) are related to the differential imposition of Tier-based local and regional restrictions from October 2020 onwards. The amount of LRSG paid is again based on rateable values of business premises, but also relates to type of activity and Tier designation, and whether or not the firm could remain open or had to close. In contrast, the ARG is a one-off grant of $£ 20$ per head to each district or unitary council. It emerged from the deals negotiated with individual metropolitan areas during September and October when they were required to move into Tier 3. It became available to all local authority areas following the extension of fuller restrictions to the whole of England in November 2020.

Analysis of the funding allocations to individual local authorities, grouped by region, reveals some instructive patterns. Bearing in mind that the aim has been to enable 
otherwise viable businesses to survive the coronavirus crisis, enabling a quicker economic recovery, there might be an expectation that differences in the degree of support would reflect geographical variation in the incidence and effects of the pandemic. In other words, the largest amounts should support those areas experiencing high deprivation levels, especially places in the North and Midlands that entered tiered regional restrictions in September and October. However, this does not seem to have been the case. For example, Figure 5.1 shows how giving flat rate Business Rates relief privileges London in particular, where rateable values and hence payments tend on average to be higher. Similarly, basing SBGF and RHLGF eligibility on the same spatially variable rateable values has provided greatest pro rata assistance again to London, as well as to other less deprived regions like the East and the South East (see Figure 5.2). At the same time, a higher proportion of businesses in these areas may have missed out since the thresholds exclude businesses whose premises have rateable values beyond the top limit (Ogden and Phillips, 2020a).

Figure 4.1: Average amount of Business Rates Relief per property by English region

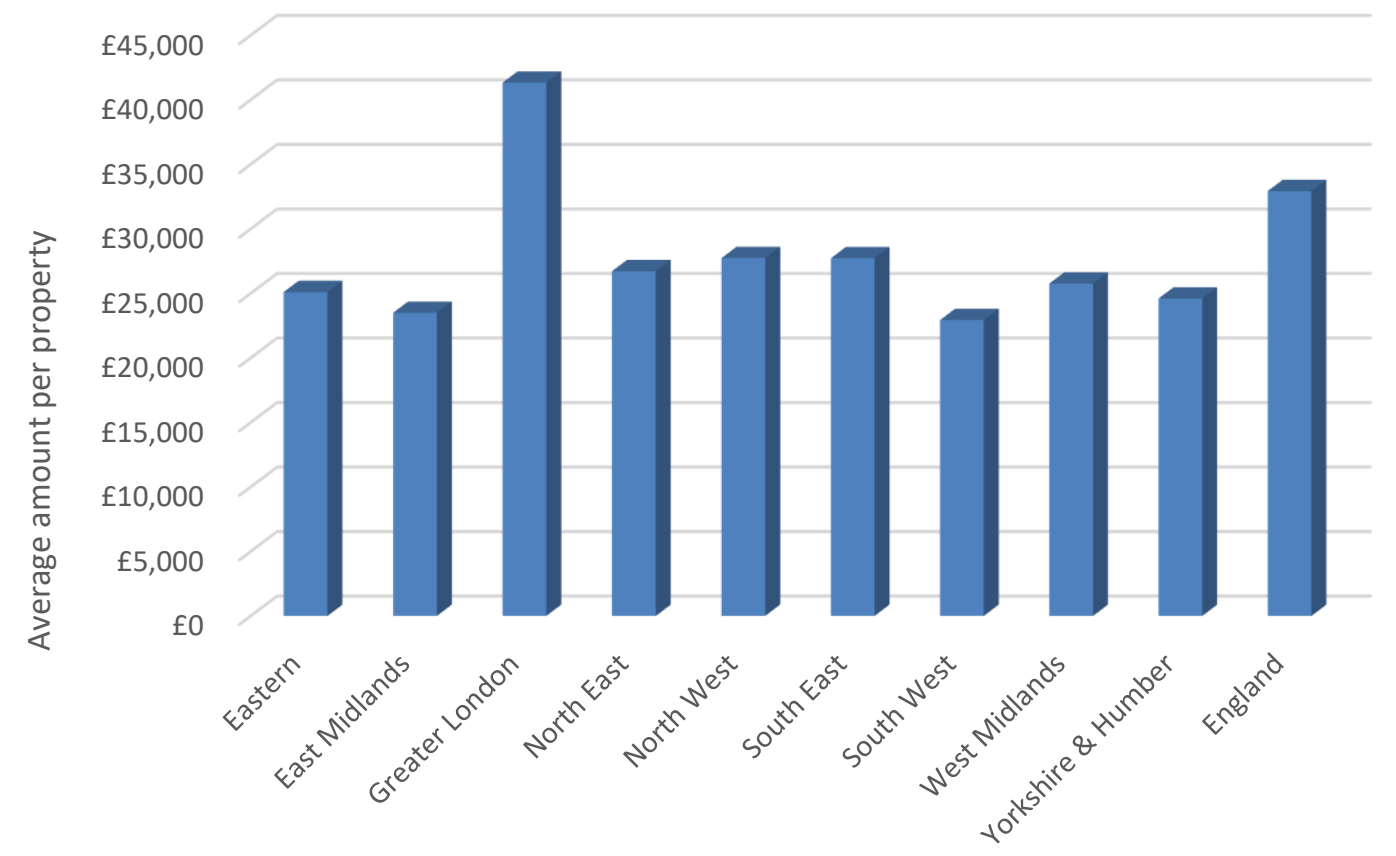


Figure 4.2: Average allocation of SBGF/RHLGF per outlet by region and nation

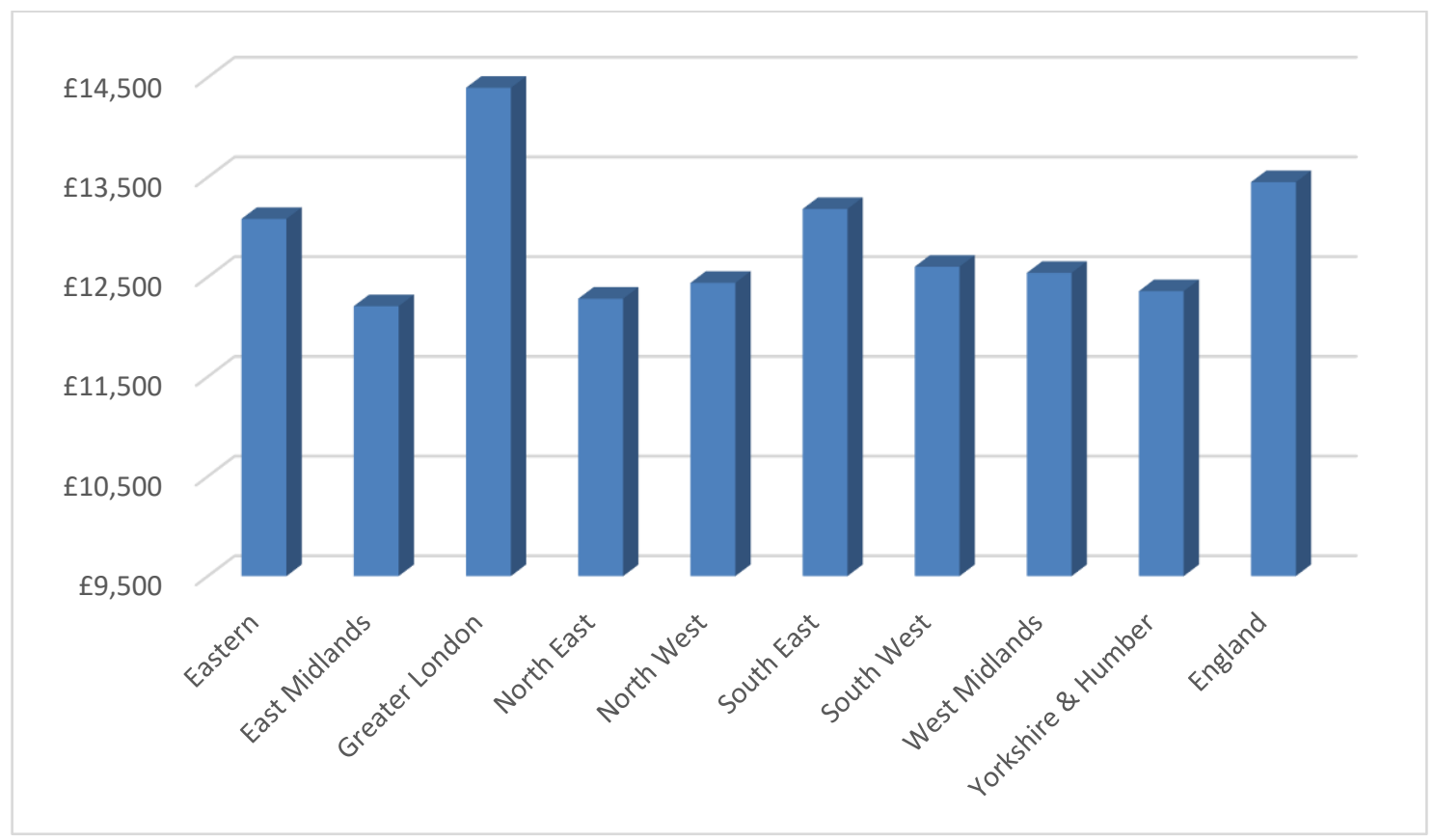

The more discretionary payments made under the LADGF present a different pattern, as shown by Figure 5.3. Here London and the South East have had the lowest per capita allocations, whilst the highest are to the North West, the South West and Yorkshire and Humber. At first sight, these differences seem to emanate from regional sectoral structures, with those having a high share of office and industrial occupiers receiving less than those containing rural and coastal areas with a high proportion of hospitality and tourism properties. However, Ogden and Phillips (2020a) also claim that it may also reflect inadequate scrutiny in estimating the extent of need, and hence the determination of allocations, on the part of BEIS, with the inclusion of ineligible beach huts one factor in the distortion. At this stage it is unclear where any unspent allocation might be directed.

Figure 4.3: Average allocation of LADGF per capita by English region

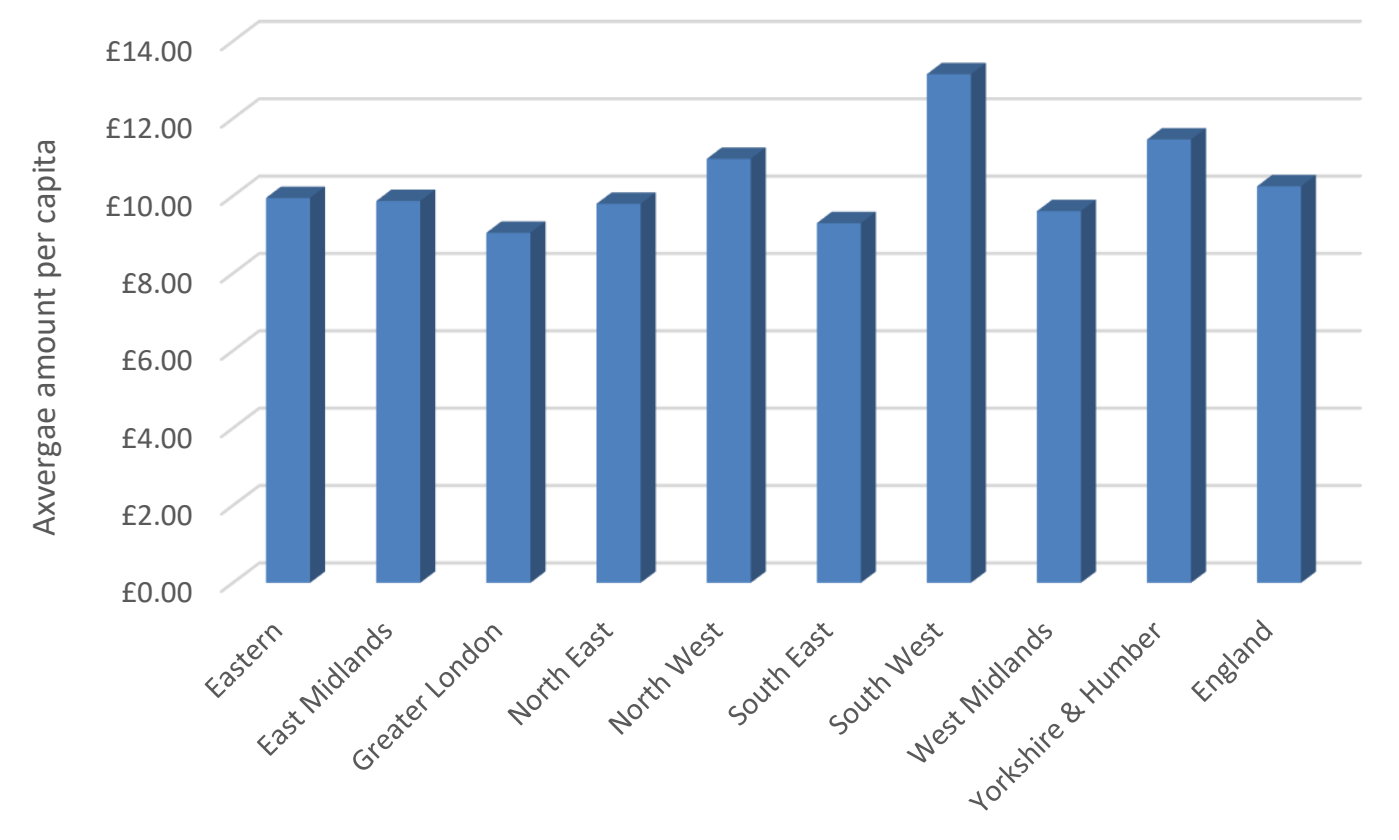


In the devolved territories similar business support measures have been put in place, including parallel versions of the grants to small businesses and retail, hospitality and tourism establishments. These have also been disbursed by local authorities; by early December over 91,000 such payments totalling $£ 1.02$ billion had been made in Scotland (an average of $£ 11,172$ per property), with another 15,400 applications still in the pipeline (Scottish Government, 2020d). Not surprisingly, $60 \%$ of this financial support has involved places in the more heavily populated central belt, where average amounts have been around $£ 1,000$ higher than in rural and coastal areas. Scottish local authorities have also been charged with administering a range of financial support mechanisms for affected businesses that differ from those in England, including:

- The Strategic Framework Business Fund provides a flat rate amount for businesses required to close or to modify their operations by law, the former receiving $£ 2,000$ or $£ 3,000$ per month according to rateable value under the Temporary Closure Grant regime; and the latter $£ 1,400$ to $£ 2,100$ per month under the Business Restrictions Grant scheme.

- As well as a $100 \%$ rates 12 -month payment holiday for retail, hospitality and tourism businesses, all business properties have been given a $1.6 \%$ reduction in their liability for Non-Domestic Rates, reversing the proposed increase in 2020/21. Both forms of relief are applied by the relevant local council, with the income foregone being reimbursed by the Scottish Government.

- The Scottish Crown Estate Fund is available in the 26 local authority areas with a coastline and has been repackaged so it can be used to offer direct support to coastal and marine-based enterprises and third sector organisations struggling due to the pandemic. The $£ 17$ million available has been divided according to the share of sea area abutting onto each area.

- The Renfrewshire Coronavirus Business Support Fund is a $£ 1.3$ million package established by the council of the same name permitting supplementary loans and grants for local companies or self-employed people to meet the costs of operational changes, or to adapt premises to allow social distancing.

In Wales local councils are distributing grants to businesses in their areas on a similar rateable value basis as in England and Scotland, although payment to those operating in more expensive properties has been discretionary. However, all tourism firms whose turnover has fallen $40 \%$ or more automatically qualify. Moreover, while the amounts paid have been capped at lower levels than elsewhere, the payments have been made in several tranches, according to the restrictions in place at different points in time (Smith, 2020). Other local authority-run funding support has taken the form of the Lockdown Discretionary Grant for home-based businesses that are assessed under Council Tax provisions, and the Lockdown Business Fund that has assisted businesses facing operational and financial challenges as a result of the October 'firebreak'. They are also administering the £10.5 million Freelance Fund, aimed at those operating on a self-employed or temporary contract basis in the arts and culture sector.

The huge number of applications for support from these different funds gives some indication of the extent of the pandemic's economic impact. To meet the demand business grant administration teams in most councils have been augmented by means of staff redeployment and new recruitment, though inevitably this has not prevented a backlog of claims building up. Some authorities have instituted expedited procedures to accelerate processing and approval times. A good example of this is Pembrokeshire County Council, a small local authority in West Wales, which has used a mixture of matrix management and secondments to draw staff in from Regeneration and Economic Development, Revenue and Benefits, External Funding Teams and Finance 
and Employability. Part of this was a recognition that no one team had the skills to deliver everything and there was a requirement to work as 'Team Pembrokeshire'. By September it had paid over £52 million worth of direct business support into the local economy (WLGA, 2020c).

Other councils have taken similar steps to streamline regulatory procedures, especially during the summer relaxation when businesses were tentatively reopening and required permission to amend the way they operated. A case in point is Sheffield City Council's accelerated process for assessing requests for outdoor service areas on pavements and in pedestrianised areas to enable pubs and restaurants to keep customers socially distanced. By assembling a joint team from different departments, average processing time was reduced from 7 weeks to 7 days, including visits to over 1,500 premises to consult on proposed measures. Free boundary marker barriers and face masks for customers were also provided as part of the package.

Others endeavoured to keep the local economy ticking by building up networks and linkages between suppliers and potential consumers. Thus, Neath Port Talbot Council in South Wales created a simple online directory called NPT Buy Local on its website, showing which local shops were providing home deliveries and support. The aim was to connect residents struggling to secure deliveries from the major supermarkets with local suppliers for whom online trading was unfamiliar. By September the site had received over 6,000 page views since its launch. Since then, further iterations of the guide have been delivered, improving the layout of the directory, creating categories to make it easier for residents to locate businesses and setting up a database to store and manage business listings (WLGA, 2020d).

More generally, most local authorities have revamped their business support website pages to provide links to the different types of funding support and how to apply for them, whilst making sure advice and guidance staff keep fully abreast with these schemes' eligibility rules and terms and conditions. In Scotland all councils were already collaborating on a nationwide service called the Business Gateway, which acts as a central point where enquirers can be redirected to a sector or area specialist depending on their needs. Its website was also quickly and regularly updated to reflect changing circumstances and initiatives (COSLA, 2020a). Other councils have repurposed their employability programmes to reflect the changing nature of the labour market, and some have even been looking to the future in advising on how companies in their local area might develop, especially in relation to opportunities linked to decarbonisation and the advancement of a green economy (COSLA, 2020b).

\subsection{Local planning for recovery}

The future of local economies has also emerged as a key theme for a local government bodies across the UK, even while they continue to be busy with the immediate effects of lockdowns and tiered restrictions. In Scotland and Wales this has included deliberations by specially formed recovery advisory groups charged with setting a national framework within which all interested parties can draw up more specific plans and strategies. The process has entailed inviting evidence from public, private and voluntary sector organisations. In Scotland proposals emanating from cross-local authority network discussions emphasised the need for "stronger collaboration and the co-production and joint implementation of actions", and a flexible approach with the option for local variation so that disproportionate impacts in a given place can be addressed. It also stressed how local additionality might be increased by aligning direct financial support to key enterprises with training and skills development for both existing staff and local residents (SLAED, 2020; COSLA, 2020b). In addition, the package might include flexible job creation initiatives to compensate for a lack of local labour market opportunities (Francis-Devine et al., 2020), offering good quality work 
experience through public and third sector efforts to meet local needs (IS/SLAED, 2020).

In Wales local authority proposals highlighted the need to modernise local economies through a complementary mixture of public and private investment, particularly spreading benefits through local procurement frameworks, prudent use of loan finance to increase and improve fixed capital assets, and identifying the skills requirements to be met by an expanded apprenticeship scheme. More substantively, the submission also included a list of "mutually reinforcing" expenditure programmes for local authorities (WLGA, 2020e):

- An increase in affordable housing construction.

- Decarbonisation of energy via sustainable generation, storage, transmission and consumption.

- Improvements in social care and primary care infrastructure.

- $\quad$ Continuation of the 21 st century schools building programme.

- Investment in 'circular economy' infrastructure for better resource management.

- Transport improvements, including greater integration and better provision for active travel.

- Further development of digital innovation and connectivity.

- Development and adaptation of appropriate industrial and commercial property.

- Expansion of sustainable environmental infrastructure and tourism.

- Investment in human capital via skills training and apprenticeships.

The two inquiries have yet to report but the inclusionary approach should give weight and acceptability to their proposals. That said, there has been no equivalent government-endorsed exercise for England, nor on behalf of the UK Government. Headline announcements have been made around the themes of 'building back better' and 'levelling up' between more affluent and poorer regions and localities. These have highlighted investment in projects that may contribute to the conditions for stronger local economies, rather than on direct measures to assist firms in rebuilding their customer bases or to create large numbers of replacement jobs. Thus, the emphasis has mostly been on new and updated infrastructure, clean energy and the green economy, with some funds allocated in the November Spending Review (HM Treasury, 2020), but there remains a lack of detail upon which local and sub-regional recovery plans might be based. There is also concern that, as with the UK's Industrial Strategy launched in 2018, the focus remains too narrow to enable all older industrial areas in northern and western Britain to benefit (Fothergill et al., 2019). It is instructive to note that the recently launched Build Back Better Council, appointed to advise the UK Government on recovery, does not have any members from the public sector in general (let alone local government), as well as minimal representation from beyond London and the South East (Pidd and Mistlin, 2021)

Although a £4.8 billion UK-wide Levelling Up Fund (LUF) has been created, plans for this pre-dated the crisis and its full launch has been postponed until the need for firefighting against the pandemic has abated. In any case LUF is designed around competitive bidding by local areas for a maximum £20 million share, so its allocation will inevitably create 'winners' and 'losers' at a time when everywhere will need a boost (Partington, 2020). Another strand of regional funding also remains in abeyance, namely the Shared Prosperity Fund, which is the replacement for the European Structural Funds following the UK's departure from the European Union (EU). The long-promised consultation on how this will work has yet to commence (Brien, 2020). 
Despite this vacuum there has been much work occurring at the local and sub-regional scale in England. A survey of local authorities and LEPs undertaken by Lichfields (2020) found that most have used their initial recovery response as an opportunity to reset longer term strategy, for instance to build future resilience within the local business base and to respond to wider structural shifts brought about by the pandemic. However, respondents were less optimistic about the prospects for short-term recovery, with $85 \%$ citing 'weak' or 'very weak' prospects, and predicting that it would be well into 2021 before any strength would return to local economies. There was some variation related to the sectoral mix in particular areas, allied to considerable uncertainty over the scale of demand for retail and commercial premises given the boom in online sales and the relative success of home working. Most are only just beginning to explore alternative possibilities to address the risk of wholesale vacation of urban centre properties in already struggling high streets.

Analysis of the priorities identified in both new and revised local economic strategies revealed several key themes, including:

- $\quad$ Building productivity back into the business base.

- Reskilling the local workforce to match emerging employment opportunities.

- Developing sector-specific support packages for affected businesses and innovative growth sectors.

- Continued intelligence gathering and signposting to support.

- Supporting the development and construction industries to kick-start activity.

- Building business resilience and future-proofing against further disruption (Lichfields, 2020).

The formulation of these recovery plans appears to have contained a strong collaborative local element. Thus, $82 \%$ of organisations reported strengthened partnership working across and between local areas in terms of intelligence gathering, sharing good practice, and joint plan development. A good example has been in Newport (South Wales), where a survey of residents and businesses was undertaken to understand people's concerns and priorities; the strategy development group included representatives from the local police, social landlords, business interests (including the Chamber of Commerce) and third sector groups. The focus was on the adaptation and revision of the council's existing economic strategy into a recovery plan to take account of the new circumstances. As well as prioritising immediate business survival, the plan has set a medium-term goal of securing more inward investment and promoting the city as a business location (WLGA, 2020f).

Similarly, in Exeter in South West England the Building Back Exeter Better group brought together a wide range of public and private sector stakeholders. Its plan adopted a place-based approach centred around key interventions such as a revolving carbon reduction fund of $£ 200 \mathrm{~m}$; investment to support the city centre as a visitor destination; £100m investment in transport infrastructure; a bespoke digital training and skills package; and actions to support the health and wellbeing of residents (Exeter City Council, 2020). Another example is in Glasgow, where the COVID-19 Recovery Group draws members from a range of existing economic development groups. It is currently still developing its Post-Pandemic Economic Recovery Plan for the city, which amongst other aims is seeking to incorporate lessons and practices that can be transferred from other cities (Glasgow City Council, 2020).

Many other local authorities and partnerships have embarked on similar exercises. Indeed, an exploratory internet search quickly identified 50 such plans and strategies, shared between all types of local authority, and including inter-area collaborations 
such as LEPs and Combined Authorities (CAs). One striking facet of this list was the extent of potential duplication in parts of England, with 10 examples of lower tier councils producing their own documents even though the wider County Council, CA or LEP area within which they sit was also the focus of parallel work. At the same time, there are some good examples of cross-boundary collaboration beyond formally designated areas. One of these is the West London Alliance, which covers 6 boroughs in west London and features the close involvement of key players in the area. Its recovery plan focuses on six themes: employment and skills, growth sectors, micro businesses, housing and infrastructure, town centres and Heathrow Airport. A telling feature is that it serves as both a plan and a lobbying document for Central Government, requesting flexibility in existing funding streams and sufficient resources to develop a local low carbon economy and to address the severe local impacts on employment in the aviation industry and its supply chains (West London Alliance, 2020).

Other economic recovery strategies that double up as requests for funding support include that produced by the West Midlands Combined Authority (2020). Essentially this represents a reshaping of its earlier Local Industrial Strategy and focuses on green manufacturing, health care and high-speed rail-related projects that would have an immediate impact. It forecasts that securing all of these will require an additional £3.2 billion. A similar approach has been taken by Liverpool City Region, whose paper identifies a list of projects that are ready to start and would together cost £203 million (Liverpool City Council and Liverpool City Region Combined Authority, 2020). Here the focus would be on new house building, retrofitting energy efficiency measures, health care innovation, investment in the creative and visitor economy and realigning workforce skills with the new opportunities.

In fact, the issue of having the wherewithal to fuel the recovery appears to be vital. Thus, $70 \%$ of the respondents to Lichfields (2020) survey stated that their local authority/LEP is unlikely to have sufficient resources to respond effectively to the longer term local economic fall-out from the pandemic. This is not just a matter of funding but also related to staff shortages and prospective budget cuts too. While these have been common issues for some time, they may well be exacerbated in the years to come without a more generous financing package from Central Government.

\subsection{Conclusions: Knowledge gaps and future research questions}

Around $80 \%$ of government funding assistance to businesses most affected by the pandemic has been administered by UK Central Government. While this may have been justified on the grounds of efficiency and consistency, inevitably it necessitated relatively narrow eligibility criteria that has excluded many operating under less conventional models, especially amongst micro businesses and the self-employed. Whilst local authorities were able to fill some of these gaps through discretionary funding, their principal role in supporting the local economy has involved the distribution of flat rate grants to business establishments on behalf of national governments. For the most part they have done this quickly and effectively through augmenting their business support teams, boosting inter-departmental working and devising expedited procedures. The latter have also been used to good effect in accelerating regulatory procedures to help firms offer more restricted or controlled services during spells of varying restrictions.

Local and sub-regional agencies have also been busy trying to prepare for future economic recovery and realignment. A major difficulty here is the lack of clarity on the part of the UK Government concerning both strategic direction and practical measures and initiatives. This is especially the case in England, where strategy formulation for local recovery is taking place in something of a vacuum. It is little surprise that many of the plans already produced represent requests for funding as much as blueprints 
for action. In contrast, in Scotland and Wales both national governments have launched exercises to set a context within which local economic recovery planning can proceed. Their inclusive consultative approach bodes well for the extent to which local agencies can align their own approaches to nationally set priorities and targets. However, it should be remembered that the devolved territories still rely on the UK Government for the bulk of their funding, with further fiscal powers currently on hold or likely only on an ad hoc basis (Eiser, 2020). The continuing hiatus over the Shared Prosperity Fund in the immediate post-Brexit period just adds more uncertainty to the equation.

Four dimensions where there are important gaps in knowledge emerge from these tentative observations, focused around the role and nature of local government with regard to economic development and its relationships with other parts of state infrastructure:

- What was the exact extent and full nature of local authorities' discretionary expenditure in ameliorating the effects of Covid-19, drawn from both nonringfenced emergency funds and their own reserves? How did this vary between different types of council, between nations and regions and in different types of place?

- To what extent has the financial support provided to business helped firms and establishments to survive? Have local government interventions had an influence on the ways in which local economic structures of different places are changing in the post-pandemic era?

- How have economic development policy content and architecture evolved, and to what extent has this been in relation to post-pandemic needs, rather than developments in the wider macro-economic and political context? To what extent can a local governance-driven and place-based approach fit with broader national and UK-wide policy frameworks aimed at shaping transition to an inclusive and decarbonised economy?

- How have the overall governance structures in the UK's constituent nations changed in response to the intertwined needs of a healthier and more equal economy? 


\section{Housing and Homelessness}

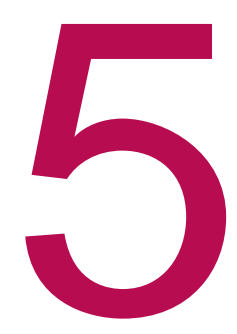

\subsection{Introduction}

Some of the starkest impacts of Covid-19 in the UK are manifest in housing and homelessness. Pre-existing social, physical and economic inequalities have not only been worsened by the pandemic but have also determined those most affected. People from Black, Asian and minority ethnic (BAME) and low-income backgrounds are all more likely to contract the disease and are most likely to die from it (PHE, 2020a; Runnymede, 2020). Alongside occupation, transport and access to healthcare, housing is a significant and intersecting risk factor where densely populated areas, over-crowded households and shared accommodation increase the risk of infection transmission.

Faced with such stark public health risks and largely driven by concern for the heightened exposure of those experiencing homelessness, housing quickly become a major focus of central government policy, strategy and action in addressing the pandemic. It has been a public health rather than a housing agenda that has driven a widespread departure from a previous 'poverty of ambition' to look beyond hostel provision (Parsell et al., 2020). In exceptional timescales, self-contained housing has been provided to people sleeping rough and to those reliant on dormitory style shelters not only in the UK, but in other countries too.

What has been achieved has been remarkable in scale and speed, building upon but accelerating a developing local infrastructure and collaboration between housing, health and social care services. However, there is a danger that this response is merely temporary, and longer-term housing provision for people who are homeless still faces an uncertain future due to drastic Central Government funding reductions. Financial responsibility has been handed over to local authorities whose budgets were already stretched before Covid-19, and which now face a combined funding shortfall of £2 billion for the 2020-21 financial year, as already outlined in section 3 (Ogden and Philips, 2020c).

Other temporary measures that are unlikely to cushion the longer-term economic and social impacts of the pandemic include a modest uplift to Local Housing Allowance, a temporary freeze on tenant evictions, and mortgage repayment holidays for homeowners (including private landlords). Meanwhile, growing economic risk may exacerbate exclusionary practices within the Private Rented Sector (PRS) and within the mortgage market, pushing would-be renters and first-time home buyers with limited funds and employment insecurity further away. With rising unemployment, access to housing and welfare will become crucial, long after the Covid-19 pandemic eases. 


\subsection{Geographies of housing and inequality}

Housing plays a crucial role in the ways that Covid-19 is being experienced across the world, bringing the well-established intersections between housing, poverty and health into sharper focus. The uneven geographies of Covid-19 impacts are perhaps most visible in cities and densely populated urban areas, where higher levels of social interaction result in higher infection transmission rates (Quinio, 2020). This has applied equally in relatively affluent countries like the UK, especially in local authority areas where socio-economic deprivation is highest (ONS, 2020).

There appear to be multiple explanatory factors that would explain the high levels of mortality across varied urban, coastal and rural areas of England (Davenport et al., 2020). These include the general health of populations, as well as household size and types of employment where workers are more likely to be exposed to the virus (PHE, 2020). Even after adjusting for age, sex and ethnicity, the worst health outcomes from Covid-19 remain in the most disadvantaged areas (PHE, 2020). Overcrowded housing has been shown to have a particularly strong correlation to high levels of Covid-19 deaths in England (Barker, 2020). The interactions between these spatially specific factors highlight the need for local policy responses (Davenport et al., 2020), as well as greater Central Government investment in disadvantaged areas.

Much of this disadvantage is structurally embedded and historic. Research has shown that one in seven people in the UK is living in an insecure, unaffordable, overcrowded or otherwise unsuitable home (NHF, 2019). Analysis of English Housing Survey and YouGov survey data has shown that $3.7 \mathrm{~m}$ people live in overcrowded homes, and 30,000 live in a home that consists of just one room (NHF, 2020b). Between 1911 and 2011 overcrowding declined in absolute terms in England. However, using a relative measure of inequality in housing space shows that overcrowding among low-income groups increased dramatically from the 1980s and undermined any previous progress (Tunstall, 2015). There are several factors at play here, including changes in household composition, the distribution of households geographically, and changes in design and build standards. However, policies around the allocation and development of housing have been instrumental in each of these factors (Tunstall, 2015).

Following a recent raft of UK government reforms to welfare, households facing the most significant financial challenges often experience formal and informal exclusion from social rented housing waiting lists on the grounds of economic or social risk (Preece et al., 2020; Powell, 2015). Increasingly automated systems and algorithms have also reinforced the seemingly arbitrary decisions made about individuals' suitability for social and private rented accommodation, drawing attention to the role of technology in governing access to housing and welfare (Eubanks, 2019; Fields, 2019; Marsh and MacIntyre, 2020). This creates further disadvantage for households already most in need of housing and social support, and disproportionately impacts ethnic minority groups. People from a BAME background are over three times more likely to become homeless than White British people in England (Shelter, 2020), and make up a quarter of households waiting for local authority support for housing (despite only accounting for $11 \%$ of all households).

Indeed, housing allocation policies have a history of creating and reproducing structural inequalities, especially for BAME households (Robinson, 2002; Henderson and Karn, 1984; Wacquant, 2007), as well as for other marginalised groups such as disabled people (Mackie, 2012). These historic inequalities are important when considering the impacts of Covid-19 and subsequent policy responses. Research has shown that BAME households are disproportionately more likely to live in the most deprived neighbourhoods, in fuel poverty, and in poor quality, overcrowded and multiple occupancy housing (Gulliver, 2016; MHCLG, 2020c; PHE, 2020). Taken together with higher fuel costs, rising unemployment and limited government support, 
people already living in inadequate housing have experienced the most harmful effects of the pandemic (Brown et al., 2020).

In response to the financial precarity already faced by many and worsened by unemployment prospects, the UK government temporarily lifted the cap on the amount of private housing benefit support that can be claimed through Local Housing Allowance (LHA) to the $30^{\text {th }}$ percentile of rents. However, even with this increase, most private rented properties remain unaffordable to people receiving welfare benefits, since $70 \%$ of private rental payments are not covered by LHA (Pennington, 2020). Although an extension to the earnings threshold required for Universal Credit support helped people who lost out financially due to the effects of the pandemic, this has been undermined by a range of disqualifying criteria that left over 77,000 households subject to an overall welfare benefits cap (CPAG, 2020). These preventative measures have provided a short-term buffer for some but not all, and as such have failed to address much existing inequality and precarity.

The impact of the pandemic on rent levels is an evolving picture but in the year leading to October 2020, the cost of renting in London fell 6.9\%, and later in the year average rent costs in cities like Manchester and Leeds also fell. A decline in interest in living in cities and near town centres reflects greater choice over location through home working, while travel bans have reduced demand for housing from tourists, international students and workers (Hammond, 2021). Nevertheless, even with some sporadic falls in the cost of renting,

It remains likely that renters with insecure employment or facing redundancy are experiencing greater precarity due to the pandemic. While renters continue to struggle in the UK, landlords with buy-to-let mortgages and homeowners have been protected by a mortgage repayment holiday that was agreed between the government and mortgage lenders. At the same time, the choices available to people looking to buy their first home have also been limited, as mortgage lender restrictions have removed almost all low deposit products and increased the rates applied to those that are available (Osborne, 2020). The price of properties has also dramatically increased following the government's stamp duty discount in July 2020. This was implemented as a market stimulus with some success, but it has also served to widen the existing wealth gap between those with access to gardens and green space and those without (Hanley, 2020), as existing homeowners who could afford to were incentivised to move. On top of employment insecurity, the consequence of the pandemic for many people at the bottom of the housing ladder has been to reduce the likelihood of accessing a mortgage, home ownership, a garden and outdoor space.

\subsection{Lockdown and spatial disadvantage}

Questions relating to the form and function of housing have a long tradition. They have also inspired a recent surge in housing research around the use value of home, and its relationship with health and well-being (Rogers and Power, 2020). The pandemic has exposed the myriad harms presented by housing conditions not only to the most disadvantaged, but also to a broader spectrum of society (Gurney, 2020). For people who have had to self-isolate over long periods of time, the absence of social interaction or life outside domestic space - including variable access to green space (see Section 6 ) - has left people physically and mentally deconditioned. Thus, loneliness, depression and related issues contribute to poor cardiac health (BHF, 2020), as well as being linked to increased suicide rates (BMJ, 2020). The physical and psychological benefits of having access to outdoor space, including private gardens, balconies or nearby parks, exposed existing inequalities in housing amenities, especially for those trapped in their homes due to shielding (Hanley, 2020). 
As well as the many individuals who had to spend lockdown in one-room accommodation, more than 3,600 children were in provision comprising just two rooms (NHF, 2020b). More permanent 'work from home' arrangements, as well as employees being placed on furlough, have also virtually eliminated the wider social interactions and activities that are crucial to health and wellbeing (ESRC, 2020). The blurring of boundaries between housing, work, school, play and exercise has combined with restricted access to private space not only to provoke greater domestic conflict, but has also compromised social distancing in local public spaces as demand for access has soared (Garber, 2020). In particular, the development and wellbeing of children living in disadvantaged households has suffered, with families living in temporary accommodation seeing healthcare and other services disappear due to the primary focus on Covid-19 cases (Shared Health Foundation, 2020).

For many cohabiting households, the limited movement, isolation and hardship created by the pandemic has led to conflict and even abuse. The UN has called domestic violence against women and girls 'the shadow pandemic', where existing abuse has worsened and options for escape are limited (Mlambo-Ngcuka, 2020). Reports of increasing domestic abuse across the world demonstrate some of the most immediate risks to safety that have been worsened by government 'stay at home' directions during periods of lockdown (Davidge, 2020), and by lack of alternative housing options (Bimpson and Reeve, 2020). The experience of domestic abuse undermines assumptions of security that go with home, and exposes the need for more nuanced understandings of private space, safety and connection to place (Meth, 2003; McCarthy, 2018; Bimpson et al., 2020).

Social landlords are particularly well placed to respond to reports of abuse by their tenants. In England and Wales some housing associations and local authorities have worked together to prioritise applicants on local housing registers with the most immediate needs, such as those fleeing violence or those leaving temporary accommodation (Heath, 2020; Timan, 2020). However, evidence suggests that housing through such emergency measures is often granted via 'excluded licenses', and more stable starter tenancies are only awarded if the temporary situation is deemed successful (CaCHE, 2020). This greater coordination between housing associations and local authorities has been particularly strong in Wales, where the devolved government has increasingly distanced itself from London in respect of housing (and other) responses to the pandemic (CaCHE, 2020). Across the UK, housing associations have utilised their empty properties to provide housing to people leaving homelessness services and other temporary accommodation, as well as people leaving hospitals (NHF, 2020). The utilisation and coordination of local resources has been crucial in addressing urgent rehousing needs for social tenants.

People in shared accommodation involving multiple households have faced increased risk of Covid-19 infection through use of communal kitchens, bathrooms and other facilities. These risks fall disproportionately on low-income households, where financial, spatial and relational inequalities provoke significant mental as well as physical health impacts (Preece and Bimpson, 2019; Barratt et al., 2015). People with no recourse to public funds (NRPF) have been subject to some of the most harmful effects of this type of housing. Temporary accommodation provided for people seeking asylum across the UK is a notable example, where already poor and dangerous conditions have been made worse with postponed maintenance works during periods of lockdown (Bulman, 2020). Companies contracted by the UK government have left residents without soap or sanitiser, or adequate food, and have continued to force multiple households to share single rooms (SYMAAG, 2020). A National Audit Office review of asylum accommodation reported inadequate Central Government monitoring of contractual obligations, highlighting a systemic issue with this lucrative shadow housing sector (NAO, 2020). Moreover, Home Office activity relating to asylum housing during the 
pandemic has operated without any consultation with local government (UK Parliament, 2020).

Other institutional accommodation such as care homes has highlighted the increased risks of infection transmission. With an estimated 48,000 deaths ${ }^{1}$ from the beginning of the pandemic to the start of November, both the NHS and the care home sector have faced substantial scrutiny, especially for initial management of the crisis (Booth, 2020). Older people living in their own homes have also faced greater vulnerability where shielding, and social distancing has seen people cut off from vital provisions such as food and medication, as well social care and support for daily living. Across the UK, locally organised volunteer networks, charities and voluntary sector organisations have responded to the isolation of older and vulnerable people (Centre for Ageing Better, 2020). Where local authorities have coordinated these responses, informal and community-based networks have been incorporated into more formal and evolving social care arrangements that aim to support people to remain independent, and in their own homes. At the same time, local mutual aid continues to operate outside formal governance structures with local residents' groups that were set up during lockdown continuing to support their neighbours (Tiratelli and Kaye, 2020). These partnerships and coordinated efforts between local government, public services, third sector and citizens represent some of the most positive and hopeful outcomes of the pandemic (see also Section 3.7).

\subsection{Homelessness}

This multi-agency and locally coordinated approach has been further demonstrated by the ways in which homelessness has been managed during the pandemic. One of the earliest and most decisive moves from the UK Government was to call for local authorities in England to accommodate all rough sleepers in self-contained housing within a month through the 'Everyone In' scheme (MHCLG, 2020a). This meant finding housing not just for people sleeping on the streets but also those in communal accommodation like hostels and night shelters where self-isolation and social distancing were not possible. A ring-fenced £3.2 billion funding allocation enabled English local authorities to accommodate an estimated $90 \%$ of all known rough sleepers (Fitzpatrick et al., 2020) through use of empty hotels (closed by lockdown) and other self-contained short-let accommodation. These temporary measures made it possible for a reported 14,610 people in England to be housed by June 2020 (Geraghty, 2020). Local responses to the scheme varied according to the availability of suitable spaces, the presence of existing partnerships and agencies, and other local governance issues (Fitzpatrick et al., 2020). Wales and Northern Ireland also followed the same approach in providing self-contained emergency accommodation through street outreach and partnership agency working. In Scotland, where homelessness legislation is more progressive in the number of people the government is legally obliged to support, the 'Everyone Home' scheme provided initial housing to rough sleepers via an enormous street outreach effort, as well as placing equal emphasis on suitable move-on accommodation.

Local authorities across the UK have worked with social landlords, social enterprises and private sector services to house people under each scheme. Rapid responses include that by East Suffolk Council, which repurposed unused sheltered accommodation, bringing it back into use within seven days; whilst Cornwall worked with charities, businesses and other partners to gain access to newly built but unsold dwellings for temporary accommodation (LGA, 2020). Another solution from modular housing companies and social enterprises has been the provision of 'pods' or containers as temporary accommodation for people sleeping rough. During lockdown

\footnotetext{
${ }^{1}$ By mid-January 2021 this figure had exceeded 100,000 .
} 
these solutions expanded across the UK, as well as in Canada and the USA. However, there have been criticisms that such tiny houses undermine space standards and reduce aspirations for the types of housing available to people in need of support (Bearne, 2019).

While the Everyone In scheme has pushed the UK closer to a model focused on independent housing rather than night shelter, its temporary nature goes against the principles of 'Housing First', which aims for longer term security and the requirement for appropriate, flexible and unconditional support to sustain those tenancies. Indeed, prior to the pandemic Housing First projects across the world had already shifted perspective to mainstream housing with intensive support and free from tenancy or other conditions, rather than the traditional 'staircase system' of providing substandard or institutional accommodation. The evidence of its effectiveness is sufficiently compelling that the UK Government is also moving in this direction (MHCLG, 2020d). After the first period of lockdown there was a period of uncertainty before Central Government announced a £161 million fund for 3,300 new supported homes as move-on options to be provided by March 2021 (MHCLG, 2020e). It also announced a further $£ 91.5$ million for 274 local authorities to secure interim accommodation for people who had been housed in hotels and other places (MHCLG, 2020f). Applications for this funding are subject to assessment and uncertainty remains for local authority plans until funding is agreed. Furthermore, during the latest lockdown period in early 2021 Central Government support has been much less than for the Everyone In scheme, despite the winter weather. Local authorities have thus faced significant uncertainty over how much funding will be available and whether it will be sufficient to house all rough sleepers (Heath and Barker, 2021).

In the autumn further restrictions under both the regional tier systems and the October/November national lockdowns also created uncertainty for winter shelter provision, where usable space may be reduced by as much as two-thirds due to social distancing requirements (Marsh and Walker, 2020). With hotels back in commercial use in some areas, and further funding for local authorities not yet agreed, councils were forced to bring some shelters back into use and to fund additional space independently. Finding additional resource for this is not open to all councils, of course, especially in the context of already programmed future expenditure cuts to a range of services that support people experiencing homelessness. For example, in Manchester the homelessness budget is scheduled to be cut by £2.8 million, and housing payments for people struggling to pay rent are set to reduce by $£ 1.5$ million (Williams, 2020).

Overall, the Everyone In scheme has provided a level of independence for many people who had previously been living in communal shelters, by providing individual cooking and cleaning facilities, and by strengthening links to health and substance misuse services (e.g., Stevenage's 'No More' scheme) (LGA, 2020). The closure of shelters and some day centres has proved especially beneficial in changing existing systems, particularly by bringing health services directly to those in need in hotels and other accommodation, rather than waiting for individuals to travel to access a range of services in dispersed locations. However, for people already living in temporary accommodation, the range of services available during periods of lockdown has been non-existent (Shared Health Foundation, 2020).

While work to bring healthcare closer to people living in homelessness provision was already under way in the UK prior to the pandemic, periods of lockdown not only highlighted the urgency of that work but also created further barriers for individuals and services. While Central Government legislation enabled day centres for people rough sleeping or experiencing homelessness to remain open during periods of lockdown, lack of staff and constraints on social distancing meant that this was not possible everywhere, leading to a lack of provision being reported in some areas. Like many 
services, the practicalities of reopening volunteer-led services after initial periods of lockdown presented significant challenges, and guidance to support and instruct those services was issued by national homelessness sector organisations and health research institutes (NIHR, 2020). Closure of services at the start of lockdown and difficulties in accessing alternatives meant that people dependent on methadone struggled to obtain it across the UK. In response, critical amendments were made to UK legislation surrounding the supply of controlled drugs. This included allowing pharmacies to provide them without prescription where individuals were already receiving those drugs as part of a treatment programme (ACMD, 2020), and facilitated greater coordination between a range of health services, support staff and people receiving drugs treatment. While these issues for rough sleeping populations had been highlighted prior to the pandemic, Covid-19 has highlighted the urgency of recognising the links between housing and harm reduction (O'Carroll et al., 2020).

While the pandemic has undoubtedly led to increased integration between health, social care and housing, the approaches taken have varied significantly between local areas, with much depending on the existing local infrastructure. Furthermore, Groundswell (2020) reported that some people returned to the streets after periods of stay in hotels under the Everyone In scheme because they struggled to access basic provisions, especially those self-isolating and without access to the necessary welfare benefit payments. The solitary experience of staying in a hotel room also proved difficult for longer-term rough sleepers, or for those with mental health issues. Lack of suitable move-on options has also undermined the success of the scheme.

Notwithstanding these challenges, a recent Lancet study has reported that the UK's response to homelessness under Covid-19 had potentially prevented 21,092 infections, 266 deaths, 1,164 hospital admissions and 338 Intensive Care Unit admissions by the end of May 2020 (Flook et al., 2020). However, the figures used to indicate the success of the approaches used to manage homelessness during the pandemic should be treated with caution. On $30^{\text {st }}$ June 2020 , an estimated 98,500 households were living in temporary accommodation in England alone, an increase of almost 14\% on the previous year (Shelter, 2020). While some of this increase may be due to the government's Everyone In scheme, it is also likely to stem from the increasingly limited supply of affordable housing. While there has been a decrease in the number housed in Bed \& Breakfast accommodation and an emphasis on leasing dwellings from the Private Rented Sector (PRS), those stuck in temporary accommodation are more likely to be sharing bathrooms, kitchens and other communal facilities.

This also applies to single person households aged 35 or below who are only eligible for rooms in shared PRS accommodation. While local authorities have distributed information leaflets regarding Covid-19 and reducing infection in shared housing, the material circumstances for people living in such multi-occupation accommodation remains the same (LGA, 2020). With restricted possibilities of sofa-surfing with family or friends due to pandemic restrictions, recorded homelessness among young people has increased almost 50\% compared to a year earlier (Marsh, 2020). This figure is likely to rise further due to the over-representation of young people amongst the recently unemployed (Resolution Foundation, 2020).

Other temporary measures have sought to prevent people from becoming homeless, including the 'evictions ban' which was announced on 27 March 2020 (MHCLG, $2020 \mathrm{~b})$. From this date, a temporary suspension of court proceedings for tenant evictions was introduced, at first for three months, but later extended on several occasions. Part of the guidance supporting this legislation was for 'tenants and landlords to work together to put in place a rent payment scheme'. While a survey undertaken by the National Residential Landlords Association suggests that the majority of landlords have been supportive of requests for help by tenants struggling to pay their rent (NRLA, 2020), renters' unions have challenged the degree of 
cooperation that has actually taken place (Generation Rent, 2020). Further evidence suggests that illegal evictions have taken place despite the ban on court proceedings, demonstrating the power that landlords have over tenants who may not be aware of or able to exercise their rights (Marsh and Walker, 2020b). The extent to which the intended shared approach between private landlords and tenants persists will be revealed once the extended ban on court eviction proceedings finally ends. Again, it is anticipated that any increase will disproportionately impact young people.

People who are homeless and have No Recourse to Public Funds (NRPF) for welfare benefits have been particularly exposed to destitution during the pandemic, as well as being increasingly targeted by the Home Office for deportation (Bulman, 2020). The March 2020 briefing by the Minister for Local Government and Homelessness advised local authorities to use alternative funding and their own discretion to house people with NRPF status (MHCLG, 2020a). However, as restrictions on accessing welfare payments have not been relaxed during the pandemic, local authorities must bear the costs where support is provided as part of statutory duties or public health. The Scottish and Welsh Governments, as well as local authorities across England, have called on the UK government for resources to be provided to enable help to be given to such cases (LGA, 2020b).

\subsection{Conclusions: Knowledge gaps and future research questions}

The Covid-19 pandemic has placed the problem of homelessness firmly on the public health agenda across the world. Framing it in terms of risks to wider public health has driven an exceptional response in housing provision not only in the UK but elsewhere too. At the same time this perspective has broken with the individualising discourses inherent within neoliberal approaches to governing homelessness (Parsell, 2020). The UK government's central response to Covid-19 in relation to housing issues has largely focused on emergency responses to the accommodation and health needs of the rough sleeping population, and local authorities have been instrumental in making them successful. The achievement is underlined when comparison with some other European countries is drawn, where the risk has been countered with exclusion and discrimination. For example, in Slovakia shelters were closed with no alternative provision and those found on the streets were dispersed out of cities by police (World Habitat, 2020). The public health risk narrative has combined with existing racist attitudes to identify Roma people as a collective threat to public health, and consequently to increase the discriminatory treatment and policing of Roma across Europe (Matatche and Bhabha, 2020).

Central Government leadership and funding clearly effected an important change in the ways that emergency homelessness services have been delivered across the UK, where a historic reliance on night shelter and dormitory-style accommodation has been replaced (at least temporarily) by self-contained provision as an emergency housing response. Local authorities of all types and their partners also espoused the new approach smoothly and efficiently. Despite some challenges especially in the initial period (Groundswell, 2020), the health benefits of self-contained provision became evident in reduced infection rates, hospital admissions and deaths among rough sleepers, as well as the opportunity for independence and dignity that individual accommodation has provided to those housed. The change in approach has responded to a long-standing need for better integration between health and housing services, and sharing best practice from local approaches will contribute to more consistent provision across localities. How long this way of addressing homelessness will last remains uncertain. Further research will be required to track the lasting impact of subsequent Central Government funding initiatives and the distribution of those resources locally, and the range and effectiveness of measures used by local authorities to deploy them. 
The pandemic has contributed to greater partnership working between local authorities and a range of local housing resources, including hotels in the initial period but also housing provided by social landlords. Changes in social housing allocation policies have meant that single homeless people who are generally excluded as low priority, or otherwise unsuitable due to arrears for example, have been given priority over existing social tenants looking to be rehoused. The reality and permanence of those changes also requires further research. Ultimately, local responses to housing and health provision are varied and more evidence is required to understand these variations in local service provision and the impacts of the Covid-19 responses outlined in this section.

The pandemic has also raised the profile of shared accommodation, not only as a resource to support the rough sleeping population and low-income households, but also as a living situation that contributes to greater risk of infection transmission. If shared accommodation is to be a fundamental part of ongoing development of moveon options through Central Government funding, the impact of living with other households for health and wellbeing must be acknowledged.

Central Government interventions to mitigate the risk of homelessness have also been temporary, and with rising levels of homelessness and unemployment, coupled with local government budget cuts, the ability for local housing authorities to respond to demands will be subject to substantial challenge. Local responses to requests for homelessness assistance, as well as rough sleeping over winter and spring, will provide some indication about the medium and longer-term impacts of Covid- 19. Evictions have continued illegally despite a temporary ban on court action, and with that set to end in the spring of 2021, figures on court-sanctioned evictions and any homelessness that ensues must be closely monitored. Furthermore, while partnerships between local authorities and social landlords have aimed to strengthen local support to meet housing needs, Central Government's expectations about the cooperation of private landlords to support renters requires greater scrutiny.

Overall, Central Government measures have done little to alleviate the existing inequalities in housing that have been highlighted and worsened by the pandemic. Moreover, given the way it is financed, local government is hardly well-positioned to mount extensive intervention. What is required here is a longer-term strategy that includes policies relating to allocation, planning and regulation. Developments in housing must be integrated with wider strategies and policies that contribute to the health of the population as a whole. This means recognition of the connections between employment, healthcare, transportation and environment, the importance of which has been so clearly highlighted by Covid- 19 . 


\section{Public Parks and Other Spaces}

\subsection{Context}

When the Covid-19 pandemic struck in early 2020, local authorities across the UK were already struggling with the impacts of ten years of spending cuts, introduced as part of the post-banking crisis austerity agenda initiated by the 2010-2015 Coalition government. In England, local authorities experienced a $49 \%$ real-term loss of government funding from 2010 to 2017 and a 29\% real-term reduction in total spending power (NAO, 2018). Public spaces, and parks and green spaces in particular, have been severely affected by these cuts, mainly because they are not a statutory service. Local authorities own and manage most public parks and streetscapes, but they have no legal duty to provide or care for public spaces. Many green spaces were provided in the past as legacies or gifts from wealthy donors, but without consideration of the long-term cost of their upkeep. There have been repeated cycles of investment and decline, in line with the political priorities of the day. This neglect and decline of parks and green spaces has been noted with increasing concern by MPs and funding bodies (Heritage Lottery Fund, 2016; House of Commons, 2017).

Against this backdrop, evidence of the benefits of public spaces to public health and wellbeing has been growing, both in terms of empirical academic research (for reviews, see WHO, 2017; Pritchard et al., 2019) and in recent policy literature. One review of 263 academic papers (Wendelboe-Nelson et al., 2019) found that in $70 \%$ of studies there were positive links between green space and mental wellbeing. However, the benefits of green space are not evenly distributed. Even where people in poorer communities have access to a similar amount of green space as those in more affluent areas, the quality of spaces in their neighbourhoods is often worse. This difference in quality highlights the importance of appropriate and consistent funding.

Evidence has also been mounting of the importance of streetscapes, civic places such as squares and markets, and community hubs that host services within neighbourhoods. Well-designed urban neighbourhoods that are compact, well connected, walkable and provided with parks and green spaces contribute to greater life satisfaction (Smith et al., 2017; Bird et al., 2018). Public spaces are also considered important in facilitating social interaction (Bagnall et al., 2018). Evidence on the benefits of a well-designed urban environment have been translated into numerous guides to good practice, including publications by Public Health England (2017) on spatial planning for health and NHS England (2018) on creating healthy places. The failure to align local authorities' asset management responsibilities fully with the need to provide and care for public spaces is echoed in the disconnect between the view of public spaces (and natural spaces in particular) as a health resource, and the absence 
of any obligation for healthcare institutions to invest in them. As mentioned in Section 1 , this reflects the historic emphasis on healthcare as the treatment of disease rather than the promotion of good public health. Public health responsibilities returned to English local authorities in 2013, but the resources involved are a tiny proportion of the UK's healthcare budget. Moreover, the public health grant to local authorities has since fallen in real terms while spending on the NHS has been protected, even though preventative public health interventions can be up to four times as cost-effective as treatment after the event (Martin, Lomas and Claxton, 2019).

Tied in with these mismatches between evidence-based policy initiatives and spending power is a history of central-local relations in the UK in which local government is positioned chiefly as the supplicant, petitioning central government for adequate powers and resources to undertake an increasing number of duties and responsibilities. In its current form this has been characterised as 'austerity localism' (Featherstone et al., 2012), in which the devolution of responsibilities from central government (for example, in local welfare support and public health) has been combined with the removal or reduction of resources. In this context local authorities are urged to strike 'devolution deals' with central government in which additional powers are exchanged for adherence to centrally directed policies, such as the adoption of mayoral governance. It is in this strained environment that local authorities have faced the challenge of Covid-19.

\subsection{Local government responses during the pandemic}

The main focus of local authorities during alternating periods of lockdown, semilockdown and more relaxed restrictions during the summer months (see Section 3) has been on keeping public spaces (especially green spaces) and activities open. With a few exceptions in the initial full lockdown (including Albert Park in Middlesbrough and Victoria Park in Tower Hamlets, east London), parks generally stayed open and government advice was that they should do so. Throughout the pandemic the governments of all four UK nations have recognised the importance of parks and open spaces for physical and mental wellbeing.

In this context, the priority has been to manage parks to ensure maximum safety and minimised risk of infection. The result is that many activities that would normally be central to the use of green spaces have been curtailed or closed - including the provision of cafes and toilets, the use of sports facilities and playgrounds, and using green spaces for group activities and community events.

In the first phase of lockdown, parks were heavily used as other gathering spaces were unavailable, and warm spring weather encouraged people to congregate outside. Local authorities installed signage to help manage movement, to ensure social distancing, to encourage people to respect the environment and to take litter home. In Newcastle-upon-Tyne circles were chalked on grass to encourage groups to sit two metres apart from each other, and in Bristol a similar initiative in Queen Square and College Green used chalked hearts to keep groups apart. Many local authorities installed signage to encourage people to use parks safely, including practical ways of working out how far to stay apart from others (in the Yorkshire Dales National Park, for example, this was the length of a Land Rover or two lined-up sheep).

Because green spaces were being more heavily used, several local authorities introduced measures to enable them to accommodate more people safely. In Birmingham two metre-wide strips were mowed into grass to create alternative footpaths; in Strathclyde Country Park, Motherwell, North Lanarkshire Council widened paths so people could pass each other comfortably. West Lothian Council widened cycle paths by clearing vegetation on either side, while in Nottingham the city 
council looked at remodelling access to the popular Colwick Country Park to prevent cars driving through it.

During the summer, parks managers were under increasing pressure because of the heavy use of green spaces for social gatherings. A survey by Keep Britain Tidy found that $81 \%$ of the 100 local authority respondents had spent more than normal on clearing up litter, while $72 \%$ had invested in measures to maintain public order and enforce lockdown rules. On average each had spent an extra $£ 33,000$ on managing parks during the three months after the first lockdown was announced in March, and had cleared 57 tonnes of additional waste compared with usual levels.

In response to this, and partly because the usual community activities would not have been possible, Keep Britain Tidy cancelled the annual Love Parks Week and instead launched a 'love parks' advertising campaign (Keep Britain Tidy, 2020) featuring park users appealing to the public to 'be kind to our local parks'. Several local authorities borrowed an anti-littering slogan from the New South Wales Environmental Protection Authority in Australia, with campaigns urging the public, 'Don't be a tosser'. Councils adopting the slogan over the summer included Aberdeenshire, Bath and North East Somerset, Newark and Sherwood, Rugby, Suffolk, Swansea, Warwickshire and York.

Organised social activities in public spaces, including events and festivals, were generally cancelled - including the children's activities that are often a staple of summer school holiday entertainment for families that are staying at home. Some local authorities took imaginative steps to replicate these activities; Watford Borough Council moved Forest School provision online, while in Nottingham the 'Story Parks' initiative run by the city's library service also went online, featuring a 'digital den' of stories which continued through the autumn.

More recently, there has been a mixed response to the November lockdown in England. In Plymouth, for example, play areas and skate parks remained open, but tennis courts were closed. In Derby cafes were open for takeaway meals and public toilets remained open, but outdoor gyms and skate parks were closed. In Trafford, Greater Manchester, bowling pavilions, public toilets and climbing walls were closed, while in Barking and Dagenham, east London, cafes, toilets, outdoor gyms, tennis and basketball courts, sports pitches and skate parks were all shut.

Some local authorities used the Covid-19 crisis as an opportunity to review greenspace management practices. Many cut back on regular mowing during the initial lockdown as staff were moved to other duties or asked to work from home, and some used this to experiment with the creation of meadow areas to encourage biodiversity instead of the traditional close-mown lawns. While some of these changes were already afoot, the pandemic provided an opportunity to accelerate plans, building on greater public awareness of the natural world on people's doorstep.

For example, Renfrewshire Council has conducted a biodiversity and wildflower assessment of uncut grass areas that will inform future practice. Somerset West and Taunton is working with Somerset Wildlife Trust to create meadow areas on council land in residential neighbourhoods as well as in several parks. A similar scheme has begun in Cheshire West and Chester, where the local council is working with environmental organisation Friends of the Earth. Plymouth City Council, meanwhile, appealed for members of the public to donate money or volunteer their time to help create new wildflower meadows.

\subsection{Enabling and coordination}

Much of the activity within parks and public spaces is undertaken by voluntary and community organisations such as 'friends of' groups, by resident and neighbourhood- 
based groups, and by arts and sporting organisations. Inevitably much of this had to cease because of the ban on large social gatherings. The Active Lives survey by Sport England (2020) found that, between mid-March and mid-May, the number of participants in team sports and the number of swimmers fell by more than half. However, there was a significant increase in exercise at home, as well as in walking, running and cycling (with over a million additional cyclists recorded).

Where local authorities and voluntary organisations have worked together, it was often to identify and implement risk assessments and safe working practices for volunteers. Parks Community UK coordinated examples of good practice in Covid-safe volunteering, while Parks for London, a pan-London charity that supports councils and other landowners, has developed guidelines for volunteering during Covid-19. During the November lockdown in England, volunteering was permitted - unlike during the March-to-May lockdown. Similarly, Play Scotland has produced 'getting it right for play' toolkits that greenspace owners and managers can use.

Some local authorities have asked community members for ideas on how to make spaces safer or to contribute other suggestions for improvements. Glasgow and Edinburgh City Councils have both used online mapping tools to generate ideas and suggestions from members of the public. Outside local government, the Royal Parks in London used its website to publicise quiet periods when its parks would be less crowded, while the Woodland Trust offered a 'wood finder' on its website to help people discover new spaces.

The Local Government Association (LGA), which as previously mentioned represents local authorities in England, published a report in July on the impact of Covid-19 on culture, leisure and sport (LGA, 2020c). While this was a relatively small-scale study, based on 19 interviews with senior officers in 16 councils, it highlighted the role of government behind the scenes, especially in supporting cultural and sporting organisations. Examples include renegotiation of contracts to extend the timescales for loan repayments; providing business rate relief to sports and cultural businesses; supporting cashflow through advance payment of grants; and redeploying local authority staff to support emergency interventions including food distribution.

The report expressed concern about the future of local leisure centres, which had been closed during the initial lockdown and had not been able to operate profitably since. There was a worry that the model of outsourcing such facilities to social enterprises was no longer viable. The report noted 'an exponential rise in usage' of parks and public spaces, necessitating extra investment in signage and security, widening cycle lanes and managing traffic. Some participants in the study suggested that this had highlighted the lack of investment since 2010 and could lead to a new understanding of the importance of parks in fostering healthy lives.

\subsection{Policy development and promotion}

Because parks and green spaces in the UK are so dependent on central government funding to local authorities, a significant aspect of the work taking place during Covid19 has involved efforts to formulate or influence government policies. At national government level, there have been potentially important developments in Scotland, Wales and, to a lesser extent, England.

In Scotland the Scottish Government's Programme for Scotland 2020-2021 (Scottish Government, 2020a) promotes the idea of the '20 minute neighbourhood' in which residents can meet most of their essential needs within a 20 minute walk. This includes 'having greenspace on your doorstep and a local environment that encourages active travel to promote health and wellbeing'. The Scottish Government has launched a review of its Town Centre Action Plan to incorporate the 20-minute neighbourhood 
idea, and has promised to invest $£ 275 \mathrm{~m}$ in supporting community-led regeneration and town centre revitalisation. In addition, the Scottish Government has issued guidance to local authorities and their partners on 'safer public spaces' (Scottish Government, $2020 b$; 2020c) with an emphasis on how to ensure physical distancing, including advice on temporary installations and public markets.

A Welsh Government planning policy document, Building Better Places (Welsh Government, 2020b), sets out a range of post-Covid priorities including 'staying local' - the equivalent of the 20-minute neighbourhood idea - active travel, revitalising town centres and promoting green infrastructure for health and wellbeing and ecological resilience. This document is a precursor to the publication of the first National Development Framework for Wales, expected in early 2021.

In England, proposed planning reforms have focused more on housebuilding targets and removing regulation. A Planning White Paper published in August 2020 (MHCLG, $2020 \mathrm{~h}$ ) proved highly controversial, prompting opposition from planning experts as well as from Conservative MPs in Southern England who feared over-development in green belt and rural areas.

At the same time, Natural England, which is responsible for protecting biodiversity, has launched a new Nature Recovery Network as part of its five-year strategy (Natural England, 2020). The agency is promoting 'nature-based solutions' to environmental challenges such as drought and flooding, as well as individual connections with nature to encourage wellbeing. This work echoes pre-Covid work by Public Health England (PHE, 2020b) on the need to improve access to greenspace, which "can help to bind communities together, reduce loneliness, and mitigate the negative effects of air pollution, excessive noise, heat and flooding" (p.11). It argues that the benefits of green spaces have a greater impact on disadvantaged groups, so a greener urban environment can help to reduce health inequalities.

While these developments affect local government and will to a large extent depend on local authorities' capacity to implement proposed changes, they do not stem from local government. Local authorities have been relatively quiet in terms of research and policy development over the last year, as they have been overwhelmingly occupied with handling the immediate impacts of the crisis. However, several organisations have drawn on the expertise of local government staff in formulating proposed policy changes. Professional organisations have been particularly prominent in this regard.

The Town and Country Planning Association (2020) noted that the extension of 'permitted development rights' in recent years, under which properties can be converted into housing without having to meet planning regulations, had created 100,000 homes in England without access to suitable outdoor space. Many developments, including conversions of offices on business parks and industrial estates, had no shops or green spaces within walking distance and no safe walking or cycling routes. In addition, exemption of such developments from the 'section 106' levy to support local public facilities deprived local authorities of money to invest in public spaces that could serve such developments.

In anticipation of an autumn public spending review that was subsequently cancelled, the National Trust (2020) called for a $£ 5.5$ billion capital investment in green infrastructure for the most disadvantaged communities, using economic analysis to argue that this would deliver benefits worth $£ 200$ billion in terms of improved health and wellbeing. The Ramblers (2020) also published a survey highlighting inequalities in terms of access to nature, which revealed that $57 \%$ of Black, Asian and minority ethnic (BAME) people intended to walk more to improve their wellbeing, compared with $45 \%$ of the population as a whole. The environmental charity, Groundwork, called for more investment in community hubs to support volunteering, arguing that "making 
green space a central component of community hubs can improve both mental and physical health and stimulate a greater appetite for action on climate change and biodiversity loss" (Groundwork, 2020, p.3).

The think tank Localis (2020) highlighted the need for more support for local social infrastructure, including parks and open spaces. It said councils should have a statutory duty to provide these and to support 'friends of' groups to engage local people in looking after them. Another think tank, the Social Market Foundation (Pardoe, 2020), called for the adoption of 'park districts', a practice in some US cities where homeowners near green spaces pay an additional property tax earmarked specifically for park upkeep. The Social Market Foundation also called for an extension of 'green prescribing' initiatives using public parks as a healthcare resource (Pardoe, 2020).

\subsection{Conclusions: Knowledge gaps and future research questions}

Local government action around parks and public spaces has centred on two connected challenges during Covid-19: to manage an unexpected upsurge in use, and to do so within the confines of already severely stretched resources. These challenges have been accentuated by a situation in which local authorities have management responsibilities without either a legal duty or the ability to raise additional resources, making them highly dependent on central government financing and policy development on the one hand, and voluntary commitment on the other.

These challenges were well known before the onset of Covid-19, but have been underlined because people who would otherwise use indoor spaces have been channelled into public space, many of them for the first time. During the national UK lockdown from March this pressure on urban green space was heightened by the need to 'stay local' alongside active restrictions on access to the countryside (National Parks in particular) for recreational purposes. While many people have gained unexpected benefits from exploring local green spaces and running, walking or cycling more, there has been no serious central government acknowledgement of the additional costs involved in keeping such public spaces open when others have been restricted.

These financial constraints have limited local government's capacity to innovate and to find new solutions that might have enabled more facilities to stay open or community activities such as volunteering to take place. While practical attention has been focused on managing demand safely, policy attention has been directed towards trying to influence central government, a process that is time-consuming and long-term in nature, and one that hinders agile adaptations to rapidly developing situations.

The clear value placed by the public on green spaces during Covid-19, and the health benefits that have been recognised by national governments, raise several practical research questions, including:

- How can innovation and best practice spread and take root in a financially constrained environment? Which actors are best placed to identify innovation and what capacity do local authorities and communities have to respond?

- What implications does Covid-19 have for the relationship between local government and the central state in relation to public spaces? Is a new legal framework and financing mechanism required to ensure equitable access to green spaces in future?

- At what scale should green and public spaces be owned and managed? Given the trend towards larger unitary local authorities and combined authorities for cityregions, what trade-offs are required between local accountability and sensitivity and efficient management? 
- How can public space be effectively integrated into healthcare planning and policy so that the natural environment and green spaces promote the health and wellbeing of all sections of the population?

Behind these questions are more theoretical (but no less important) issues about environmental justice, democracy and the right to the city. The notion of "just sustainabilities' (Agyeman, 2013) highlights inequitable access to public goods, and unfair distribution of public harms. To take that work forward, attention should be paid to opportunities that could be created for communities and localities to define their own priorities for wellbeing and to shape the institutional processes that govern resource allocation. In particular, research could focus on how to create responsive capacity so that communities can articulate their needs for environmental justice in times of emergency when action needs to be taken rapidly. 


\section{The Promotion of Active Travel}

\subsection{Context and past trends}

Active travel is defined as making journeys by physically active means, which mainly covers walking and cycling, but also includes running, scooting, self-propelled wheelchairs, and so on. Prior to the Covid-19 pandemic, increasing attention and resources had been given to ways of increasing levels of this travel mode in the UK, involving both Central and the devolved governments.

The Active Travel (Wales) Act 2013 was the first piece of legislation explicitly directed at providing for active travel. Later the same year the Northern Ireland Government published a high level strategy setting out the active travel plans for the country (Department for Regional Development, 2013) ${ }^{2}$.The following year saw Scotland present a long-term vision for active travel leading through to 2030 (Transport Scotland, 2014a). In England, the Cycling and Walking Investment Plan (Department for Transport, 2017) outlined the approach to increased levels of active travel.

At local and regional levels, active travel has also received growing attention from policy makers recognising the potential of active modes in addressing problems such as pollution and congestion. UK government funding programmes, such as the Local Sustainable Transport Fund, opened up some opportunities for local authorities to deliver active travel programmes. There has also been an expectation placed on local authorities to develop their own active travel strategies, building on the national level vision and funding programmes (Transport Scotland, 2014b).

A more recent development in the UK has been the creation of 'Walking and Cycling', or 'Active Travel' Commissioners. These are often high-profile individuals appointed to help deliver a step-change in active travel in local areas. Notable examples include Chris Boardman (former Olympic and professional road and track cyclist) as Greater Manchester's Walking and Cycling Commissioner in 2017 and Dame Sarah Storey (Britain's most decorated female Paralympian) as the Sheffield City Region's Active Travel Commissioner in 2019. The advent of a Commissioner tends to be associated with a development of a comprehensive vision for active travel and a significant package of investment in the facilities and activities needed to make the vision a reality.

${ }^{2}$ In 2016 the Department for Regional Development was renamed the Department for Infrastructure. 
The Covid-19 pandemic has been accompanied by a need for greater physical and social distancing, with a clear direction from Governments to avoid public transport and to encourage the use of more active modes. This unprecedented request has intersected with existing visions and strategies for active travel, rapidly accelerating the existing work being undertaken by local authorities and metropolitan areas to increase levels of active travel. It has also laid bare the historic imbalances in provision, with the already limited space given over to active travel being further squeezed by the need for social distancing (Nurse and Dunning, 2020). This has led to the rapid reallocation of road space from motor vehicles in favour of these active modes.

This section investigates local authority 'active travel' responses to the Covid-19 pandemic. It details the immediate actions taken, the factors that enabled these responses, the implications for future policy directions, and where gaps in evidence and understanding lie.

\subsection{Local government responses during the pandemic}

The Covid-19 pandemic has caused a substantial disruption to the transport system and challenged local authorities to find a way of keep their residents safe whilst ensuring the transport network could keep operating, particularly as the restrictions were gradually eased. In the immediate term, the nationwide lockdown that came into force in late March dramatically reduced the volume of journeys being made. Conversely, it also led to an increase in those being made by active modes, although overall people's mobility levels decreased during this period (Hadjidemetriou et al., 2020). Evidence from the Department for Transport's National Travel Attitudes Study showed that in England 39\% of respondents were walking more than before the pandemic. Similarly, 38\% were cycling more than before. This included respondents interviewed between May and July 2020 (Department for Transport, 2020d).

Local government transport-related responses to the pandemic have appeared in different ways. One of the most prominent and commonly used approaches has been a rapid reallocation of road space to favour more active modes and to enable social distancing. Many local authorities have widened pavements to allow for the safe movement of pedestrians in built-up areas, including suburbs. Examples include King Street in Hammersmith, London where Hammersmith and Fulham Council temporarily installed barriers to widen pavements in busy a shopping area. In Edinburgh, the City Council widened pavements in a range of locations, including Portobello High Street, which helped local businesses to reopen safely. These examples were replicated countless times across the UK during the initial weeks of the national lockdown. Since then, these alterations have mostly remained in place as social distancing requirements have been maintained.

Another widely adopted local authority intervention has been the creation of temporary or 'pop-up' cycle/active travel lanes on the road network. These lanes provide a formal, albeit temporary, segregation of users from the rest of the road traffic. They have a dual purpose of discouraging the use of private vehicles whilst providing a safer space for people to travel actively. Cycle lanes have often been at the centre of conflicts between motorists and other road users (Wild et al., 2018) and as such have the potential to be a high profile and emotive issue. Despite the temporary nature of the cycle lanes introduced in the wake of the Covid-19 pandemic, their rapid introduction has provoked vociferous opposition from other (usually motorised) road users. One example is in Sheffield where the introduction of a 'pop-up' cycle lane along a primary road route, which included the removal of a lane of traffic on a dual carriageway for a short length, received a mixed response. Whilst it was heralded by proactive travel groups as an important piece of infrastructure it was regarded by some as being responsible for increased congestion. However, it also coincided with the introduction 
of restricted vehicular access to the adjacent area, which offered a quieter through route for cyclists, so after a few months it was removed (Walsh, 2020).

In November 2020 West Sussex County Council similarly removed a 'pop-up' cycle lane in Shoreham that had been introduced at the height of the lockdown in March. It was reported that this was a response to traffic levels returning to normal, and the circumstances that warranted the initial need for the cycle lane were no longer relevant (Ames, 2020b). This has been disputed by others, who claim that the lane has more than doubled levels of cycling along that stretch of road (Wills, 2021). In other places poorly designed facilities seem to have alienated everyone. Thus, in Swansea at least one cycle lane proposed by the local authority has been strongly opposed even by local cycling and walking groups (Youle, 2020).

A further infrastructure intervention that has sought to allocate more road space for active modes has taken the form of the Low Traffic Neighbourhood (LTN). LTNs are groups of residential streets where restrictions are put in place to reduce the flow of motor traffic whilst retaining access for residents. Installation of street furniture helps to prioritise space for more vulnerable users such as pedestrians and cyclists. These modal filters include bollards, gates or planters, which are used to discourage through 'rat-run' traffic. LTNs had already seen application in the UK, for example in Waltham Forest, but the Covid-19 pandemic has thrust them more prominently onto the policy agenda and dozens more have now been introduced across the UK.

One such LTN is in the Lee Green area of Lewisham in London. This was initially planned as part of a Healthy Neighbourhood programme announced in 2019, but when introduced in June 2020 was repurposed as part of the response to Covid-19. The intervention has not been without its problems, with traffic congestion and increased air pollution reported in surrounding residential areas as a result. Although the proposal predates the pandemic, the council appears to have rushed its introduction, with limited consultation with not only local residents but also other public sector bodies like the ambulance service (Cuffe, 2020). In October, the local authority announced a series of changes that will ultimately ease the restrictions (Lewisham Council, 2020). This experience is not uncommon; LTNs have received much attention in the press because of the opposition to them. Whilst Lewisham has chosen to refine its intervention, some local authorities have quickly decided to remove the restrictions completely.

The evidence around LTNs remains limited and therefore it is difficult to say whether they do cause increased congestion. In some places like Enfield, where they have been a long-term programme, they seem to have worked well. Here they form part of a wider package of measures that relate to the public realm as a whole and people's utilisation of it, rather than the mere installation of different types of barrier (Rawlinson and Black, 2020). In areas that are catching up, a highly politicised debate based largely on anecdotal evidence is under way as to the merits of this form of intervention. Reactions by local authorities to remove them appear to be the result of vocal opposition from a minority and not the result of robust monitoring and evaluation. In addition, opinion polls have indicated that most people support such changes. Indeed, the challenges of implementing LTNs have not prevented some local authorities from continuing to pursue them, even into the autumn and winter of 2020. For example, in November Leeds City Council began a pilot of its first 'Active Travel Neighbourhood' or ATN (Leeds City Council, 2020a).

Beyond the installation of physical infrastructure, in some places behavioural programmes have sought to help in increasing levels of active travel in response to the pandemic. Some have been targeted directly at key workers, for example, the 'Key Worker Cycle Scheme' launched by the Isle of Wight Council in April 2020. This provided access to bicycles or provided a voucher to allow repairs to an existing bike. 
Similar programmes were introduced by councils in Derby and Leicester. These were not solely local authority funded schemes; thus, the 'Leicester Bike Aid' programme also included contributions from local bike shops and other businesses, alongside contributions from cycling organisations Sustrans and British Cycling. Links have also been made to these bodies' existing behavioural change support programmes, with Derby's programme, for example, signposting participants to the route planning and other support tools on offer.

Some programmes have supported specific groups. For example, East Sussex Council has developed a 'School Streets' programme to support schools, pupils and their families to adopt active travel not just during the pandemic but also over the longer term. School Streets projects are also being piloted by Leeds City Council, with six schools currently involved but with plans for expansion, albeit subject to future funding (Leeds City Council, 2020b). Another measure that sought to prioritise pedestrians at the expense of other 'active travellers' at certain times of the day was the temporary closure of the Thames Path in Hammersmith and Fulham (London) to cyclists and runners. This was a response to concerns around health and safety, and the need to ensure social distancing (Hammersmith and Fulham Council, 2020).

Alongside these infrastructure and behavioural measures, there are also examples of more innovative methods implemented by local authorities. Examples include Newcastle City Council, which partnered with other local organisations to develop a website (howbusyistoon.com) that allows residents to access real-time information on footfall in the city centre and thereby adjust their planned journeys so they can avoid the busiest periods. This enables them to comply more easily with social distancing requirements.

Brighton and Hove City Council commissioned a technology and behaviour change company to deploy a 'rewards' programme to encourage active travel in the city. This is implemented through a mobile app that tracks use of active travel infrastructure by individuals, with the most frequent users awarded prizes. At the same time it provides detailed monitoring figures that will be used by the local authority to evaluate the use of infrastructure and to guide where amendments might be needed (BetterPoints, 2020).

A key feature of many of these measures is that they have been temporary or 'pop-up' interventions designed to alleviate immediate pressures on the transport system and to foster a shift towards more active modes of travel. This temporary nature has meant that measures can be easily removed if necessary. This has occurred where local authorities have experienced a great deal of negativity towards an intervention as well as in cases they have not quite worked as envisaged. As the alternating lockdown/partial relaxation regime has become more familiar, attention has started to shift towards longer-term behavioural change for when life returns to normal, or at least to a 'new normal'.

As an illustration, after implementing a range of temporary interventions during the summer of 2020, Nottingham City Council is now transitioning to a longer-term view. This includes the creation of a new 120 space secure cycle parking facility in the city centre and a permanent (but flexible) barrier system along the city's Victoria Embankment that would allow the road to be closed for longer periods (Nottingham City Council, 2020).

Similarly, in Leicester, the City Council has also announced a new electric bike hire system. Whilst this was planned before the pandemic, the local authority is utilising the scheme as part of the city's post-Covid recovery as it seeks to achieve higher levels of active travel (Leicester City Council, 2020). Surrey County Council has also stated a clear intention to implement permanent schemes in response to the pandemic, with 
the details being outlined on its website giving residents the opportunity to provide input on planned changes (Surrey County Council, 2020).

\subsection{Enabling and coordinating the local government response}

One key enabling factor in local authority responses to the pandemic has been the various action taken by national governments. In England, statutory guidance was issued in May 2020 to local authorities outlining how they could reallocate road space to accommodate active travel and social distancing (Department for Transport, 2020c). The government also brought into force emergency legislation in late May. This temporarily amended the following legislation:

- $\quad$ The Road Traffic (Temporary Restrictions) Procedure Regulations 1992.

- The Local Authorities' Traffic Orders (Procedure) (England and Wales) Regulations 1996.

- The Secretary of State's Traffic Order (Procedure) (England and Wales) Regulations 1990.

The core purpose of these changes was to enable local authorities to make more rapid changes to the road network and to make it easier for them to introduce temporary or 'pop-up' measures. It also created new traffic sign guidance to support social distancing and temporary road space measures. The Department for Transport also supported local authorities by commissioning an update of their Active Mode Appraisal Toolkit (AMAT) guidance, which was designed to enable more effective appraisal of proposed road space reallocation measures (Ames, 2020c).

To give substance to these legislative changes existing resources were quickly repackaged into the Emergency Active Travel Fund (EATF) (Department for Transport, 2020a). The first round of this funding (Tranche 1) provided $£ 42$ million to English local authorities for emergency active travel projects to be implemented because of the pandemic. The second tranche of funding, announced in November 2020 (Department for Transport, 2020b) is providing a further $£ 175$ million for upper tier local authorities or combined authorities to support active travel projects in England. At the same time the fund was renamed as the 'Active Travel Fund' (ATF), highlighting the shift from 'emergency' responses to longer-term projects to support future active travel. Indeed, a condition of this funding is that councils are required to submit more detailed plans and evidence of consultation, alongside a commitment to monitor and evaluate the schemes that are funded (Ames, 2020a). This approach also dovetails with the ambitious 'Gear Change' vision for increased cycling and walking introduced in July 2020, involving a new coordinating body (Active Travel England), intensive investment in 12 non-London council areas, and integration with place-making and health improvement policies (Department for Transport, 2020c).

The pro rata regional EATF/ATF allocations are shown in Figure 7.1. This reveals that the three northern regions (North East, North West and Yorkshire) have fared best, closely followed by the East of England and the South East. In contrast, the East Midlands, London and the South West have received the lowest relative amounts. The greater disparities evident in Phase 2 allocations largely reflect variations in the extent and ambition of the plans drawn up by local authorities in each region. In turn these generally follow a rural/urban split at an individual local authority level, with shire counties and county unitaries generally allocated relatively lower amounts, presumably because of a perceived lack of widespread need. That said, some urban authorities like Bedford, Stoke-on-Trent, Telford and Torbay are being given markedly lower amounts compared to more interventionist councils like Brighton, Hull, Nottingham and Reading. Finally, the relatively meagre amount for Greater London may reflect the 
already extensive cycling infrastructure in the city. Even so, at £25 million its total absolute budget under the fund is the fourth largest of all the English regions.

Figure 7.1: Active Travel Fund Per Capita Allocations by English Region, 2020

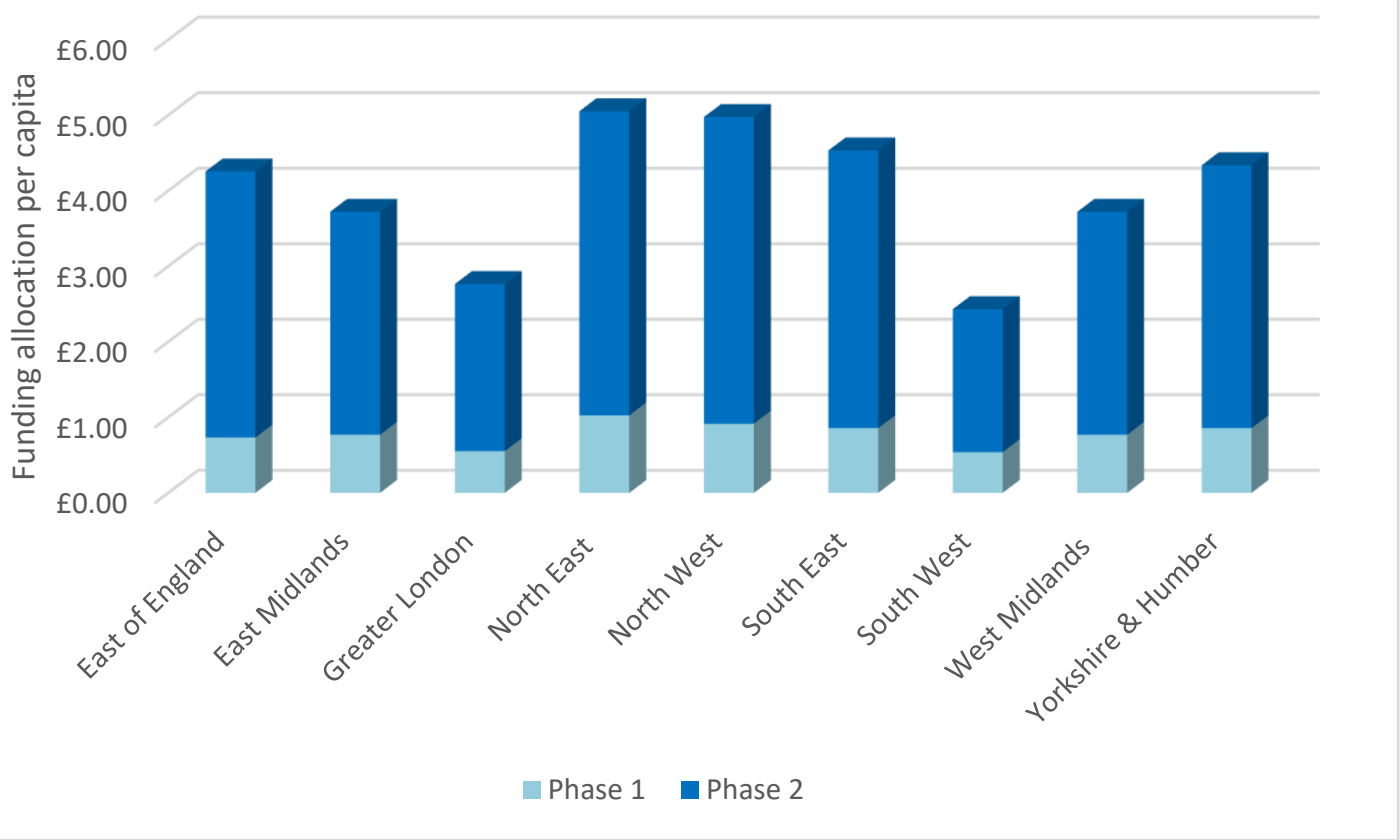

In a similar vein, the Scottish Government launched an initiative called 'Spaces for People', which supported local authorities in providing temporary infrastructure to enable more active travel (Sustrans, 2020b). Initially, £10 million was reallocated from an existing programme called 'Places for Everyone', but subsequently a further $£ 29$ million was allocated through this funding programme, which has now ended (Transport Scotland, 2020c; 2020a). The Scottish Government has now turned its attention to the longer term, adjusting the 'Places for Everyone' programme to reduce the amount of match funding needed for individual projects, and thereby giving more opportunities for local authorities to pursue permanent measures (Transport Scotland, 2020c). In addition to funding, the Scottish Government also issued renewed guidance on the temporary traffic regulation orders and notices available to local authorities (Transport Scotland, 2020b). This was to ensure that local authorities were fully aware of these opportunities and were using the measures effectively.

In Wales, the devolved Government supported active travel through a £15.4 million 'Local Sustainable Transport Covid Response' funding programme (Waters, 2020). This allocated funds directly to local authorities to implement measures to support more sustainable transport in response to the pandemic. By its nature, many of the measures were focused directly on active travel. £2 million of the fund is being used specifically for school travel measures and schemes. A full list of funded schemes has been published (Welsh Government, 2020a). Beyond this, 14 councils have been awarded a share of a £20 million pot for major schemes from the Welsh Government's version of the Active Travel Fund, with a further $£ 9$ million going to the rest, partly for 'in-fill' projects but mainly to assist development of integrated plans for future developments (Waters, 2020). As in England and Scotland, this funding would probably have been made available anyway, but the pandemic has given it added urgency.

Northern Ireland has taken a more limited approach to promoting active travel in response to Covid-19. Whilst measures have been put in place, detailed information on them is limited. The Department for Infrastructure announced that it would appoint a 'Walking and Cycling Champion' (Department for Infrastructure, 2020a), albeit from 
existing departmental staff rather than a high-profile individual. Nevertheless, the pandemic has sparked discussions around the need for an Active Travel Act in Northern Ireland to provide statutory backing to help generate more substantial investment in and promotion of active travel (Murray, 2020).

Beyond national governments, several other organisations have provided coordination or support for local authorities during the pandemic. Thus, Transport for London, which has responsibility for the city's transport network, launched a 'Streetspace for London' scheme (Transport for London, 2020). This aimed to install its own 'on the ground' interventions but also provided funding and resources for London Boroughs to implement their own schemes. This included guidance on best practice for interventions such as LTNs, School Streets, cycle and car parking, and social distancing guidelines.

Outside London, Sustrans (the walking and cycling charity) has also provided support to local authorities around active travel measures. Its online guidance on the reallocation of road space signposted local authorities to best practice, information on legislative changes, and support for implementing their own schemes (Sustrans, 2020a). In addition, it has produced a 'Space to Move' map, which allows residents to give feedback on temporary schemes that have been implemented by local authorities. This does not appear to have had a high level of uptake, probably because many local authorities have created their own feedback websites, or because of competition from similar online tools, such as the Widen My Path (widenmypath.com). This was produced by the team behind the Cycle Streets journey planner and allows residents to identify where cycle lanes and widened pavements are needed to support social distancing. The pedestrian support group Living Streets also launched a campaign to provide more space for walkers and cyclists for social distancing, including a tool to allow supporters to email their own local authorities with suggestions (Living Streets, 2020).

\subsection{Policy changes and promotion of active travel}

Since the Covid-19 pandemic prompted a national lockdown across the UK there has been a significant, reactive shift in policy from both national and local governments. In the short term, the need to move travellers away from public transport and onto more 'Covid-safe' modes prompted significant investment of capital and legislative resources to support local authorities to implement temporary road space reallocations and other measures. In turn, local authorities have also invested time and resources into this challenge. Whilst the UK still faces continuing restrictions, national and local governments have begun to look to the next steps required to build on this legacy.

These next steps include making permanent some of the temporary measures introduced during 2020. They also include developing a programme of funding and plans to produce other permanent measures, along with a policy environment that supports this. Efforts towards this are being pushed forward by national governments, but also by leading local authorities and other relevant organisations (such as sustainable transport charities like Sustrans, Cycling UK and Living Streets). There are also questions about how streets and neighbourhoods might be reimagined and reconfigured in ways that would further enhance health and wellbeing (Russell and Stenning, 2020).

The transition between Tranches 1 and 2 of the UK Department for Transport's Emergency Active Travel Fund in England signalled a shift from temporary to permanent infrastructure interventions. The Covid-19 pandemic has initiated significantly increased support from national government towards active travel, with this rapid funding a key example. However, it is important to note that the funding being made available is not strictly 'new' money; it is drawn from funding already committed 
to active travel prior to the pandemic (Department for Transport, 2020a). Whilst it is still an important step for enabling more active travel, it does also highlight how policy development with regard to active travel as a result of Covid-19 remains quite limited in England.

In contrast, Scotland has developed an evolving 'Transport Transition Plan'. This fulfils two functions. Firstly, it provides up to date information about current travel guidance and rules. Secondly, it is also a forward-looking plan that is seeking to elicit longerterm behavioural changes, specifically around active travel (Transport Scotland, 2020d). These longer-term efforts also include developing and issuing design guidance for public spaces to ensure that good practice is followed (Scottish Government, 2020).

In Wales, an updated transport strategy is currently under consultation (launched in November 2020). The previous strategy was published in 2008, so this will deliver a much-needed updated vision for transport in Wales, albeit under the shadow of the Covid-19 pandemic. The first priority in the draft strategy is to reduce travel-related greenhouse gas emissions through more home/remote working and more active travel. Although detailed policy proposals are yet to emerge, this suggests that active travel is likely to play an important role, although further policy development and promotion will of course be critical to this.

Although there are examples of active travel investment in Northern Ireland in response to the pandemic, there is less clarity on future policy development. Legislation to allow electric bikes on NI roads was brought forward in May 2020 (Department for Infrastructure, 2020b), although much later than the other devolved governments. In addition, NI has faced some criticism around the relatively low level of investment being provided for active travel (the lowest in the UK) (McHugh, 2020), highlighting the extent of the 'policy lag' in this sphere. Agendas around policy development have also been pushed by key charities and stakeholders. For example, Cycling UK has been advocating a Northern Ireland Active Travel Act, as part of a push for increased investment around active travel (Murray, 2020).

Local authorities have responded to the pandemic by delivering a wide-ranging package of active travel interventions in a short period of time. Unfortunately, the hasty introduction of some temporary schemes that were not properly integrated with existing active travel infrastructure has combined with low levels of consultation and inadequate design standards to provoke considerable opposition. Although much of this has emanated from those affected by restricted access and reduced road space, in some places active travel campaign groups have also advocated against poorly conceived interventions.

For some city councils and combined authorities, the response to the pandemic coincided with on-going strategic plans for active travel. In Sheffield City Region (SCR) for instance, the appointment of an Active Travel Commissioner in 2019 has been part of growing support and resources to increase levels of active travel in the region. This has included significant effort in the past two years to develop a long-term vision for active travel, to identify priority locations for measures to be introduced, and to develop a funding plan to support the capital investments needed. In short, SCR's response to the pandemic was influenced and guided by its existing strategic plans for active travel. In essence, then, the pandemic has acted as an accelerant to existing intentions and interventions. The SCR experience is not unique (it has been shared, for example, by Greater Manchester) but it does indicate how different authorities are likely to have had different levels of preparedness to respond to the active travel challenges posed by the pandemic. 


\subsection{Conclusions: Knowledge gaps and future research questions}

This section has outlined numerous examples of the rapid deployment of active travel measures in response to the Covid-19 pandemic. The experiences outlined demonstrate how existing infrastructure can be very quickly repurposed for active travel modes (Dunning and Nurse, 2020). It has also underlined the dangers of a rushed approach to infrastructure adjustments, especially where the goal is to foster long-term modifications in travel behaviour. Again, it appears that those councils which had already gained experience of redesigning road space to enable more active travel and to introduce traffic calming have found it easier to integrate Covid-related additions. This is based on their multiple advantages of a ready-made consultative network and process, a series of already established well-designed schemes and an ability to demonstrate from these that any negative impacts would be much lower than predicted (Rawlinson and Black, 2020).

However, there remain gaps in understanding of the actual impact of such interventions on levels of active travel. This is partly a function of time, of course, but also reflects the fact that life has not yet returned to normal, or the 'new normal'. Remote working or furlough is still commonplace for many, thereby radically enforcing change in people's travel patterns. It remains unclear what forms and frequencies will characterise future commuting, education, shopping and leisure travel in the longer term, and the extent to which active modes will make up a growing proportion of these journeys.

Historically, the monitoring and evaluation of active travel interventions has been inconsistent and sometimes completely lacking. The UK and devolved governments have placed requirements on local authorities to monitor and evaluate active travel interventions, particularly those that are destined to become more permanent. Advice and guidance have been made available, but experience shows that it is difficult to build a robust evidence base on the impacts of such measures. This evidence base is important not only for building on successes, but also to allow learning from unsuccessful measures.

Another challenge is how to institutionalise and formalise changes that have been made during the pandemic. The severe restrictions have generated significant disruption but also opportunities in terms of shifts in behaviour. However, realising these may need a stronger steer from government. So far the funding that has been provided is principally from existing packages of active travel investment, the legislation used to implement road space reallocation measures is temporary, and advice to avoid public transport has meant that levels of car use have returned to (or exceeded) pre-lockdown volumes. A longer-term increase in active travel will require expanded investment and a concerted policy push. Local authorities supported by other stakeholders are well placed to advance this agenda but there remain questions around how best to achieve it. Will funding continue to be scaled up to match ambition? What are the ingredients for achieving the culture change necessary? 


\section{Conclusions: Towards a Future Research Agenda}

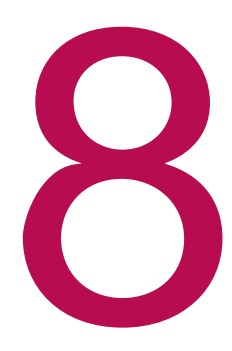

This report examines a range of ways in which local government bodies in the UK have responded to the pressing issues associated with the Covid-19 pandemic during 2020. Based on a review of currently available evidence, it looks in turn at aspects of the general support provided to local residents and their communities; at financial and other assistance to local businesses, as well as at measures being put in place to chart a path towards future economic recovery; at revised arrangements to protect those affected by homelessness and other forms of housing insecurity; at the management of parks and other public spaces as key venues for exercise during lockdown; and at efforts to boost active travel modes and to foster cleaner and safer residential environments through road space reallocation and traffic management.

The far-reaching impacts of the pandemic have meant that local responses have required the involvement of not just official government bodies, but also organisations in all segments of society. Despite inevitable variations, most localities have seen concerted and well-coordinated efforts to meet the needs of local residents, communities and businesses. This has entailed substantial joint working not just between different public service providers alongside long-established voluntary sector bodies, but also drawing in a myriad of neighbourhood mutual aid groups, concerned local businesses and members of the general public. In many places, positive 'complementary' relationships between these actors have been fostered and embedded into remodelled ways of working. A potential consequence for such areas is a longer term strengthening of local governance, featuring a commitment to closer joint operations in the future. In view of the reduction in resources and capacity imposed on local government over the previous decade, this is certainly an impressive achievement. In the best cases it may justifiably be claimed to represent an exemplary instance of collaborative local governance in practice.

However, there have been inevitable variations both between different places and across different policy domains, the latter often within the same locality. To some extent this observation pertains to the predominance of positive or negative reporting styles on different topics. Thus, coordination of support mechanisms tends to be illustrated by warm stories of appropriate help being delivered to people in need, whereas reports on active travel and low traffic neighbourhood interventions generally focus on initiatives that have prompted vociferous opposition from certain quarters. To counter these tendencies, each section of the report endeavours to look beyond these headlines to furnish a more balanced perspective. The review also tries to keep sight of the wider context in which much of what can be done by local government in the UK is driven by national governments' policy-making and resource allocation, as well as their attitude on how local authorities fit into the UK's overall system of territorial governance. 
This is not to imply that local authorities lack any scope for developing distinctive approaches, whether this be launching additional business support measures to fill the gaps in nationally administered schemes, or adopting the role of flexible response coordinators rather than centralised directors in community support initiatives. Nevertheless, a great deal has rested on the scale of additional resources that a given local council has been able to muster, either from its own reserves, via loan finance or through emergency government funding. Again, both availability and extent of involvement will vary considerably between different places as a result, and the exact nature of what has been possible and how will require further comparative research once local authority expenditure returns have been finalised. Similarly, the extent to which different local authorities have managed to introduce streamlined grant application and regulatory procedures remains unclear, as does their effectiveness; again, this will require further detailed research.

In broader terms claims about such local responses to the pandemic creating a permanent transformation in the ways in which public services are designed and delivered similarly require further investigation. Thus, reframing homelessness in terms of public health has broken with the previously dominant individualising discourses inherent within the neoliberal approach, but whether this rolls forward in the post-pandemic period remains uncertain. Further research is needed to track the nature of subsequent Central Government funding initiatives, the distribution of those resources to local authorities, and the range and effectiveness of measures used to deploy them. In terms of housing provision more broadly, the extent to which partnerships have been strengthened between local authorities and accommodation providers in both social and private sectors will be another important avenue for future research, especially in terms of their persistence over time.

The overwhelming importance of parks and other public spaces for people's physical and mental health have underlined the anomaly whereby the essential role of the public realm is not matched by any legal duty nor dedicated financial resources to manage and maintain it, still less to extend it as a means of achieving more equal access. Even before the pandemic local authorities have had to find varying solutions to the difficulties of maintaining good quality public spaces. Without a rethink on the part of Central Government this will remain the case, despite the manifest public health benefits. The potential varied range of innovative practice will need to be subject to continued research, so that lessons can be shared, and pitfalls avoided. Future developments are likely to continue relying on productive local authority/civil society relationships, which as the report emphasises take time and nurturing to come to fruition. It appears that the same approach needs to become embedded in the adjustments linked to active travel and traffic management in residential areas. Here further research will be required to distil the ingredients of the approaches taken by local authorities over a sustained period in building a context in which new installations can become commonplace and uncontroversial.

Each section of the report concludes with an outline of some of the key questions that should form the core of an emerging research agenda. Clearly this is not just about immediate responses to Covid-19; as with so many other things, the pandemic has brought to the fore needs and issues which have been brewing for some time. These also point towards a need for governance across the UK to be more inclusive and equitable. In this sense, the local lessons emerging from this review, around the need for productive collaboration, coordination and negotiation, might equally apply to the governance of the UK in general. Indeed, in the words of one observer, the "overall response to the pandemic has exposed the fractured and poorly coordinated nature of government at different levels across the UK" (Kenny, 2020, p.39).

Successive governments have attempted to continue centralised control despite the realities of 20 years of devolution, and a consequent lack of appreciation that the 
country is now less a unitary state and more "a multi-level patchwork of governing authorities" (Kenny, 2020, p.40). As such Central Government is part and parcel of the networks and relationships that comprise the overall system of governance, albeit the most important component. This in turn implies replacing the current dictatorial, adversarial model with a set of constructive relationships that enables it to steer others in the same general direction. Part of this 'metagovernance' role involves recognition of the increasingly blurred boundaries between the state and civil society (Jessop, 2020), especially at the local scale, and as part of this empowering local government bodies to entrench the enabling and coordinating roles that have been so important in getting support to where it is needed during the pandemic. 


\section{Bibliography}

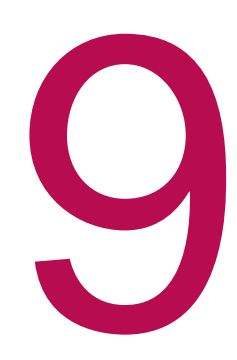

Advisory Council on the Misuse of Drugs (ACMD) (2020) Letter to the Home Secretary RE: COVID-19: ACMD advice on proposed legislative changes to enable supply of controlled drugs during a pandemic. 7th April 2020. Available at: https://assets.publishing.service.gov.uk/government/uploads/system/uploads/attachment da ta/file/878524/COVID-

19 ACMD advice on proposed legislative changes to enable supply of controlled drug s during a pandemic1.pdf (Accessed: 30/10/20)

Agyeman, J. (2013) Introducing just sustainabilities: policy, planning and practice. London: Zed Books.

Ames, C. (2020a) DfT warns of conditions on $£ 175 m$ active travel cash. Transport Network. Available at: https://www.transport-network.co.uk/DfT-warns-of-conditions-on-175m-activetravel-cash/16965

Ames, C. (2020b) "More traffic" sees council ditch cycle lanes. Transport Network. Available at: https://www.transport-network.co.uk/More-traffic-sees-council-ditch-cycle-lanes/16942

Ames, C. (2020c) New guidance aims to seize active travel opportunity. Transport Network. Available at: https://www.transport-network.co.uk/New-guidance-aims-to-seize-active-travelopportunity/16666

Amin-Smith, N. and Phillip, D. (2019) English council funding: what's happened and what's next? IFS Briefing Note BN250. London: Institute for Fiscal Studies (IFS).

Ashton, L. (2020a) 'Pressure’ prediction. Sheffield Telegraph, 21st May 2010.

Ashton, L. (2020b) Council opens its 'war chest' to help plug Covid-19 gap. Sheffield Telegraph, 30th July 2014.

Association for Public Service Excellence (APSE) (2020) APSE Public Opinion Poll 2020: Trust and Confidence in Councils during COVID-19: What the Public Think. Available at: https://www.apse.org.uk/apse/assets/File/APSE\%20Survation\%20Survey\%20Dec\%202020. $\underline{\text { pdf }}$

Atkins, G. (2020) Croydon council's bankruptcy is a warning for the UK government. Comment, Institute for Government. Available at: https://www.instituteforgovernment.org.uk/blog/croydon-councils-bankruptcy-warning-ukgovernment

Audit Wales (2020) Financial Sustainability of Local Government as a Result of the COVID19 Pandemic. Cardiff. 
Bagnall, A-M., South, J., Di Martino, S., Southby, K., Pilkington, G., Mitchell, B., Pennington, A., and Corcoran, R. (2018) Places, spaces, people and wellbeing: full review. Leeds: What Works Centre for Wellbeing.

Barker, N. (2020) The housing pandemic: four graphs showing the link between COVID-19 deaths and the housing crisis. Inside Housing, 29th May 2020. Available at: https://www.insidehousing.co.uk/insight/insight/the-housing-pandemic-four-graphs-showingthe-link-between-covid-19-deaths-and-the-housing-crisis-66562 (Accessed: 30/10/2020)

Barratt, C., Green, G. and Speed, E. (2015) Mental health and houses in multiple occupation. Journal of Public Mental Health, 14 (2), pp. 107-117.

BBC News (2020) Coronavirus: UK councils fear bankruptcy amid Covid-19 costs. 25th June 2020. Available at: https://www.bbc.co.uk/news/uk-53069772 (Accessed: 07/12/2020)

Bearne, S. (2019) Are micro-houses the solution to Britain's homelessness crisis? The Guardian, 27th October 2019. Available at: https://www.theguardian.com/society/2019/oct/27/homelessness-homes-micro-charities (Accessed: 26/01/21)

Beatty, C. and Fothergill, S. (2021) The Impact of the Coronavirus Crisis on Older Industrial Britain, report for the Coalfields Regeneration Trust and Industrial Communities Alliance. Sheffield: Centre for Regional Economic and Social Research, Sheffield Hallam University.

Bennett, M. (2020) From front-line defence to back-foot retreat: The diminishment of local government's roles in social health outcomes. In: Bonner, A. (ed.), Local Authorities and the Social Determinants of Health. Bristol: Policy Press, pp. 347-364.

BetterPoints (2020) BetterPoints transport behaviour change for Brighton and Hove. Available at: $\quad$ https://www.betterpoints.Itd/blog/betterpoints-transport-behaviour-change-for-brightonand-hove-city-council/

Billingham, Z. (2020) Why the government needs to pay up before levelling up. Working Paper. London: Centre for Progressive Policy. Available at: https://www.progressivepolicy.net/publications/why-the-government-needs-to-pay-up-before-levelling-up

Bimpson, E., Parr, S. and Reeve, K. (2020) Governing homeless mothers: the unmaking of home and family. Housing Studies.

Bird, E., Ige, J., Pilkington, P., Pinto, A., Petrokofsky, C. and Burgess-Allen, J. (2018) Built and natural environment planning principles for promoting health: An umbrella review. BMC Public Health, 18 (1), pp. 930.

Booth, R. (2020) Grieving daughter wins first stage of legal fight on Covid releases to care homes. The Guardian, 19th November 2020. Available at: https://www.theguardian.com/uknews/2020/nov/19/grieving-daughter-wins-first-stage-of-legal-fight-on-covid-releases-tocare-homes (Accessed on: 24/11/20)

Brien, P. (2020) The UK Shared Prosperity Fund, Briefing Paper No. 08527. London: House of Commons Library.

British Heart Foundation (n.d.) Does loneliness increase your risk of heart attack or stroke? Heart Matters. Available at: https://www.bhf.org.uk/informationsupport/heart-mattersmagazine/news/behind-the-headlines/loneliness-and-stroke-or-heart-

attack\#: :text=The\%20research\%2C\%20from\%20the\%20University,risk\%20of\%20having\% 20a\%20stroke (Accessed: 30/10/20) 
British Medical Journal (2020) Trends in suicide during the covid-19 pandemic. BMJ, 371:m4352. Available at: https://www.bmj.com/content/371/bmi.m4352

Brown, A. (2020) Councils are critical to beating the pandemic. MJ (Municipal Journal), 26 November, pp. 20-21.

Brown, P., Newton, D., Armitage, R. and Monchuck, L. (2020) Lockdown. Rundown. Breakdown. The Covid-19 lockdown and the impact of poor quality housing on occupants in the north of England. Hull: University of Hull.

Browning, S. (2020) Coronavirus: Support for businesses, Briefing Paper No. 8847. London: House of Commons Library.

Buck, D. (2020) The English local government public health reforms: An independent assessment. Report for the Local Government Association. London: The King's Fund.

Bulman, M. (2020a) 'Animals don't get treated like this': How asylum housing problems have been exacerbated by the pandemic. Independent, 26th October 2020. Available at: https://www.independent.co.uk/news/uk/home-news/asylum-housing-coronavirus-pandemichome-office-refugees-migrant-help-b1258294.html (Accessed on: 30/10/20)

Bulman, M. (2020b) Ministers urged to scrap 'deeply immoral' plans to deport foreign rough sleepers. Independent, 6th November 2020. Available at: https://www.independent.co.uk/news/uk/home-news/covid-immigration-rules-homelessdeportation-brexit-b1621239.html

Butler, P. and Barr, C. (2020) English councils poised to make cuts amid loss of commercial income. The Guardian, 13th July 2020. Available at: https://www.theguardian.com/society/2020/jul/13/english-councils-poised-cuts-services-joblosses-loss-commercial-income

Calkin, S. (2020) Distribution of $£ 500 m$ Covid funding announced. Local Government Chronicle, 16th July 2020. Available at: https://www.Igcplus.com/finance/distribution-of-500mcovid-funding-announced-16-07-2020/

Carrell, S. (2020) How Outer Hebrides were perfectly primed to tackle coronavirus. The Guardian, 24 ${ }^{\text {th }}$ April 2020. Available at: https://www.theguardian.com/uknews/2020/apr/24/how-outer-hebrides-scotland-perfectly-primed-tackle-coronavirus

Clements, L. (2020) The area of Wales that missed coronavirus - and the simple system it set up. Wales Online, $6^{\text {th }}$ June 2020. Available at: https://www.walesonline.co.uk/news/walesnews/area-wales-missed-coronavirus-simple-

18348215?utm source=bestforbritain.org\&fbclid=IwAR0N97aopeZhDr06twRrNsHOu0r3dOFumPXg8cWUGdygpKUonqJY7Crppo

Centre for Ageing Better (2020) Real Time Evaluation of Leeds Neighbourhood Networks. Response to the COVID 19 Pandemic. Snapshot Report July 2020. Sheffield: Centre for Regional Economic and Social Research, Sheffield Hallam University.

Child Poverty Action Group (2020) Covid Capped. Child Poverty Action Group, 6th August 2020. Available at: https://cpag.org.uk/news-blogs/news-listings/covid-capped (Accessed: 29/10/20)

Clarke, O. (2020) Covid: UK governments 'took eye off ball' on pandemic. BBC News website, 23th September 2020. Available at: https://www.bbc.co.uk/news/uk-wales-54248320

Compass (2020) BD-CAN Plus: How the council and civil society have mobilised support for thousands of local people in Barking \& Dagenham in a time of crisis. 
Convention of Scottish Local Authorities (COSLA) (2020a) Covid-19: Economic \& Environmental Recovery and Renewal. Paper for Environment and Economy Board, June 2020. Available at: https://www.cosla.gov.uk/ data/assets/pdf file/0024/18285/20-06-05Item-04-Covid-19-Economic-and-Environmental-Recovery-and-Renewal.pdf

Convention of Scottish Local Authorities (COSLA) (2020b) Covid-19: Employability Response. Paper for Environment and Economy Board, June 2020. Available at: https://www.cosla.gov.uk/ data/assets/pdf file/0026/18287/20-06-05-Item-06-Covid-19Employability-Update.pdf

County Councils Network (2020) Autumn Budget Survey. CCN Analysis, November 2020. Available at: https://www.countycouncilsnetwork.org.uk/wpcontent/uploads/dlm uploads/CCN-Autumn-Budget-Survey-document-2.pdf

Coutts, P., Bowyer, G., Heydecker, R., Ormston, H., Pennycook, L., Thurman, B. and Wallace, J. (2020) COVID-19 and Communities Listening Project: A Shared Response. Dunfermline, Scotland :Carnegie UK Trust.

Cox, J. (2020) Systems change in local government: learning from COVID-19. Government Innovation, 21st September 2020. Available at: https://www.nesta.org.uk/projectupdates/change-in-local-government-learning-from-covid-

19/?utm source=Nesta+Weekly+Newsletter\&utm campaign=7d3f33cf0f-

EMAIL CAMPAIGN 202005261141 COPY 10\&utm medium=email\&utm term=0 d1 7364114d-7d3f33cf0f-181271041

Cretu, C., Bone, J. and Symons, T. (2020) A Catalyst for Change: What COVID-19 has taught us about the future of local government. New Operating Models Handbook, Upstream Collaborative, London: Nesta. Available at: https://www.nesta.org.uk/report/catalyst-change/

Cuffe, D. (2020) Lewisham Council announces changes to controversial Low Traffic Neighbourhood. London News Online, 19th October 2020. Available at: https://londonnewsonline.co.uk/lewisham-council-announces-changes-to-controversial-lowtraffic-neighbourhood/

Dahlgren, G. and Whitehead, M. (1993) Tackling inequalities in health: what can we learn from what has been tried? Working paper prepared for the King's Fund International Seminar on Tackling Inequalities in Health, September 1993, Ditchley Park, Oxfordshire. London: King's Fund (mimeo).

Davenport, A., Farquharson, C., Rasul, I., Sibieta, L. and Stoye, G. (2020) The geography of the COVID-19 crisis in England. London: The Institute for Fiscal Studies. Available at: https://www.ifs.org.uk/inequality/the-geography-of-the-covid-19-crisis-in-england/

Davidge, S. (2020) A Perfect Storm - The impact of the Covid-19 pandemic on domestic abuse survivors and the services supporting them. Women's Aid.

Dayson, C. and Damm, C. (2020) Re-making state-civil society relationships during the COVID 19 pandemic? An English perspective, People, Place and Policy, 14 (3), pp. 282-289.

Department of Health and Social Care (2020) COVID-19 contain framework: a guide for local decision-makers. Available at: https://www.gov.uk/government/publications/containing-andmanaging-local-coronavirus-covid-19-outbreaks/covid-19-contain-framework-a-guide-forlocal-decision-makers\#annex-1

Department for Infrastructure (2020a) Mallon announces new walking and cycling Champion. Available at: https://www.infrastructure-ni.gov.uk/news/mallon-announces-new-walking-andcycling-champion 
Department for Infrastructure (2020b) Mallon to bring new legislation to the Assembly to encourage use of electric bikes. Available at: https://www.infrastructureni.gov.uk/news/mallon-bring-new-legislation-assembly-encourage-use-electric-bikes

Department for Regional Development (2013) Building an active travel future for Northern Ireland. Belfast: Department for Regional Development. Available at: https://www.infrastructure-ni.gov.uk/sites/default/files/publications/drd/drd-active-travelstrategy.pdf

Department for Transport (2017) Cycling and Walking Investment Strategy. Department for Transport.

Department for Transport (2020a) £2 billion package to create new era for cycling and walking. Available at: https://www.gov.uk/government/news/2-billion-package-to-create-new-era-forcycling-and-walking

Department for Transport (2020b) Active travel fund: final allocations. Available at: https://www.gov.uk/government/publications/emergency-active-travel-fund-local-transportauthority-allocations/emergency-active-travel-fund-total-indicative-allocations

Department for Transport (2020c) Reallocating road space in response to COVID-19: statutory guidance for local authorities. Available at: https://www.gov.uk/government/publications/reallocating-road-space-in-response-to-covid19-statutory-guidance-for-local-authorities

Department for Transport (2020d) Statistical Release: National Travel Attitudes Study - Wave 4 (Provisional). Available at: https://assets.publishing.service.gov.uk/government/uploads /system/uploads/attachment data/file/924959/national-travel-attitudes-study-wave-4provisional.pdf

Department for Transport (2020e) Gear Change: A bold vision for cycling and walking. Available at: https://assets.publishing.service.gov.uk/government/uploads/system/uploads/attachment da ta/file/904146/gear-change-a-bold-vision-for-cycling-and-walking.pdf

Dunning, R. and Nurse, A. (2020) The surprising availability of cycling and walking infrastructure through COVID-19. Town Planning Review, $26^{\text {th }}$ October 2020. Available at: https://livrepository.liverpool.ac.uk/3104975.

Eiser, D. (2020) What are the implications of coronavirus for fiscal devolution in the UK? Economics Observatory. Available at: https://www.coronavirusandtheeconomy.com/question /what-are-implications-coronavirus-fiscal-devolution-uk

ESRC (2020) Is the glass half-full or half-empty? Working from home and its impact on household relations and well-being. Stirling: University of Stirling. European Social Research Council. Available at: https://www.workingathome.org.uk/wp-content/uploads/2020/06/Firstsurvey-insights-infographics-1806-2020.pdf (Accessed: 29/10/20)

Eubanks, V. (2020) Automating Inequality. How High-Tech Tools Profile, Police, And Punish The Poor. New York: Picador.

Exeter City Council (2020) Building Exeter Back Better: a collaborative recovery plan for Exeter. Available at: https://news.exeter.gov.uk/building-exeter-back-better-a-collaborativerecovery-plan-for-exeter/

Farha, L. (2020) COVID-19 Guidance Note. Protecting Residents of Informal Settlements. 2nd April 2020. Available at: http://www.unhousingrapp.org/user/pages/07.press- 
room/Guidance\%20Note\%20-\%20Informal\%20Settlements\%20April\%20FINAL[3].pdf (Accessed: 29/10/20)

Featherstone, D., Ince, A., Mackinnon, D., Strauss, K., and Cumbers, A. (2012) Progressive localism and the construction of political alternatives. Transactions of the Institute of British Geographers, 37 (2), pp. 177-182.

FE News Editor (2020) "More attractive" Kickstart scheme is beginning to displace apprenticeships. FE News, $26^{\text {th }}$ November. Available at: https://www.fenews.co.uk/pressreleases/217-resources/59327-more-attractive-kickstart-scheme-is-beginning-to-displaceapprenticeships

Fields, D. (2019) Automated landlord: Digital technologies and post-crisis financial accumulation. Environment and Planning A: Economy and Space, $1^{\text {st }}$ May 2020, pp. 1-22. https://doi.org/10.1177/0308518X19846514

Fitzpatrick, S., Watts, B. and Sims, R. (2020) Homelessness Monitor England 2020: COVID19 Crisis Response Briefing. Scotland: Heriot-Watt. UK Collaborative Centre for Housing Evidence. Crisis.

Flook, M., Grohmann, S. and Stagg, H.R. (2020) Hard to reach: COVID-19 responses and the complexities of homelessness. Comment. The Lance, 23rd September 2020.

Fothergill, S., Gore, T. and Wells, P. (2019) Industrial strategy and the UK regions: sectorally narrow and spatially blind. Cambridge Journal of Regions, Economy and Society, 12, pp. 445466. doi:10.1093/cjres/rsz016

Francis-Devine, B., Powell, A. and Foley, N. (2020) Coronavirus: Impact on the labour market, Briefing Paper No. 8898. London: House of Commons Library.

Generation Rent (2020) Web article 'Relying on compassion isn't working'. 13 May 2020. Available at: https://www.generationrent.org/relying on compassion isn $t$ working (Accessed: 29/10/20)

Geragty, L. (2020) Government reveals that 14,600 people have been housed during Covid19 crisis. Big Issue, 3rd June 2020. Available at: https://www.bigissue.com/latest/governmentreveals-that-14600-people-have-been-housed-during-covid-19-crisis/ (Accessed: 24/11/20)

Garber, M. (2020) Homes Actually Need to Be Practical Now. One of the ironies of social distancing is that it can put privacy in short supply. The Atlantic. Available at: https://www.theatlantic.com/culture/archive/2020/03/finding-privacy-during-

pandemic/608944/ (Accessed: 29/10/20)

Glasgow City Council (2020) Post-Pandemic Economic Recovery Plan for Glasgow to be developed. Available at: https://www.glasgow.gov.uk/article/25869/Post-PandemicEconomic-Recovery-Plan-for-Glasgow-to-be-developed

Gore, T. (2018) Cities and their hinterlands 10 years on: Local and regional governance still under debate. People, Place and Policy, 11 (3), pp. 150-164.

Grant Thornton (2020) County Councils Network: Analysing the impact of COVID-19 on County Authority Finances. Available at: http://ow.ly/w7YV30qQUAB

Groundswell (2020) Monitoring the Impact of Covid-19 Fortnightly Homelessness Briefing 6: Focus on Emergency Accommodation. 3rd July 2020. Available at: https://groundswell.org.uk/wp-content/uploads/2020/07/COVID-19-Fortnightly-Briefing-6-

FINAL.pdf (Accessed: 30/10/20) 
Groundwork (2020). Growing spaces: Community hubs and their role in recovery. Available at: https://www.groundwork.org.uk/about-groundwork/reports/growingspaces/

de Gruchy, J. and McManus, J. (2020) The role of English local authorities in addressing the social determinants of health: A public health perspective. In Bonner, A. (ed.), Local Authorities and the Social Determinants of Health. Policy Press, Bristol, pp. 33-48.

de Gruchy, J. (2020) Why Coronavirus is more than a public health crisis. New Statesman: Spotlight on Healthcare, 14th December 2020, pp. 8-9.

Gurney, C. (2020) OUT OF HARM'S WAY? Critical remarks on harm and the meaning of home during the 2020 COVID-19 social distancing measures. UK Collaborative Centre for Housing Evidence.

Hadjidemetriou, G., Sasidharan, M., Kouyialis, G. and Parlikad, A. (2020) The impact of government measures and human mobility trend on COVID-19 related deaths in the UK. Transportation Research Interdisciplinary Perspectives, 6, pp. 1-6. doi: 10.1016/..trip.2020.100167

Halliday, J. and Elgot, J. (2020) Local authority sets up test-and-trace system to plug gaps in English scheme. The Guardian, 4th August 2020. Available at: https://www.theguardian.com/uk-news/2020/aug/04/local-authority-blackburn-with-darwensets-up-test-trace-system-english-scheme-covid

Hammersmith and Fulham Council (2020) Thames path to remain closed to runners and cyclists. Available at: https://www.lbhf.gov.uk/articles/news/2020/04/thames-path-remainclosed-runners-and-cyclists

Hammond, G. (2021) Residential rents plummet in major UK cities. The Financial Times, 16 January 2021. Available at: https://www.ft.com/content/2d81120b-da42-4e3e-a1658fc20f415cbd (Accessed: 24/02/21)

Hanley, L. (2020) Lockdown has laid bare Britain's class divide. The Guardian, 7th April 2020. Available at: https://www.theguardian.com/commentisfree/2020/apr/07/lockdown-britainvictorian-class-divide (Accessed: 30/10/20)

Harris, J. (2020a) 'Way behind the curve': test, trace and a local credibility gap. The Guardian, 4th June 2020. Available at: https://www.theguardian.com/world/2020/jun/04/way-behind-thecurve-test-trace-and-a-local-credibility-gap (Accessed: 07/12/2020)

Harris, J. (2020b) Where Do We Go From Here? Boundless, July/August, pp. 54-58. Available at: https://fliphtml5.com/uuuh/xtgt/basic

Heath, L. (2020) Welsh housing associations limit repairs and focus on emergency lettings as country enters lockdown. Inside Housing, 27 October 2020. Available at: https://www.insidehousing.co.uk/news/welsh-housing-associations-limit-repairs-and-focuson-emergency-lettings-as-country-enters-lockdown68321 ?utm source=Ocean\%20Media\%20Group\&utm medium=email\&utm campaign=119 29142 IH-DAILY-27-10-2020-GR\&dm i=1HH2,73OL2,7UMYY3,SPHH1,1 (Accessed: 29/10/20)

Heath, L. and Barker, N. (2021) Minister indicates Everyone In funding will not increase during lockdown in letter to councils. Inside Housing, 7th January 2021. Available at: https://www.insidehousing.co.uk/news/news/minister-indicates-everyone-in-funding-will-notincrease-during-lockdown-in-letter-to-councils-69111 (Accessed: 26/01/20)

Henderson, J. and Karn, V. (1984) Race, Class and the Allocation of Public Housing in Britain. Urban Studies, 21 (2), pp. 115-128. 
Heritage Lottery Fund (2016) State of UK Public Parks 2016. Available at: https://www.heritagefund.org.uk/sites/default/files/media/attachments/state of uk public par ks 2016 final for web\%281\%29.pdf

Heritage, N. (2020) Covid hit and the community responded - but what comes next? LGiU Blog, London: Local Government Information Unit, 24th September 2020. Available at: https://lgiu.org/covid-hit-and-the-community-responded-but-what-comes-next/

Hill, R., Pickford, R., West, S. and Potter, A. (2020) Communications and the Covid-19 Pandemic Rapid insights from practitioners and research. Nottingham: Nottingham Trent University. Available at: https://www.ntu.ac.uk/ data/assets/pdf file/0027/1177902/NTUC19-NFG-Report-0920-Communications)and-the-Covid-19-Pandemic-Rapid-Report.pdf

Hine, Dame D. (2010) The 2009 Influenza Pandemic: An independent review of the UK response. London: Cabinet Office. Available at: https://assets.publishing.service.gov.uk/government/uploads/system/uploads/attachment da ta/file/61252/the2009influenzapandemic-review.pdf

HM Treasury (2020) Spending Review 2020, Presented to Parliament by the Chancellor of the Exchequer by Command of Her Majesty, CP330. London: HMSO.

House of Commons Public Accounts Committee (2020) Whole of Government Response to COVID-19. Thirteenth Report of Session 2019-21, Report HC404. London: House of Commons. Available at: https://assets.publishing.service.gov.uk/government/uploads /system/uploads/attachment data/file/938054/SR20 print.pdf

Hunter, D. (2020) Strictly come partnering: Are health and wellbeing boards the answer? In: Bonner, A. (ed.) Local Authorities and the Social Determinants of Health. Bristol: Policy Press, pp. 67-81.

Hutton, G. and Keep, M. (2020) Coronavirus business support schemes: Statistics. Briefing Paper No. CBP 8938. London: House of Commons Library.

Insall, L. (2020) Fixing the Plumbing: Resetting the Framework of Local Government Funding. London: Tony Blair Institute for Global Change. Available at: https://institute.global/policy/fixing-plumbing-resetting-framework-local-government-funding

Improvement Service/Scottish Local Authorities Economic Development Group (IS/SLAED) (2020) Employability Response to Covid-19, note for Convention of Scottish Local Authorities.

Jessop, B. (2020) Putting Civil Society in its Place: Governance, Metagovernance and Subjectivity. Civil Society and Social Change series. Bristol: Policy Press.

Keep Britain Tidy (2020). New campaign launched in face of littering epidemic in parks. Available at: https://www.keepbritaintidy.org/news/new-campaign-launched-face-litteringepidemic-parks

Kenny, M. (2020) The State we're in: How the pandemic has exposed the institutional failings of the British state. New Statesman, 26th June 2020, pp. 38-40.

Lawson, N. (2020) Paternalism to Participation: How one London borough dealt with the Covid crisis and built a new collaborative institution. London: Compass.

Leeds City Council (2020a) First "Active Travel Neighbourhood" pilots across Leeds. Available at: https://news.leeds.gov.uk/news/first-active-travel-neighbourhood-pilots-across-leeds 
Leeds City Council (2020b) Leeds City Council announces emergency walking and cycling plans in response to Covid-19. Available at: https://news.leeds.gov.uk/news/leeds-citycouncil-announces-emergency-walking-and-cycling-plans-in-response-to-covid-19

Leicester City Council (2020) Ride On announced as partner in Leicester's new e-bike scheme. Available at: https://news.leicester.gov.uk/news-articles/2020/november/ride-on-announcedas-partner-in-leicester-s-new-e-bike-scheme/

Lewisham Council (2020) Changes to Lewisham and Lee Green Low Traffic Neighbourhood Announced. Available at: https://lewisham.gov.uk/articles/news/changes-to-lewisham-andlee-green-low-traffic-neighbourhood-announced

Lichfields (2020) Planning for Covid-19 economic recovery. Available at: https://lichfields.uk/content/insights/planning-for-covid-19-economic-recovery

Lilly, A., Tetlow, G., Davies, O. and Pope, T. (2020) The Cost of Covid-19: The impact of coronavirus on the UK's public finances. Whitehall Monitor 2020 Snapshot. London: Institute for Government.

Liverpool City Council and Liverpool City Region Combined Authority (2020) Liverpool Economic Recovery and Renewal. Available at: http://councillors.liverpool.gov.uk/documents/s244011/Appendix\%201\%20-\%20Economic\%2 0Recovery\%20Plan.pdf

Living Streets (2020) Walking + Distancing needs more space. Available at: https://www.livingstreets.org.uk/get-involved/campaign-with-us/walking-and-covid-19-makemore-space

Local Government Association (LGA) (2013) The General Power of Competence: Empowering councils to make a difference. Available at: https://www.local.gov.uk/sites/default/files/documents/general-power-competence--0ac.pdf

Local Government Association (LGA) (2020a) COVID-19: good council practice. Available at: https://www.local.gov.uk/covid-19-good-council-practice (Accessed: 30/10/20)

Local Government Association (LGA) (2020b) Councils call for suspension of No Recourse to Public Funds during COVID-19 crisis. 12th June 2020. Available at: https://www.local.gov.uk/councils-call-suspension-no-recourse-public-funds-during-covid-19crisis (Accessed: $30 / 10 / 20$ )

Local Government Association (LGA) (2020c). The impact of COVID-19 on culture, leisure, tourism and sport. Available at: https://www.local.gov.uk/impact-covid-19-culture-leisuretourism-and-sport

Local Government Association (LGA) (2020d) Social Determinants of Health and the Role of Local Government. Available at: https://www.local.gov.uk/sites/default/files/documents/22.52\%20Social\%20Determinants\%20 of\%20Health $050 . p d f$

Local Government Association (LGA) (2020e) A Councillor's Workbook on Health in All Policies and Covid-19, August. Available at: https://local.gov.uk/councillor-workbook-healthall-policies-and-covid-19

Localis (2020) Local delivery: protecting social infrastructure. Available at: http://www.localis.org.uk/wp-content/uploads/2020/06/032 LocalDelivery AWK.pdf

Local Trust/New Local Government Network (NLGN) (2020) How is COVID-19 changing the relationship between communities and public services? Note of online panel discussion, $14^{\text {th }}$ 
May 2020. Available at: https://localtrust.org.uk/news-and-stories/blog/how-is-covid-19changing-the-relationship-between-communities-and-public-services/

Mackie, P. (2012) Housing Pathways of Disabled Young People: Evidence for Policy and Practice. Housing Studies, 27, pp. 805-821.

Mackie, P. and Smith, B. (2020) Housing policies and the COVID-19 pandemic. A perspective from the Wales Knowledge Exchange Hub. UK Collaborative Centre for Housing Evidence.

Macmillan, R. (2021) Community responses to COVID-19: communities and local authorities. Briefing No 9, Rapid Research COVID-19. Local Trust/Sheffield Hallam University/Third Sector Research Centre. Available at: https://localtrust.org.uk/wp-content/uploads/2021/01/COVID19-Briefing-9.pdf

Marmot, M., Allen, J., Boyce, T., Goldblatt, P. and Morrison, J. (2020a). Health Equity in England: The Marmot Review 10 Years On. London: Institute of Health Equity/Health Foundation. Available at: https://www.health.org.uk/publications/reports/the-marmot-review10-years-on

Marmot, M., Allen, J., Goldblatt, P., Herd, E. and Morrison, J. (2020b) Build Back Fairer: The COVID-19 Marmot Review. The Pandemic, Socioeconomic and Health Inequalities in England. London: Institute of Health Equity. Available at: http://www.instituteofhealthequity.org/resources-reports/build-back-fairer-the-covid-19marmot-review/build-back-fairer-the-covid-19-marmot-review-executive-summary.pdf

Marsh, S. and Walker, A. (2020a) UK distancing measures could leave homeless people out in cold, experts warn. The Guardian, 23rd September 2020. Available at: https://www.theguardian.com/society/2020/sep/23/coronavirus-distancing-measures-couldleave-homeless-people-out-in-cold-experts-warn (Accessed: 30/10/20)

Marsh, S. and Walker, A. (2020b) Tens of thousands made homeless despite UK ban on evictions during pandemic. The Guardian, 8th November 2020. Available at: https://www.theguardian.com/society/2020/nov/08/tens-thousands-homeless-despite-ukban-evictions-covid-pandemic (Accessed: 24/11/20)

Marsh, S. (2020) Covid restrictions push more under-25s than ever to sleep rough in London, charities say. The Guardian, 30th October 2020. Available at https://www.theguardian.com/society/2020/oct/30/covid-restrictions-push-more-under-25sthan-ever-to-sleep-rough-in-london-charities-say (Accessed: 24/11/20)

Martin, S., Lomas, J., and Claxton, K. (2019) Is an ounce of prevention worth a pound of cure? Estimates of the impact of English public health grant on mortality and morbidity. Centre for Health Economics, CHE Research Paper 166. Available at: https://www.york.ac.uk/media/che/documents/papers/researchpapers/CHERP166 Impact P ublic Health Mortality Morbidity.pdf

Matatche, M. and Bhabha, J. (2020) Anti-Roma Racism is Spiraling during COVID-19 Pandemic. Health and Human Rights Journal, 22 (1), pp. 379-382.

Matsu, J. and Woolley, P. (2020) How local authorities can prepare for coming challenges. London: CIPFA. Available at: https://www.cipfa.org/cipfa-thinks/cipfa-thinks-articles/howlocal-authorities-can-prepare-for-coming-challenges

McCarthy, L. (2018) (Re)conceptualising the boundaries between home and homelessness: the unheimlich. Housing Studies, 33 (6), pp. 960-985. 
McHugh, M. (2020) Northern Ireland "on bottom rung" for investment in active travel. Available at: $\quad$ https://www.belfasttelegraph.co.uk/news/northern-ireland/northern-ireland-on-bottomrung-for-investment-in-active-travel-39757665.html

McKinley, S., Brett, M. and Lawrence, M. (2020) Democratic by Design: A New Community Wealth Building Vision for the British Economy After Covid-19. London: Common Wealth/Democracy Collaborative. Available at: https://www.commonwealth.co.uk/reports/democratic-by-design

Meth, P. (2003) Rethinking the 'domus' in domestic violence: Homelessness, space and domestic violence in South Africa. Geoforum, 34 (3), pp. 317-327.

Ministry of Housing, Communities and Local Government (MHCLG) (2020a) Coronavirus (COVID-19): letter from Minister Hall to local authorities on plans to protect rough sleepers. Ministry of Housing, Communities and Local Government. Available at: https://www.gov.uk/government/publications/letter-from-minister-hall-to-local-authorities

Ministry of Housing, Communities and Local Government (MHCLG) (2020b) Guidance for landlords and tenants. Ministry of Housing, Communities and Local Government. 21st September 2020. Available at: https://www.gov.uk/government/publications/covid-19-andrenting-guidance-for-landlords-tenants-and-local-authorities/coronavirus-covid-19-guidancefor-landlords-and-tenants

Ministry of Housing, Communities and Local Government (MHCLG) (2020c) 'Overcrowded households'. 9th September 2020. Available at https://www.ethnicity-factsfigures.service.gov.uk/housing/housing-conditions/overcrowded-households/latest

Ministry of Housing, Communities and Local Government (MHCLG) (2020d) 200 people to spend Christmas off the streets and in their own homes thanks to innovative government programme Housing First. Press Release, 24th December 2019. Available at: https://www.gov.uk/government/news/200-people-to-spend-christmas-off-the-streets-and-intheir-own-homes-thanks-to-innovative-government-programme-housing-first

Ministry of Housing, Communities and Local Government (MHCLG) (2020e) Funding allocated for 3,300 new homes for rough sleepers. Press release, 29th October 2020. Available at: https://www.gov.uk/government/news/funding-allocated-for-3-300-new-homesfor-rough-sleepers

Ministry of Housing, Communities and Local Government (MHCLG) (2020f) 274 councils set to receive housing support for vulnerable people. Press release, 17th September 2020. Available at: https://www.gov.uk/government/news/274-councils-set-to-receive-housingsupport-for-vulnerable-people (Accessed: 24/11/20)

Ministry of Housing, Communities and Local Government (MHCLG) (2020g). Planning for the future: white paper August 2020. London: MHCLG. Available at: https://assets.publishing.service.gov.uk/government/uploads/system/uploads/attachment dat a/file/907647/MHCLG-Planning-Consultation.pdf

Ministry of Housing, Communities and Local Government (MHCLG) (2020h) Council Tax: COVID-19 hardship fund 2020-21 - Local Authority Guidance. London: MHCLG. Available at: https://assets.publishing.service.gov.uk/government/uploads/system/uploads/attachment da ta/file/919743/COVID-19 Council Tax Hardship Fund Guidance.pdf

Mlambo-Ngcuka, P. (2020) Violence against women and girls: the shadow pandemic. UN Women. Available at: https://www.unwomen.org/en/news/stories/2020/4/statement-edphumzile-violence-against-women-during-pandemic (Accessed: 29/10/20) 
Munro, J. and Burbidge, I. (2020) Seizing the moment: building local bridges to the future. London: RSA.

Murray, J. (2020) Cycling UK CAN help achieve an NI Active Travel Act. Cycling UK. Available at: https://www.cyclinguk.org/blog/cycling-uk-can-help-achieve-ni-active-travel-act

National Audit Office (NAO) (2018). Financial sustainability of local authorities 2018. Available at: https://www.nao.org.uk/report/financial-sustainability-of-local-authorities-2018/

National Audit Office (NAO) (2020a) Asylum accommodation and support. London: The Home Office. Available at: https://www.nao.org.uk/report/asylum-accommodation-and-support/

National Audit Office (NAO) (2020b) The Government's Approach to Test and Trace in England. Interim Report HG1070, London. Available at: https://www.nao.org.uk/report/thegovernments-approach-to-test-and-trace-in-england-interim-report/

National Audit Office (NAO) (2021) Local Government Finance in the Pandemic. Report HC1240, London. Available at: https://www.nao.org.uk/report/local-government-finance-inthe-pandemic/

National Housing Federation (NHF) (2019) Briefing: 'How many people need a social rented home? Available at: https://www.housing.org.uk/globalassets/files/resourcefiles/nhf briefing how many people need a social rented home final.pdf (Accessed: 26/10/20)

National Housing Federation (NHF) (2020) How housing associations are using voids during the coronavirus crisis. 1st May 2020. Available at: https://www.housing.org.uk/globalassets/files/resource-files/briefing-managing-voids-duringthe-coronavirus-crisis-may-2020.pdf (Accessed: 29/10/20)

National Housing Federation (NHF) (2020b) Poor housing causing health problems for nearly a third of brits during lockdown. 1st July 2020. Available at: https://www.housing.org.uk/newsand-blogs/news/poor-housing-causing-health-problems-for-nearly-a-third-of-brits-duringlockdown/ (Accessed: 29/10/20)

National Trust (2020) New research shows £5.5bn fund needed to level up access to urban green space as part of UK's green recovery. Available at: https://www.nationaltrust.org.uk/press-release/new-research-shows-55bn-fund-needed-tolevel-up-access-to-urban-green-space-as-part-of-uks-green-recovery

Natural England (2020). Building partnerships for nature's recovery. Available at: https://assets.publishing.service.gov.uk/government/uploads/system/uploads/attachment dat a/file/924682/Natural-England-building-partnerships-for-natures-recovery.pdf

NHS England (2018) Putting health into place: introducing NHS England's healthy new towns programme. Available at: https://www.kingsfund.org.uk/sites/default/files/2018-09/puttinghealth-into-place-nhs-england.pdf

New Local Government Network (NLGN) (2020) Councils and Covid-19: The Response. Bulletin \#2, $3^{\text {rd }}$ April 2020.

National Institute of Health Research (NIHR) (2020) Helping adult day centres to 'unlock lockdown'. London: Kings College. https://www.kcl.ac.uk/scwru/res/arc-sl/info/part-1-helpingadult-day-centres-to-unlock-lockdown-july2020.pdf

Nottingham City Council (2020) Emergency Active Travel Fund (Covid-19) Measures. Available at: https://www.transportnottingham.com/projects/emergency-active-travel-fundcovid-19-measures/ 
Nurse, A. and Dunning, R. (2020) Is COVID-19 a turning point for active travel in cities? Cities \& Health, pp. 1-3. doi: 10.1080/23748834.2020.1788769.

O'Carroll, A., Duffins, T., and Collins, J. (2020) Saving Lives in the time of COVID-19. Case Study of Harm Reduction, Homelessness and Drug Use in Dublin. Ireland: LSE.

Ogden, K. and Phillips, D. (2020a) COVID-19 support through the business rates system: how does the pattern of support vary across England? Briefing note, $13^{\text {th }}$ June 2020. London: Institute for Fiscal Studies (IFS). Available at: https://www.ifs.org.uk/publications/14882

Ogden, K. and Phillips, D. (2020b) The financial risk and resilience of English local authorities in the coronavirus crisis. Briefing note, $19^{\text {th }}$ August 2020. London: Institute for Fiscal Studies (IFS). Available at: https://www.ifs.org.uk/publications/14893

Ogden, K. and Phillips, D. (2020c) COVID-19 and English council funding: how are budgets being hit in 2020-21? IFS Report R174. London: Institute for Fiscal Studies (IFS). Available at: $\quad$ https://www.ifs.org.uk/uploads/R-174-COVID-19\%20and\%20English-council-fundinghow-are-budgets-being-hit-in-2020\%E2\%80\%9321.pdf

Ogden, K. and Phillips, D. (2020d) Assessing England's 2021-22 Local Government Finance Settlement. Briefing note BN314, December 2020. London: Institute for Fiscal Studies (IFS). Available at: https://ifs.org.uk/uploads/BN314-Assessing-England\%27s-2021-22-LocalGovernment-Finance-Settlement-4.pdf

Ogden, K., Phillips, D. and Spiliotis, J-C. (2020) COVID-19 and English council funding: what is the medium-term outlook? $24^{\text {th }}$ September 2020. London: Institute for Fiscal Studies (IFS). Available at: https://www.ifs.org.uk/publications/15041

Office for National Statistics (ONS) (2020) Deaths involving COVID-19 by local area and socioeconomic deprivation: deaths occurring between 1 March and 31 July 2020. ONS Bulletin, 28th $2020 . \quad$ August avalable https://www.ons.gov.uk/peoplepopulationandcommunity/birthsdeathsandmarriages/deaths/b ulletins/deathsinvolvingcovid19bylocalareasanddeprivation/latest

Osbourne, H. (2020) Mortgage for average first-time property in Great Britain needs income of £37,096. The Guardian, 24th October 2020. Available at: https://www.theguardian.com/money/2020/oct/24/mortgage-first-time-property-income

Pardoe, L. (2020). Recreating parks: securing the future of our urban green spaces. Social Market Foundation. Available at: http://www.smf.co.uk/wpcontent/uploads/2020/05/Recreating-parks.pdf

Parsell, C., Clarke, A. and Kuskoff, E. (2020) Understanding responses to homelessness during COVID-19: an examination of Australia. Housing Studies, $5^{\text {th }}$ October 2020, pp. 1-14. https://doi.org/10.1080/02673037.2020.1829564

Partington, R. (2020) Rishi Sunak’s £4.8bn 'levelling-up’ UK fund met with scepticism. The Guardian, 25th November 2020.2 Available https://www.theguardian.com/politics/2020/nov/25/rishi-sunaks-48bn-levelling-up-uk-fundmet-with-scepticism

Pidd, H. and Mistlin, A. (2021) Johnson's 'levelling up' council criticised as most members based in London. The Guardian, 20 ${ }^{\text {th }}$ January 2020. Available at: https://www.theguardian.com/politics/2021/jan/20/johnsons-levelling-up-council-criticised-asmost-members-based-in-london 
Pennington, J. (2020) New LHA rates: what do they mean? Shelter Blog, 26 March 2020. Available at: https://blog.shelter.org.uk/2020/03/new-lha-rates-what-do-they-mean/ (Accessed: 30/10/20)

Phillips, D. (2020) How much emergency coronavirus funding are different councils in England receiving? And is the funding allocation sensible? Briefing Note, $10^{\text {th }}$ April 2020 . London: Institute for Fiscal Studies (IFS). https://www.ifs.org.uk/publications/14803 (Accessed: $11 / 11 / 2020)$

Pow, J. (2018) Northern Ireland: Local government and politics. In: Dunleavy, P., Park, A. and Taylor, R. (eds). The UK's Changing Democracy: The 2018 Democratic Audit. London: LSE Press, pp. 323-330.

Powell, R. (2015) Housing Benefit Reform and the Private Rented Sector in the UK: On the Deleterious Effects of Short-term, Ideological "Knowledge". Housing, Theory and Society, 32 (3), pp. 320-345.

Preece, J. and Bimpson, E. (2019) Housing Insecurity and Mental Health: An Evidence Review. UK Collaborative Centre for Housing Evidence.

Preece, J., Bimpson, E., Robinson, D., McKee, K. and Flint, J. (2020) Forms and mechanisms of exclusion in contemporary housing systems. UK Collaborative Centre for Housing Evidence.

Pritchard, A., Richardson, M., Sheffield, D. and McEwan, K. (2019). The relationship between nature connectedness and eudaimonic wellbeing: a meta-analysis. Journal of Happiness Studies, 21, pp. 1145-1167. https://doi.org/10.1007/s10902-019-00118-6

Proctor, K. (2020) Covid-19 crisis means England's local authorities could go bust, warn mayors. The Guardian, 11th June 2020. Available at: https://www.theguardian.com/society/2020/jun/11/covid-19-crisis-means-englands-localauthorities-could-go-bust-warn-mayors

Public Health England (PHE) (2017): Spatial planning for health. London. Available at: https://assets.publishing.service.gov.uk/government/uploads/system/uploads/attachment dat a/file/729727/spatial planning for health.pdf

Public Health England (PHE) (2020a) Disparities in the risk and outcomes of COVID-19. London. Available

at: https://assets.publishing.service.gov.uk/government/uploads/system/uploads/attachment da ta/file/908434/Disparities in the risk and outcomes of COVID August 2020 update.pdf

Public Health England (PHE) (2020b). Improving access to greenspace: A new review for 2020. London. Available at: https://assets.publishing.service.gov.uk/government/uploads/system/ uploads/attachment data/file/904439/Improving access to greenspace 2020 review.pdf

Quinio, V. (2020) Have UK cities been hotbeds of the Covid-19 pandemic? Centre for Cities, 5th May 2020. Available at: https://www.centreforcities.org/blog/have-uk-cities-been-hotbedsof-covid-19-pandemic/ (Accessed: 26/10/20)

Ramblers (2020) The grass isn't greener for everyone: Why access to green space matters. Available at: https://www.ramblers.org.uk/get-involved/campaign-with-us/why-access-togreen-space-matters.aspx

Rawlinson, S. and Black, C. (2020) Infrastructure for Active Travel. Building, 7th December 2020. Available at: https://www.building.co.uk/infrastructure-for-active-travel/5109389.article 
Reeve, K. and Bimpson, E. (2020) Forgotten mothers: the case for a policy focus on the experiences of motherhood and homelessness. Sheffield: Centre for Regional Economic and Social Research, Sheffield Hallam University.

Resolution Foundation (2020) 'Covid has created a U-shaped crisis as majority of young adults and pensioners stopped working'. 8th October 2020. Available at: https://www.resolutionfoundation.org/press-releases/covid-has-created-a-u-shaped-crisis-asmajority-of-young-adults-and-pensioners-stopped-working/ (Accessed: 29/10/20)

RLA (2020) Web article. 'Landlords offering widespread support to tenants'. 13th May 2020. Available at: https://news.rla.org.uk/landlords-offering-widespread-support-to-tenants/ (Accessed: 29/10/20)

Robinson, D. (2002). Missing the Target? Discrimination and Exclusion in the Allocation of Social Housing. In: Somerville, P. and Steele, A. (eds). 'Race', Housing and Social Exclusion, London: Jessica Kingsley, pp. 94-113.

Rogers, D. and Power, E. (2020) Housing policy and the COVID-19 pandemic: the importance of housing research during this health emergency. International Journal of Housing Policy, 20 (2), pp. 177-183.

Runnymede (2020) Over-Exposed and Under-Protected. The Devastating Impact of COVID19 on Black and Minority Ethnic Communities in Great Britain. Runnymede Trust. Available at: https://www.runnymedetrust.org/uploads/Runnymede\%20Covid $19 \% 20$ Survey\%20report\%20 v3.pdf

Russell, W. and Stenning, A. (2020) Beyond active travel: children, play and community on streets during and after the coronavirus lockdown. Cities \& Health, 4th August 2020, pp. 1-4. DOI: $\underline{10.1080 / 23748834.2020 .1795386}$.

Sandford, M. (2020) Coronavirus: Support for local government. Insight article, House of Commons Library, 4th 2020.2 Available at: https://commonslibrary.parliament.uk/coronavirus-support-for-local-government/

Sandford, M. and Muldoon-Smith, K. (2020) COVID-19 has emphasised the importance of the local state - but how to solve a problem like local government funding? LSE BPP Blog. Available at: https://blogs.Ise.ac.uk/politicsandpolicy/local-government-funding/

Scott, J. (2021) English councils battling financial ruin. BBC News website, 22nd January 2020. Available at: https://www.bbc.co.uk/news/uk-politics-55754882

Scottish Government (2020a). Protecting Scotland, renewing Scotland: The government's programme for Scotland 2020-2021. Available at: https://www.gov.scot/publications/protecting-scotland-renewing-scotland-governmentsprogramme-scotland-2020-2021/pages/7/

Scottish Government (2020b). Coronavirus (COVID-19): Safer public spaces for Scotland: urban centres and green spaces. Available at: https://www.gov.scot/publications/coronaviruscovid-19-safer-public-spaces-scotland-urban-centres-green-spaces/

Scottish Government (2020c) Coronavirus (COVID-19): safer public spaces - updated guidance. Available at: https://www.gov.scot/publications/coronavirus-covid-19-safer-publicspaces-updated-guidance/pages/5/

Scottish Government (2020d) Coronavirus (COVID-19): business support fund grant statistics. 17th December 2020. Available at: https://www.gov.scot/publications/coronavirus-covid-19-businesssupport-fund-grant-statistics/ 
Scottish Local Authorities Economic Development (SLAED) Group (2020) Response to Call for Views: Advisory Group on Economic Recovery. Evidence submission, June 2020.

Sergeant, J. (2020) Co-ordination and Divergence: Devolution and coronavirus. IfG Insight, October 2020. London: Institute for Government.

Shared Health Foundation (2020) A Call to Action: To safeguard homeless families during the Covid-19 pandemic and in its aftermath. Available at: https://www.sharedhealthfoundation.org.uk/hf-call-to-action (Accessed: 24/11/20)

Shelter (2020a) Black people are more than three times as likely to experience homelessness. 1st October 2020. Available at https://england.shelter.org.uk/media/press release/black people are more than three tim es as likely to experience homelessness (Accessed: 26/10/20)

Shelter (2020b) 'Almost 100,000 homeless households were stuck in temporary accommodation during the first national lockdown'. Press Release, 29th October 2020. Available

https://england.shelter.org.uk/media/press release/almost 100000 homeless households t emporary accommodation during first national lockdown (Accessed: 24/11/20)

Sillett, J. (2020) Three tier system: deja vu or a new dawn? LGiU Blog, $13^{\text {th }}$ October 2020. London: Local Government Information Unit. Available at: https://lgiu.org/three-tier-systemdeja-vu-or-a-new-dawn/

Smith, M., Hosking, J., Woodward, A., Witten, K., MacMillan, A., Field, A., Baas, P., and Mackie, $H$. (2017) Systematic literature review of built environment effects on physical activity and active transport - an update and new findings on health equity. International Journal of Behavioral Nutrition and Physical Activity, 14 (158), pp. 1-27. DOI:10.1186/s12966-017-06139

Smith, M. (2020) The full list of grants for businesses that have to shut in Wales Christmas lockdown. Wales Online, 18th December 2020. Available at: https://walesonline.co.uk/news/politics/full-list-grants-available-businesses-19483276

Smulian, M. (2016) A Patchwork of Power How devolution is unfolding in England's regions. The Planner, $1^{\text {st }}$ June 2020, pp. 26-29.

Sport England (2020). Active Lives Adult Survey mid-March to mid-May 2020. Coronavirus (Covid-19) report. London: Sport England.

Stone, J. (2020) Government hindering Covid response by ignoring councils and failing to share data, MPs told. The Independent, 26th August 2020. Available at: https://www.independent.co.uk/news/uk/politics/coronavirus-government-local-councils-dataleicester-peter-soulsby-a9689606.html (Accessed: 09/12/2020)

SURF (2020) Covid-19: Lessons from the Frontline. Glasgow: SURF: Scotland's Regeneration Forum. Available at: https://www.surf.scot/wp-content/uploads/2020/08/SURFCovid-19-Key-Messages-Report.pdf

SYMAAG (2020) Mears Group, Urban House and Covid 19. South Yorkshire Migration and Asylum Action Group, 13 July 2020. Available at: https://www.symaag.org.uk/mears-groupurban-house-and-covid-19/2250/ (Accessed: 30/10/20)

Surrey County Council (2020) Active Travel Fund for roads and pavements. Available at: https://www.surreycc.gov.uk/roads-and-transport/roadworks-and-

maintenance/maintenance/roads/department-for-transport-capital-funding/roads-andpavements 
Sustrans (2020a) Re-allocating road space to make walking and cycling safer. Available at: https://www.sustrans.org.uk/for-professionals/urban-design-and-planning/re-allocating-roadspace-to-make-walking-and-cycling-safer-during-covid-19-and-beyond/

Sustrans (2020b) Spaces for People: Making essential travel and exercise safer during Covid19. Available at: https://www.sustrans.org.uk/our-blog/projects/2020/scotland/spaces-forpeople-making-essential-travel-and-exercise-safer-during-

coronavirus\#: :text=Spaces\%20for\%20People\%20is\%20a, and\%20exercise\%20during\%20 Covid\%2D19

Timan, J. (2020) Rise in homelessness drives social housing demand as over 200 apply for each home. Manchester Evening News, 28 October 2020. Available at: https://www.manchestereveningnews.co.uk/news/greater-manchester-news/homelessnesssocial-housing-demand-200-19178062 (Accessed: 29/10/20)

Tiratelli, L. and Kaye, S. (2020) Communities vs. Coronavirus: The rise of mutual aid. New Local Government Network. https://www.newlocal.org.uk/wp-content/uploads/CommunitiesVs-Corona-Virus-The-Rise-of-Mutual-Aid.pdf

Town and Country Planning Association (2020) No place for place-making. Available at: https://www.tcpa.org.uk/report-no-place-for-place-making

Transport for London (2020) Streetspace for London. Available at: https://www.surreycc.gov.uk/roads-and-transport/roadworks-and-

maintenance/maintenance/roads/department-for-transport-capital-funding/roads-and-

pavements

Transport Scotland (2014a) A long-term vision for active travel in Scotland 2030. Glasgow: Transport Scotland. Available at: https://www.transport.gov.scot/media/33649/long-termvison-for-active-travel-in-scotland-2030.pdf

Transport Scotland (2014b) Appendix B: Active Travel Strategy Guidance.

Transport Scotland (2020a) £10 million to support pop-up active travel infrastructure. Available at: $\quad$ https://www.transport.gov.scot/news/10-million-to-support-pop-up-active-travelinfrastructure/

Transport Scotland (2020b) Coronavirus (COVID-19): Guidance on temporary traffic regulation orders and notices. Glasgow. Available at: https://www.transport.gov.scot/media/47432/coronavirus-covid-19-guidance-on-temporarytraffic-regulation-orders-and-notices.pdf

Transport Scotland (2020c) Over £38 million allocated for pop-up active travel infrastructure. Available at: https://www.transport.gov.scot/news/over-38-million-allocated-for-pop-up-activetravel-infrastructure/

Transport Scotland (2020d) Transport Transition Plan. Available at: https://www.transport.gov.scot/coronavirus-covid-19/transport-transition-plan

Tunstall, B. (2015) Relative housing space inequality in England and Wales, and its recent rapid resurgence. International Journal of Housing Policy, 15 (2), pp. 105-126.

UK Parliament (2020) Elements of new asylum services "set up to fail". Committees, 20th November 2020. Available at: https://committees.parliament.uk/committee/127/publicaccounts-committee/news/132736/elements-of-new-asylum-services-set-up-to-fail/

(Accessed on: 24/11/20) 
Vilenica, A., McElroy, E., Ferreri, M., Fernandez-Arrigoitia, M., Garcia-Lamarca, M. and Lancione, M. (2020) Covid-19 and housing struggles: The (re)makings of austerity, disaster capitalism, and the no return to normal. Radical Housing Journal, 2 (1), pp. 09-28.

Wacquant, L. (2007) Territorial Stigmatization in the Age of Advanced Marginality. Thesis Eleven, 91 (1), pp. 66-77.

Walker, A. (2020) Lockdown resistance and the role of mayors. LGiU Blog, $16^{\text {th }}$ October 2020. London: Local Government Information Unit. Available at: https://lgiu.org/lockdownresistance-and-the-role-of-mayors/

Walsh, D. (2020) "Pop-up" bike lane in Sheffield city centre set to be removed. The Sheffield Star. Available at: https://www.thestar.co.uk/business/pop-bike-lane-sheffield-city-centre-setbe-removed-2914667

Waters, L. (2020) Written Statement: Funding for local sustainable transport measures in response to Covid 19. Available at: https://gov.wales/written-statement-funding-localsustainable-transport-measures-response-covid-19-0

Welsh Government (2020a) Local Council Sustainable Transport Measures: Allocation of fund. Available at: https://gov.wales/sites/default/files/publications/2020-06/local-councilsustainable-transport-measures-allocation-of-funds.pdf

Welsh Government (2020b) Building better places: The planning system delivering resilient and brighter futures. Available at: https://gov.wales/sites/default/files/publications/202007/building-better-places-the-planning-system-delivering-resilient-and-brighter-futures.pdf

Welsh Local Government Association (WLGA) (2020a) Evidence submitted to Inquiry into COVID-19 by the Equality, Local Government and Communities Committee, July, WLGA, Cardiff. Available at: https://www.wlga. wales/SharedFiles/Download.aspx?pageid=62\&mid=665\&fileid=2772

Welsh Local Government Association (WLGA) (2020b) Councils welcome Welsh Government support package on Covid-19 financial pressures. Press release, 17th August 2020. Available at: https://www.wlga.wales/councils-welcome-welsh-government-support-package-on-covid19-financial-pressures

Welsh Local Government Association (WLGA) (2020c) Cross-departmental working to deliver business grants (Pembrokeshire CC). Good Council Practice case study, 17th September 2020. Available at: http://www.wlga.wales/cross-departmental-working-to-deliver-businessgrants-pembrokeshire-cc

Welsh Local Government Association (WLGA) (2020d) Council Buy Local directory (Neath Port Talbot CBC). Good Council Practice case study, 17th September 2020. Available at: http://www.wlga.wales/council-buy-local-directory-neath-port-talbot-cbc

Welsh Local Government Association (WLGA) (2020e) Paper on Local Government Schemes for Consideration. Submission to Recovery Sub-group of Partnership Council for Wales, 6th July 2020.

Welsh Local Government Association (WLGA) (2020f) Residents, businesses and local stakeholders involved in economic recovery (Newport CC). Good Council Practice case study, 17th September 2020. Available at: http://www.wlga.wales/residents-businesses-and-localstakeholders-involved-in-economic-recovery-newport-cc

Wendelboe-Nelson, C., Kelly, S., Kennedy, M. and Cherrie, J. W. (2019) A Scoping Review Mapping Research on Green Space and Associated Mental Health Benefits. International Journal of Environmental Research and Public Health, 16, pp. 1-49. 
West London Alliance (2020) Six West London Councils announce proposals which will drive UK economic recovery. Available at: https://www.westlondon.com/six-west-london-councilsannounce-proposals-which-will-drive-uk-economic-recovery/

West Midlands Combined Authority (2020) Recharge the West Midlands: Kickstarting the West Midlands Economy: Our investment case to government. Available at: https://www.wmca.org.uk/media/3975/west-midlands-economic-recovery-our-ask-and-offerhd-spreads.pdf

Wild, K., Woodward, A., Field, A. and Macmillan, A. (2018) Beyond "bikelash": engaging with community opposition to cycle lanes. Mobilities, 13 (4), pp. 505-519. https://doi.org/10.1080/17450101.2017.1408950

Williams, J. (2020) 'Manchester is living through an unparalleled homeless crisis - yet an axe hangs over vital support services, mid-pandemic'. Manchester Evening News, 8th November 2020. Available at: https://www.manchestereveningnews.co.uk/news/greater-manchesternews/manchester-living-through-unparalleled-homeless-19238455 (Accessed: 24/11/20)

Willis, B. and Fernandez, S. (2020) Stories of Oxford lockdown. LGiU Blog, $19^{\text {th }}$ October 2020. London: Local Government Information Unit. Available at: https://lgiu.org/stories-of-oxfordlockdown/

Wills, A. (2021) Beat the bikelash: Backlash against bike lanes doesn't reflect public opinion - and local authorities tearing them out need to be told. Cycle, 29th January 2020. Available at: https://www.cyclinguk.org/cycle-magazine/beat-bikelash

Wilson, D. (2005) The United Kingdom: an increasingly differentiated polity? In: Denters, B. and Rose, L. (eds). Comparing Local Governance: Trends and Developments. Government Beyond the Centre series. Palgrave-Macmillan, pp. 155-173.

World Habitat (2020) Responding to the COVID-19 pandemic. Case studies from the European End Street Homelessness Campaign. The European Ending Street Homelessness Campaign. https://world-habitat.org/wp-content/uploads/2020/06/EESHC-Responding-toCovid19-case-studies-FINAL-1.pdf

World Health Organisation (2016) Urban green spaces and health: A review of evidence. Available at: http://www.euro.who.int/ data/assets/pdf file/0005/321971/Urban-greenspaces-and-health-review-evidence.pdf?ua=1

Youle, R. (2020) Dispute over Swansea cycle path. Newyddion Cymru Ar-Lein/Wales News Online, 30 July 2020. Available at: https://walesnewsonline.com/dispute-over-swansea-cyclepath/ 


\section{Sheffield Hallam University}

Local Government Responses to the COVID-19 Pandemic in the UK: A Thematic Review

GORE, Anthony <http://orcid.org/0000-0002-0997-7198>, BIMPSON, Emma, DOBSON, Julian and PARKES, Stephen <http://orcid.org/0000-0002-4379-2058>

Available from the Sheffield Hallam University Research Archive (SHURA) at:

http://shura.shu.ac.uk/29300/

\section{Copyright and re-use policy}

Please visit http://shura.shu.ac.uk/29300/ and http://shura.shu.ac.uk/information.html for further details about copyright and re-use permissions. 